THE UNIVERSITY SUPERVISOR AND POST-OBSERVATION CONFERENCES: PERCEPTIONS OF UTILITY FROM STUDENT TEACHING TRIADS

\author{
A Capstone Project \\ Presented to \\ The Faculty of the Curry School of Education \\ University of Virginia \\ In Partial Fulfillment \\ of the Requirements for the Degree \\ Doctor of Education \\ by \\ Katie L. Loftin, B.A., M.Ed.
}

August 2017 
C Copyright by

\section{Katie Loftin}

All Rights Reserved

May 2017 
Katie Loftin

Curriculum, Instruction, and Special Education

Curry School of Education

University of Virginia

Charlottesville, Virginia

\section{APPROVAL OF THE CAPSTONE}

This capstone, The university supervisor and post-observation conferences: Perceptions of utility from student teaching triads, has been approved by the Graduate Faculty of the Curry School of Education in partial fulfillment of the requirements for the degree of Doctor of Education.

Susan Mintz, Ph.D., Chair

Jennifer Pease, Ph.D., Committee Member

Julie Cohen, Ph.D., Committee Member

Patrice Grimes, Ph.D., Committee Member 
Table of Contents

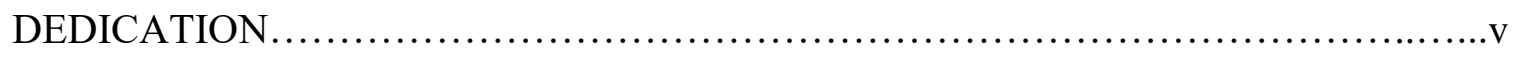

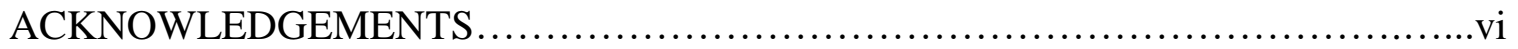

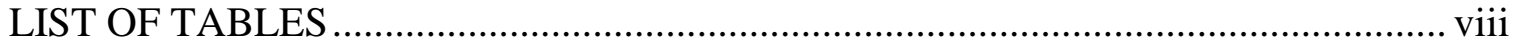

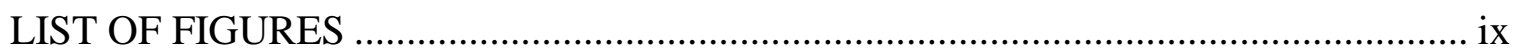

CHAPTERS

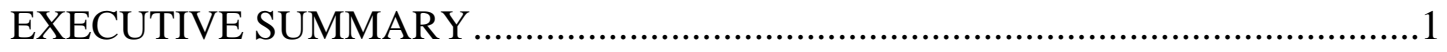

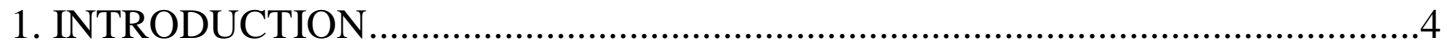

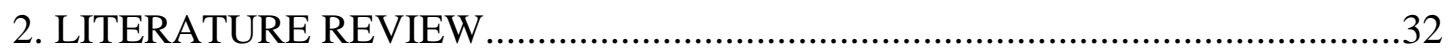

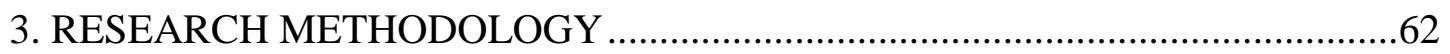

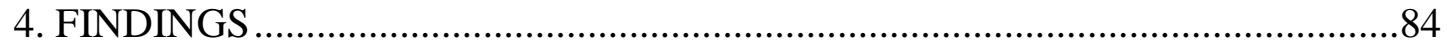

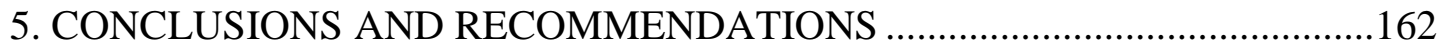

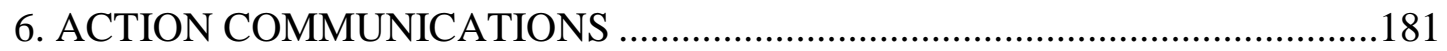

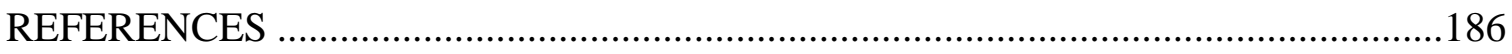

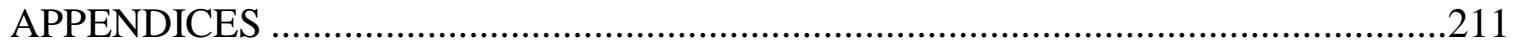




\section{Dedication}

This capstone project is dedicated to Amber because it could not have been done without your unwavering support. 


\section{Acknowledgements}

I could not have completed this project without the support of many individuals, some of whom I would like to thank here.

Thank you, Dr. Susan Mintz, for your incredible patience as you guided and supported me through this process. You were my advisor, mentor, teacher, and sometimes what felt more like my life coach, therapist, and mom away from home. You have shown me what it means to be a teacher that guides and facilitates a student's learning without doing it for them. Thank you for having confidence in me even in times when I did not have confidence in myself.

Thank you, Dr. Jen Pease, for serving as an incredible model of effective teaching. I genuinely felt like I walked away with a deeper understanding of what it means to be a teacher educator every single time I attended your class. You reminded me of the importance of building relationships and showing students you care, and I will never forget the example you have set for me.

Thank you, Dr. Julie Cohen, for the feedback you provided on this capstone. You challenged me to think more deeply about many aspects of my project, and I know that it is better because of it.

Thank you, Dr. Patrice Grimes, for modeling a strong passion for social studies teaching and helping me see the importance of the subject in new and exciting ways.

To all of my friends I met here at Curry, I thank you so much for your support and encouragement from day one. I am so grateful to have had the opportunity to work with such passionate educators, and I often felt I learned just as much from you all as I did my coursework. I know that I would not have made it to this point without you all. 
Thank you to all of my teachers throughout my twenty-two years of education that have put up with me and helped me think about so many things in new ways. I am proud to follow in your footsteps and continue to do such important and fulfilling work.

Thank you to all of my past students whose memories have kept me motivated. I entered this program in order to become a better teacher and to learn more about addressing your needs. Thank you to my current students, who provided mental support, frequently checked to make sure I was making progress, and cheered me along the way.

Thank you, Mom, for showing me the importance of education and always telling me I could do whatever I wanted with my life. Your moments of turning every experience into a learning opportunity, although often annoying at the time, were my first experiences with effective teaching methods and the idea that learning can happen anywhere. No, I still don't want to calculate how much it would cost to bring two cookies for each of my twenty-four classmates at school if they cost seventy-nine cents each, but thank you for asking. Although you are not around to see me earn my doctorate, Tom, I know that you never doubted I would get it done, and for that I thank you.

Most importantly, thank you to my amazing wife, Amber. You have supported me in more ways than I can count, and I know this accomplishment would never have been possible without you. Thank you for your love, patience, sacrifice, dedication, understanding, and willingness to listen, even about what you called "boring education stuff." I am so thankful for you each and every day and cannot wait to see where life takes us next. I'm just hoping it's near a school with a department of library and information science because I don't know about you, but I'm missing being in school already! 
List of Tables

Table

Page

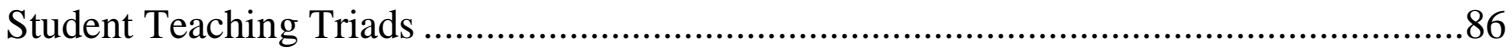

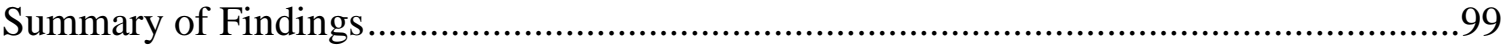

Findings and Recommendations for Sequoyah Teacher Education Office ....................164 


\section{List of Figures}

Figure

Page

MTPтм Supervision Model .................................................................................... 16

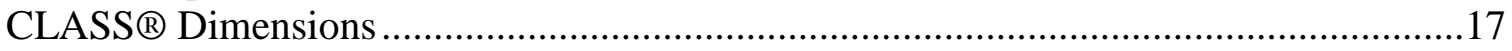

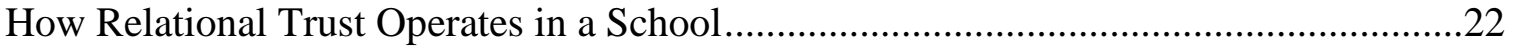

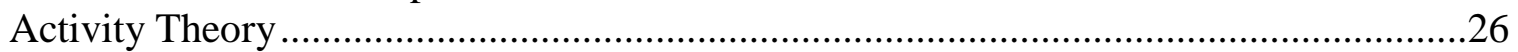

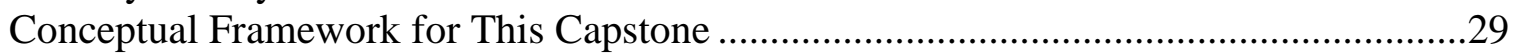

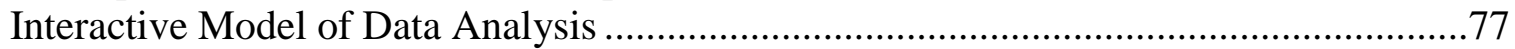




\section{Executive Summary}

Several factors have led to an increased focus on ways to improve teacher education in the United States. One area of research, student teaching, has been the center of much of this focus. However, few of the studies addressing this topic have looked deeply at the role of university supervisor and the perceived importance of postobservation triad conferences and other features of supervision. Many of the studies that have been conducted are dated, suffer from methodological flaws, focus on a specific subject area, or were conducted in foreign contexts. Due to the variety of models for student teaching supervision and the several contextual factors that influence them, it is important to provide specific analysis of university supervision in particular settings when possible.

\section{Purpose}

The purpose of this study was to provide the faculty and staff in the teacher education program at Sequoyah University with information about how university supervisors, student teaching triad conferences, and other practices of supervision are perceived by the student teachers, mentor teachers, and university supervisors that engage in them.

\section{Methodology}

This study was structured as a qualitative comparative multiple-case study of three student teaching triads from one teacher education program. Interviews, observations, and document analysis were conducted in order to assess the perceptions of 
utility of university supervisors and triad conferences. Purposive convenience sampling was used to identify the nine participants.

\section{Findings}

Findings based on interview, observation, and document analysis data are presented in this capstone. The three findings from this case study are as following;

1. Positive relationships, viewed as central to providing effective supervision, can be built by conveying a sense that the triad is a central priority for all members. This is demonstrated through flexibility, availability, and engagement within supervision. Prolonged, cross-contextual relationships can contribute to more positive interactions.

2. Previous teaching experiences and level of experience within the triad role may affect supervision and how it is perceived by triad members. Supervisors should present themselves in a way that emphasizes the knowledge and experiences they bring to a triad.

3. The student teaching experience should be perceived as formative in nature. Tools used in providing formative feedback must be used effectively in order to impact student teachers' classroom decision-making.

\section{Conclusions and Implications}

Based on the findings, I have made several recommendations to the faculty and staff of the Sequoyah teacher education program:

1. Place a heavy emphasis on building relationships among university supervisors, mentor teachers, and student teachers by providing triad members with policies, 
resources, and structures directed at increasing perceptions of competence and maintaining high levels of engagement among all triad members.

2. Evaluate the aspects of supervision that participants identified as problematic by conducting a review of various structures and policies in light of the goals of the program and accreditation requirements. Supervisors should be instructed on how to present themselves in a way that emphasizes the knowledge and experiences they bring to a triad.

3. Continue emphasizing the central goal of preparing student teachers and the structures of university supervision that are viewed positively, especially as they relate to using video to guide the provision of positive, formative feedback in order to impact student teachers' classroom decision-making. 


\section{Chapter 1}

Introduction

It has been widely accepted in recent years that teacher quality is one of the most significant factors related to student achievement (Darling-Hammond, 2000; Hightower et al., 2011; Tucker \& Stronge, 2005). Partially based on this idea, The No Child Left Behind (NCLB) Act of 2001 required states to provide "highly qualified" teachers to all students. Although this mandate has been replaced with less stringent certification requirements with the passage of the Every Student Succeeds Act (ESSA), it, coupled with findings about the importance of teacher quality (Darling-Hammond, 2000), led to increased attention focused on teacher education programs throughout the United States, with several publications (Levine, 2006; National Council on Teacher Quality, 2013) claiming that recently graduated students are unprepared for the classroom (Levine, 2006). Critiques of teacher preparation programs have existed for several decades (Popham \& Greenberg, 1958; Zeichner \& Liston, 1990), but these newest criticisms have been well-publicized in mainstream media with attention-grabbing headlines such as "Teacher prep programs get failing marks" (Sanchez, 2013) and "Too many teachers, too little quality" (Elliot, 2013). Coinciding with criticisms of teacher preparation programs is the growing belief shared by many that our education system is failing millions of American children, leaving them without the skills they need to succeed in the $21^{\text {st }}$ century. 
While this claim of America's failing schools has been vehemently disputed and called a myth (Berliner \& Glass, 2014), these widespread criticisms have forced teacher preparation programs to "reflect, rethink, and reform their methods for training new teachers" (Asplin \& Marks, 2013, p. 1). Unfortunately, there is little research demonstrating what kind of training is most likely to produce a successful teacher, a fact that education researchers are now trying to remedy through long-term study (Otterman, 2011). In the meantime, states, which are tasked with setting the rules for certifying educators, have been raising the standards for existing schools (Zeichner, 2016) while simultaneously opening the door to new kinds of organizations (Teach for America, The Relay Graduate School of Education, Match Teacher Residency, etc.) to train their teachers (Darling-Hammond, Chung, \& Frelow, 2002). The number of these programs is not only increasing, but they are also gaining wider acceptance by state lawmakers (Education Commission of the States, 2016). In fact, over 500,000 of the 3.6 million teachers in the United States have entered the field through alternative routes (Otterman, 2011). This deregulation of the preparation of teachers and expansion of independent, alternative routes into teaching has put added pressure on traditional teacher preparation programs. Some have argued, however, that too little is known about these alternative pathways and that the claims of success of independent programs like The Relay Graduate School of Education and Match Teacher Residency have not been substantiated by peer-reviewed research and program evaluations (Zeichner, 2016).

\section{Teacher Education Reform Efforts}

Despite a lack of clear evidence of the success of alternative teacher training programs, this increased pressure on traditional, university-based programs has led to the 
implementation of many reform efforts across some universities such as more rigorous standards, new or additional courses, an increased focus on teacher evaluation (e.g. more Praxis exams, edTPA), and steps to tie student test scores to teacher evaluation in an effort to develop stronger and more effective teacher preparation programs (Fraser, 2014).

Part of this process has included looking more deeply at student teaching experiences, viewed as an essential and perhaps the most important component to improving teacher education (Asplin \& Marks, 2013; Gimbert \& Nolan, 2003; Griffin \& Combs, 2000; Johnson \& Napper-Owen, 2011), a fact which has also motivated the creation of residency programs such as Relay and the Match Teacher Residency. Student teaching offers a practical field experience where students are able to refine the critical teaching skills they will need as practitioners while being supervised and mentored by the more experienced professionals of a mentor teacher and a university supervisor. In order for this refining of critical teaching skills to take place, quality support from the mentor teacher and university supervisor is extremely important in helping student teachers bridge the gap between theory and practice (Bowman \& McCormick, 2000; Fletcher, 2013).

Researchers have looked at several reform efforts untaken in order to attempt to improve the student teaching experience including increasing the length of student teaching internships, working to build close partnerships with schools, and providing additional pre-student teaching field experiences (see Devlin-Scherer, Mitchel, \& Mueller, 2007; Latham \& Vogt, 2007; McKinney, Haberman, Stafford, \& Robinson., 2008). The triad relationship between student teacher, mentor teacher, and university 
supervisor (discussed in more detail below) in particular has drawn much attention because of the critical role the triad plays in the student teacher's education and transformation to classroom teacher (Asplin \& Marks, 2013; Kent, 2001; Valencia, Martin, Place, \& Grossman, 2009).

Much of this attention has also been placed on ensuring student teachers have access to quality cooperating or mentor teachers. Because the mentor teacher observes and interacts with the student teacher on a daily basis during the student teaching experience, there is little doubt about the powerful influence of the mentor teacher (Johnson \& Napper-Owen, 2011). Research (Glenn, 2006; Zhen \& Webb, 2000) indicates that mentor teachers are often "seen as the most important figure in student teaching" (Asplin \& Marks, 2013, p. 1) due to the fact that many student teachers mirror the instructional practices of their mentor teachers, even when those practices are in direct conflict with practices learned in university courses (Bates \& Burbank, 2008; Glenn, 2006; Zheng \& Webb, 2000). Some studies (Bullough \& Draper, 2004; Veal \& Rikard, 1998) have found evidence of conflict between mentor teachers and university supervisors that can negatively impact student teaching experiences. According to Marks (2002), student teachers often believe that their mentor teachers have "real" experience and are more knowledgeable than university teacher education faculty.

\section{Role of the University Supervisor}

Perhaps this is the reason the role and influence of the university supervisor has been largely discounted or ignored within the student teaching process (Marks, 2002) and discounted by many in the field of teacher education. Most of the literature surrounding this topic of the importance of university supervisors is somewhat dated due to a lack of 
recent studies. Additionally, there is a lack of a theoretical framework that considers the place of the university supervisor in the development of the student teacher. However, the research that does exist offers important insight regarding the necessity of this proposed study.

Ongel, Capa, and Vellom (2002) found that university supervisors are viewed more as "inspectors" rather than collaborative partners that provide additional insights and support and that they are seen as less qualified than mentor teachers to evaluate student teachers (Zheng \& Webb, 2000), although there is no clear evidence that this is actually the case beyond what student teachers are reporting. Research (Silva, 2000; Tsui, Lopez-Real, Law, Tang, \& Shum, 2001; Wilder \& Croker, 1999) focusing on improving communication within the student teaching triad (student teacher, mentor teacher, and university supervisor) has indicated that the university supervisor is "the weak link" (Asplin \& Marks, 2013, p.2). This lack of influence on the student teacher has even led some researchers to imply that university supervisors are superfluous to the student teaching process (Asplin \& Marks, 2013). This is perhaps due, in part, to the incomplete theoretical and conceptual ideas surrounding the student teaching triad as outlined within the literature.

However, other researchers have noted the importance of university supervisors to the student teaching process due to their experiences as former classroom teachers and their current roles as teacher educators (Anderson \& Randencich, 2001; Asplin \& Marks, 2013; Slick, 1997). Fernandez and Erbilgin (2009) found, for example, that university supervisors play a vital role in "supporting student teachers' implementation of recent reforms and theories learned in coursework" (p. 94), a finding well-supported by earlier 
studies as well (Blanton, Berenson, \& Norwood; 2001; Freidus, 2002; LaBoskey \& Richert, 2002). While there are differing perspectives on the exact roles of university supervisors, research has shown they are expected to act as a resource, mentor, evaluator, and university liaison (Johnson \& Napper-Own, 2011; Vuran, Ergenekon, \& Unlu, 2014). These roles are accompanied by a wide range of job duties and responsibilities including integrating university coursework and practical classroom experiences, conducting observations, providing feedback to student teachers, evaluating lesson plans (Banville, 2006), modeling effective teaching techniques, providing classroom management advice (Banville, 2006; Coleman \& Mitchell, 2000), pointing out teacher behaviors such as enthusiasm and voice quality (Coleman \& Mitchell, 2000), encouraging the development of content knowledge (Coleman \& Mitchell, 2000) and directing attention to specific teacher behaviors (Fletcher, 2012; Johnson \& Napper-Owen, 2011; Steadman \& Brown, 2011). Each of these roles indicates that the university supervisor is responsible for contributing to the development of a student teacher in moving from a linear understanding to something much more complex. In addition to these specific goals, a common larger goal of all university supervisors is to make the student teaching experience a productive time for professional growth and orientation to the world of teaching (Johnson \& Napper-Owen, 2011).

In her dissertation, Marks (2002) noted that university supervisors influenced the transfer of learning from the university to the classroom when several factors were present: (a) positive relationship between student teacher and supervisor; (b) student teacher recognition of the supervisor's expertise and professionalism; (c) the supervisor is accessible to student teachers; and (d) the supervisor regularly holds the student teacher 
to university expectations as expressed in coursework or the student teacher handbook. This study took place over a period of two years and followed six preservice teachers through the final two years of their five-year teacher education program. Observation, interviews, focus groups, and document analysis were the primary methods used.

In addition to increasing connections between university coursework and field experiences, university supervisors have also been shown to provide much needed emotional support to student teachers during their field experiences (Caires \& Almeida, 2007; Caires, Almeida, \& Martins, 2010; Hyland \& Lo, 2006), with student teachers citing university supervisors" "personal features" of being supportive, non-judgmental, and helpful when it comes to helping student teachers overcome obstacles during student teaching.

Unfortunately, several factors can negatively influence the university supervisor's ability to perform their duties (Fletcher, 2012; Slick, 1997). These include time limitations (Fletcher, 2012; Johnson \& Napper-Owen, 2011), the assignment of too many student teachers to the point a university supervisor is not able to supervise each of them effectively (Vuran et al., 2014), the experiences that the supervisor brings to the job (Johnson \& Napper-Owen, 2011), and a lack of clarity of role expectations (Johnson \& Napper-Owen, 2011).

There is more supporting evidence that university supervisors play a vital role in the student teaching process than not (Vuran et al., 2014). However, there is still a lack of research focusing on university supervisors in general. In fact, university supervisors have been said to be the least studied member of the student teaching triad (Johnson \& Napper-Owen, 2011). In particular, little work has been done to analyze the specific 
practices of university supervisors that members of the student teaching triad view as most helpful.

\section{The Student Teaching Triad}

The student teaching triad is a collective body of three distinct members (student teacher, mentor teacher, and university supervisor) whose goal it is to work cooperatively and cohesively throughout the student teaching experience. There are many different models of university supervision, so by clearly discussing these roles and providing more information about each of them, I hope to clarify the traditional model of supervision that will be focused on throughout the majority of this study.

The student teacher, having successfully completed the content and methodology coursework of a particular discipline, engages in the student teaching experience, which is the culminating event of many teacher preparation programs (Hunt, Mitchell, Maina, \& Griffin, 2015). During student teaching, the student teacher is faced with many instructional and non-instructional responsibilities wherein compliances and successful navigation of the experience is mandatory based on university requirements. These include teaching responsibilities, observational responsibilities that promote metacognitive development, and many others that demonstrate the student teacher's ability to assimilate into the role of practitioner (Hunt et al., 2015).

The mentor teacher's primary responsibility is to facilitate instructional and noninstructional practices in an authentic school setting, ideally while collaborating with the university supervisor to help develop the pedagogical content knowledge of the student teacher (Hunt et al., 2015). Research (Coleman \& Mitchell, 2000; Johnson \& NapperOwen, 2011) indicates the mentor teacher is pivotal in providing day-to-day mentorship, 
guidance, and feedback to facilitate student teacher development. Coleman and Mitchell (2000) analyzed eighteen mentor teachers' responses to student teachers' videotaped lessons and found that the mentor teachers were able to provide clear targets for corrections, explicit rationales for their feedback, and prescriptive comments for future remediation. Johnson \& Napper-Owen (2011) used interviews, observations, video analysis, and field notes in order to conduct a case study of how six members of student teaching triads perceived the roles of student teachers, mentor teachers, and university supervisors. Findings showed that mentor teachers were viewed as responsible for mentoring, knowledge sharing, encouraging, and providing feedback. While these are similar to roles the university supervisor also plays, the mentor teacher role is unique because mentor teachers are primarily responsible for facilitating the non-instructional practices that are necessary in the student teacher's transition to become an independent teacher (Anderson, 2007). One such non-instructional practice usually includes information related to successful immersion into the school setting including how to navigate school rules, policies, and procedures (Grimmett \& Ratzlaff, 1986) ; build relationships with other staff members (Koskela \& Ganser, 1998), and provide "productive assimilation procedures that allow the student teacher to feel welcomed and comfortable in the instructional setting (Hunt et al., 2015, 217-218).

The final member of the triad, the university supervisor, occupies a position with many responsibilities and the role is not clearly defined. Under many supervisory models currently being used, the primary responsibilities of the university supervisor revolve around practices and procedures connected to conducting observations of the student teacher's performance in the field setting (Hunt et al., 2015). These observations have 
traditionally been conducted in person, but some university supervisors are also using video recorded lessons to fulfill observation requirements as outlined by their respective teacher education programs (Baecher \& McCormack, 2015). There is strong evidence (Sherin \& van Es, 2005, 2009; Tripp \& Rich, 2012) that video encourages teacher reflection on practice.

In addition to the observations themselves, Hunt et al. (2015) found in a study analyzing twenty supervisors' approaches taken to supervision that university supervisors may also engage in pre-observation meetings in which the student teacher and supervisor engage in dialogue concerning the events that will take place during the lessons to be observed, providing lesson plan feedback, prompting reflection on student teachers' decision-making during the observed lesson, and engaging in post-observation triad conferences with both the student teacher and mentor teacher. In order to fulfill these duties, university supervisors need to be familiar with systematic observation instruments needed to record the necessary data being displayed during the observation accurately and effectively (Hunt et al., 2015). Additionally, university supervisors need to be adept at structuring the post-observation conferences in a way that allows the supervisor and mentor teacher to provide constructive, specific, and congruent feedback that encourages the student teacher to develop desired knowledge and skills throughout the student teaching experience (Metzler, 2011). In order for this feedback to occur and be accepted, it is important for university supervisors to help build relationships among the triad members (Caires \& Almeida, 2007). 


\section{Statement of the Problem}

Increased attention on the quality of teachers in the United States, coupled with the increase in alternative certification and teacher training pathways, has led some universities to look carefully at their teacher education programs. The experiences of preservice teachers in their student teaching placements in particular has been a large area of focus (Asplin \& Marks, 2013). While studies have paid particular attention to the roles of mentor teachers, few have focused on the university-based member of the student teaching triad — the university supervisor. Of these studies, many are dated, have methodological flaws, focus on a narrow subgroup of preservice teachers, or come from foreign (non-United States) contexts.

University supervisors are responsible for serving as a connection between university coursework and student teachers' field experiences. This includes helping the student teachers make sense of the classroom and the pragmatic decisions that need to be made in light of the research and skills studied within the teacher education program. However, due to gaps in the literature, little is definitively known about the utility of specific practices university supervisors engage in while fulfilling this role. Little is also known about student teachers' and mentor teachers' views about the usefulness of these practices.

Within the context of this particular study, teacher education faculty want to better understand the value of the student teaching triad conference and the role that university supervisors play in supporting student teachers. Increased understanding of this crucial role could serve to benefit all members of the student teaching triad as well as the university teacher education program as a whole. By isolating specific practices that 
are viewed as successful by triad members, we can later begin to ask and answer additional questions about what makes them successful, under what conditions they are most successful, how they can be taught and encouraged in university supervisor training, and how they can further develop the necessary knowledge and skills student teachers will need as they become practitioners in the field. Furthermore, findings from this study might identify soft skills such as communicating effectively or working within a team that are required for triads to benefit the professional development of student teachers.

\section{The Purpose}

The purpose of this study is to provide teacher education faculty at Sequoyah University with a better understanding of the usefulness of triad conferences and to identify specific practices of university supervisors that members of the student teaching triad find to be most helpful. Interviews, observations, and document collection were the primary methods used.

The university supervisors at Sequoyah University primarily consist of a group of former principals, superintendents, instructional coaches, classroom teachers, and current doctoral students in the curriculum and instruction program. Doctoral students in the administration program at Sequoyah also supervise one student teacher each. Although they do not supervise students in their full student teaching placements, a group of additional doctoral students and current classroom teachers also supervise students in their practicum placements that take place the semesters prior to full student teaching. As I will discuss later in the methods section of this capstone, the participants for this study make up a very small subset of these university supervisors. 
University supervisors at Sequoyah are assigned a variable level of student teachers to observe based on level of experience and how many students the supervisor is willing to take on. All supervisors, with the exception of the doctoral students, are paid per the number of students they supervise. The teacher education office makes an effort to match supervisors with school settings that they have at least some experience with in terms of subject or grade level when possible, although this is not always the case.

University supervisors are also assigned to as few schools as possible in order to make it easier for them to visit these settings throughout the supervision cycles.

The university supervisors observe student teachers using The Classroom Assessment Scoring System ${ }^{\circledR}$ (CLASS $\left.{ }^{\circledR}\right)$ as part of the MyTeachingPartner ${ }^{\mathrm{TM}}$-Preservice (MTPTM_P) supervision model. This model provides an opportunity for all student teachers, mentor teachers, and university supervisors to learn and use a common language and lens throughout a student teacher's field experience. The model consists of a sevenstep cycle (Figure 1) in which the student teaching intern submits a lesson plan for supervisor feedback and video records herself teaching a lesson.

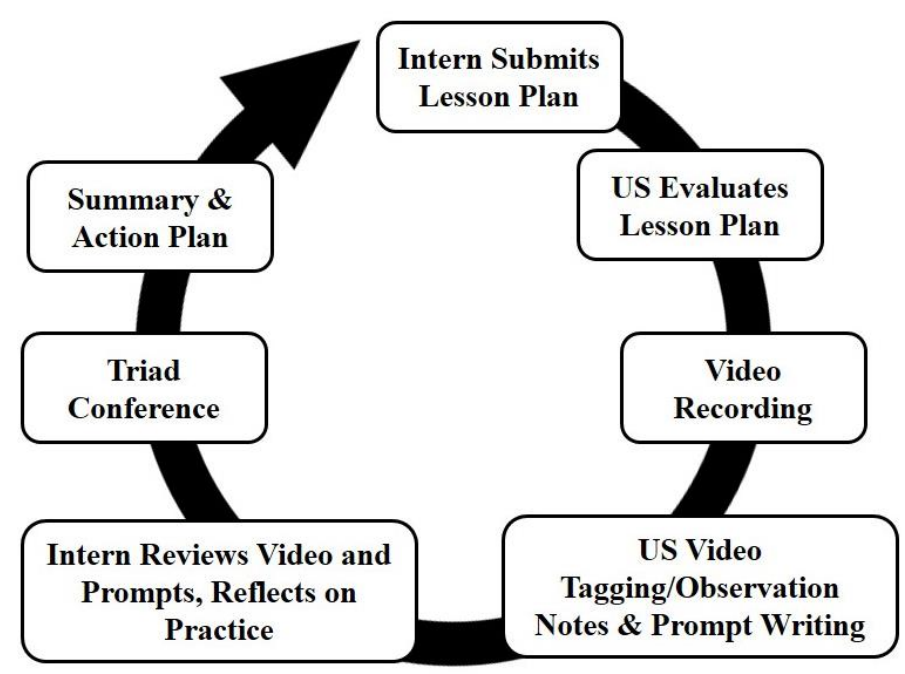

Figure 1. MTP'M-P Supervision Model 
Each cycle focuses on two dimensions of teaching across the three broad domains of emotional support, classroom organization, and instructional support. Within each domain are dimensions that focus on different features of effective teacher-student interactions. These dimensions can be seen in Figure 2.

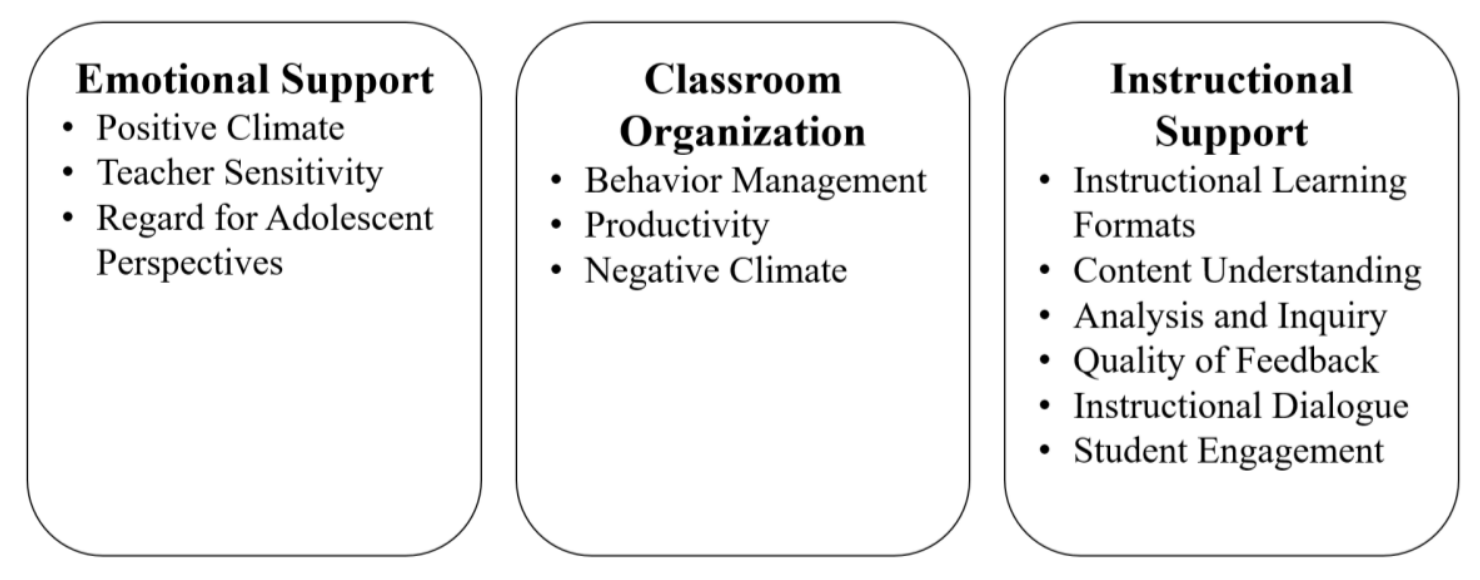

Figure 2. CLASS® Dimensions

The university supervisor then reviews the video, tags four separate moments of focus during the lesson, and provides the intern with specific prompts about the video clips to respond to as she reflects on her practice. These prompts have different titles and are meant to serve different purposes. The "nice work" prompt always comes first, and the purpose is to help the student teacher recognize a moment in the clip where she did something well in relation to the dimension of focus. This prompt is followed by the "enacting a plan" prompt that references the lesson plan that was submitted at the beginning of the cycle. Next comes the "consider this" prompt that asks the student teacher to consider how her actions may have affected an interaction or what she could do differently if given the chance. One dimension is typically carried through these first three prompts, meaning that each of these prompts is associated with that particular dimension of focus. Finally, the "making the most of instructional support" prompt 
focuses on a specific dimension from the instructional support domain and is meant to ensure that the student teacher consider how students are making sense of the content. A sample set of prompts from one of the triads that participated in this study is shown in Appendix A. The student teacher responds to each of these prompts after having watched the corresponding video clip.

Within a few days of the student teacher responding to her prompts, she, the university supervisor, and the mentor teacher will participate in a triad conference in which they discuss the specific lesson as well as the student teaching experience in general. Following this triad conference, the university supervisor sends a summary of the observation cycle as well as an action plan for moving forward. This observation cycle is repeated five more times throughout a student teaching placement. Although triads have some flexibility in determining how they will conduct their conferences, the teacher education office at Sequoyah asks that supervisors visit each of their assigned student teaching settings at least three times during the six supervision cycles. Basic guidelines for the progression of dimensions of focus are provided by the teacher education office, but it largely up to the student teaching triads to determine the order in which they focus on the dimensions. A larger emphasis is placed and classroom management and student engagement at the beginning of the placement while instructional support becomes a larger focus toward the end.

Sequoyah is currently in their third year of implementing the CLASS® and MTPтм-P supervision model. Prior to this, the MTPтм system had been implemented verbatim, and it has since been adapted to align more closely to a preservice teacher education setting. Another recent change is the switch from using all doctoral students as 
university supervisors to the mixed group that was described above. Although the findings and recommendations I will present later in this capstone will focus on the current program context, it is important to note that the various teacher education programs at Sequoyah are in the midst of considering redesign. The secondary program, for example, is considering moving to a one year program rather than the current two year track. These changes, combined with other factors, result in a higher level of flux when it comes to structures that may affect university supervision. These include the people that are supervising, the training that supervisors receive, where students are placed for student teaching experiences, and more. Each of these structures will be described in more detail throughout the remaining chapters of this capstone.

It is important to note that the teacher education office at Sequoyah University gathers data on several components of the supervision cycle through the use of an online platform called Chalk \& Wire. This includes the lesson plan feedback, videotaped lessons, and the supervisor-written prompts as well as their responses written by student teachers. These components are collected for multiple reasons, but primarily in order to ensure student teachers are being guided through their experience, are meeting benchmarks for planning, are in engaging in guided reflection on their teaching, , and as a way to show growth in their professional development. Some of these data sources are also used for program accreditation sources. Conference summaries and action plans are submitted to members of the student teaching triad, but this data is not collected by the teacher education department. Therefore, very little is known about the triad conferences and the impacts they have on the development of student teachers at Sequoyah University, an issue that has also been reported in the teacher education field in general 
(Asplin \& Marks, 2013). Additional information regarding the specific context in which the proposed study will take place will be provided in the methods section of this report.

As previously mentioned, this study seeks to provide greater understanding of the value of the student teaching triad conference and the specific practices that university supervisors engage in that members of the triad view as helpful. Knowing more about these specifics will perhaps provide crucial information about the development of preservice teachers. The triad conference is the only step in the MTP ${ }^{\text {TM}}-\mathrm{P}$ Supervision Model where all three members of the triad are participants. Other components, such as lesson plan feedback, are of course important, but they usually take place only between the student teacher and university supervisor. While student teachers are encouraged to work in conjunction with mentor teachers in order to plan their lessons and submit them to mentor teachers for feedback, this is not an official structure that is required or documented as part of each cycle. Because of this, as well as the desire to learn more specifically about the conferences and ways to improve practice, I have chosen to primarily focus on the triad conference rather than the other steps of the supervision model. However, it should be noted that it is nearly impossible to isolate the conference from other events that take place in the supervision cycle because each step builds on the last. Post-observation conferences and supervisor feedback will be discussed more in depth through the literature review. Specific gaps in the literature such as a lack of recent studies, methodological flaws, lack of variety in participants' subject areas, and nonUnited States contexts will also be discussed.

In this study, I address questions about the triad conference by observing triad conferences as well as collecting qualitative interview data from all members of the 
student teaching triad. Additionally, I collected documents associated with the conferences including notes, summaries, and action plans. Analyzing data collected from these sources of information allows me to provide a clearer picture regarding the usefulness of triad conferences and the specific practices of university supervisors that are viewed as being beneficial in the growth and development of student teachers at Sequoyah University. These findings inform my recommendations to the teacher education faculty about ways to encourage promising supervision practices through training and on-going support.

\section{Theoretical Frameworks}

Two theoretical frameworks, Relational Trust and Activity Theory, provide a context for examining my research questions and conceptual framework. Additionally, these frameworks inform my research design and ultimately guide my interpretations and findings.

\section{Relational Trust Theory}

Building upon Coleman's social capital theory, Bryk and Schneider (2002) developed a theory to describe the central role of trust in building effective education communities. According to their theory of relational trust, distinct role relationships characterize the social exchanges of schooling: teachers with students, teachers with other teachers, teachers with parents, and all groups with the school principal. Each person within a relationship has an understanding of her role's obligations and holds expectations about the obligations of the other people as well. In order for a school community to be successful, it must achieve agreement in each role relationship regarding the central understandings about obligations and expectations of everyone. 
Regardless of the power associated with each role, all participants are mutually dependent upon one another to achieve the desired outcomes of the school community (Bryk \& Schneider, 2002). Figure 3 demonstrates how relational trust how relational trust operates within a school.

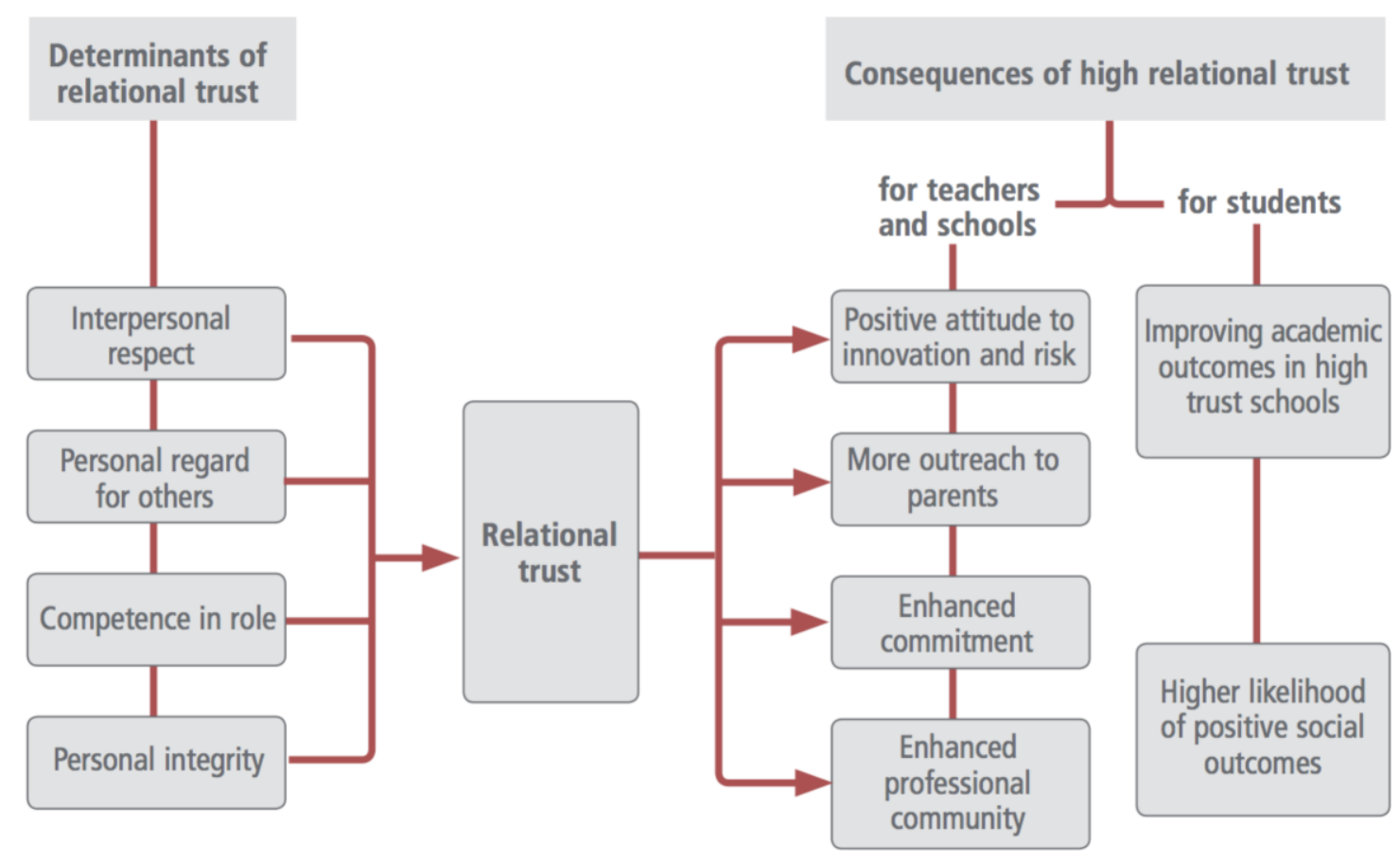

Figure 3. How relational trust operates in a school. From Robinson V., Hohepa M., \& Lloyd, C., (2009). School leadership and student outcomes: Identifying what works and why best evidence synthesis. Wellington: Ministry of Education.

Although a student teaching triad is slightly different than a school community, many of the goals and roles are extremely similar, and each of the participants are dependent on one another in order to achieve the desired outcomes of the student teaching placement. The student teaching triad can also be thought of as a small community within the overall teacher education program. Just as the goal of a school is to educate students, the ultimate goal of the student teaching experience is to educate and prepare preservice teachers to enter the field of teaching and to teach competently. The 
central roles of the student teaching experience are student teachers, mentor teachers, and university supervisors. While the teacher education department composed of faculty and staff are also important players in what takes place during student teaching, they are not considered core actors when thinking about the central relationships of the student teaching experience. This is similar to Bryk and Shneider's (2002) original conception of the theory that did not include other stakeholders in the school such as counselors and staff, school board members, or superintendents when thinking about the core role relationships that characterize the social exchanges of schooling. Each of these stakeholders is of course important to the everyday functions of school environments, but they are not the core actors and most central relationships when it comes to educating students. Similarly, while the faculty and staff and other stakeholders associated with teacher education are important in preparing teachers, these parties are not involved in the central interactions that take place regularly throughout the student teaching experience. However, it should be noted that these stakeholders were heavily involved throughout the student's program through coursework and other interactions that may have resulted in residual influence that may continue to impact students and the student teaching experience as a whole. Because they are well beyond the scope of this study, these complexities will not be addressed further.

Student teachers, mentor teachers, and university supervisors are all dependent on one another in order to achieve the central goal of preparing preservice teachers to teach. Student teachers are dependent on the structure, support, guidance, and feedback provided by mentor teachers and university supervisors that will allow them to complete their student teaching experience successfully. Mentor teachers are dependent on student 
teachers to take into consideration their suggestions and feedback in order to maintain an environment where their shared students can learn. Mentor teachers are dependent on university supervisors to help guide and support them through their role of mentoring the student teacher by serving as a connection to the university and helping mentor teachers navigate the structures of the student teaching requirements. University supervisors are dependent on student teachers and mentor teachers to engage in the tasks and assignments associated with the student teaching placement such as submitting lesson plans and videos, teaching lessons, setting the tone for the incorporation and use of the teacher education curriculum, responding to prompts, providing information about the placement classroom, and attending and contributing to discussions held during triad conferences. As in the original conception of relational trust, each of these dependencies between the parties create a sense of vulnerability for everyone involved, and therefore any steps taken to reduce this sense of vulnerability in another-to make them feel safe and secure—-builds trust across the community (Bryk \& Schneider, 2002).

Bryk and Schneider (2002) asserted that relational trust is based on personal beliefs and observed behavior of others. Through their interactions with one another, student teachers, mentor teachers, university supervisors, and the teacher education department faculty and staff discern the intentions motivating the actions of others. Each party considers how others' actions advance their own interests or appropriately reflect the central beliefs and goals of the overall community, which in this case is to prepare student teachers. If relational trust is successfully built and maintained among the parties, it will ultimately result in increased likelihood that the goals of the community are accomplished (Bryk \& Schneider, 2002). 
According to Bryk and Schneider (2002), relational trust is based on four considerations: respect, personal regard for others, competence in core role responsibilities, and personal integrity. Respect includes genuinely listening to what others have to say and taking those views into account as you continue working with one another. Even when disagreements do arise in a respectful environment, people can still feel valued if it is clear that others respect their opinions. Without the presence of respect, people may avoid working with one another in order to avoid negative situations or perpetual conflict may erupt. Personal regard stems from the willingness of people to go beyond the formal job requirements. This includes practices such as a willingness to reach out, being consistently available when needed, and conveying a sense of openness to others. Trust is also built upon perceptions of competence in core role responsibilities. Trust is built when everyone does their jobs and does them competently. Regular instances of negligence, incompetence, or lack of fulfillment of assigned responsibilities can undermine trust and result in negative relationships that ultimately detract from the attainment of overall community goals. Finally, personal integrity informs feeling of trust based on whether others can trust you to keep your word and ensure that community goals are the central focus. In the case of a student teaching triad, it is important for each member to know that everyone's main goal is to successfully prepare the student teacher to assume the professional responsibilities of a teacher and to teach competently.

The four considerations upon which relational trust are built align well with the existing literature addressing student teaching triads. This alignment will be further clarified as I explore previous findings on student teaching triads and the four considerations of relational trust in my literature review. In this capstone, I use Bryk and 
Schneider's (2002) relational trust theoretical framework, and its four considerations upon which relational trust is built, as a lens through which to view and better understand the factors that influence student teaching triads and the perceptions of their members. This framework not only contributed to my conceptual framework overall, but also served as an organizational tool through which I viewed and structured my findings.

\section{Activity Theory}

Activity theory also serves as a useful framework through which to view my work because it is useful for understanding how a wide range of factors work together to impact an activity (Engestrom, Miettinen, \& Punamaki, 1999). The central feature of activity theory is that it considers an entire activity system beyond just one actor or user and accounts for multiple factors such as the community, role of artifacts, motivations, complexity of real life action, and more (Engestrom et al., 1999). Every activity we do relies on a network of actors to make it possible, and these actors are the people, ideas, rules, and tools that make the activity possible (see Figure 4).

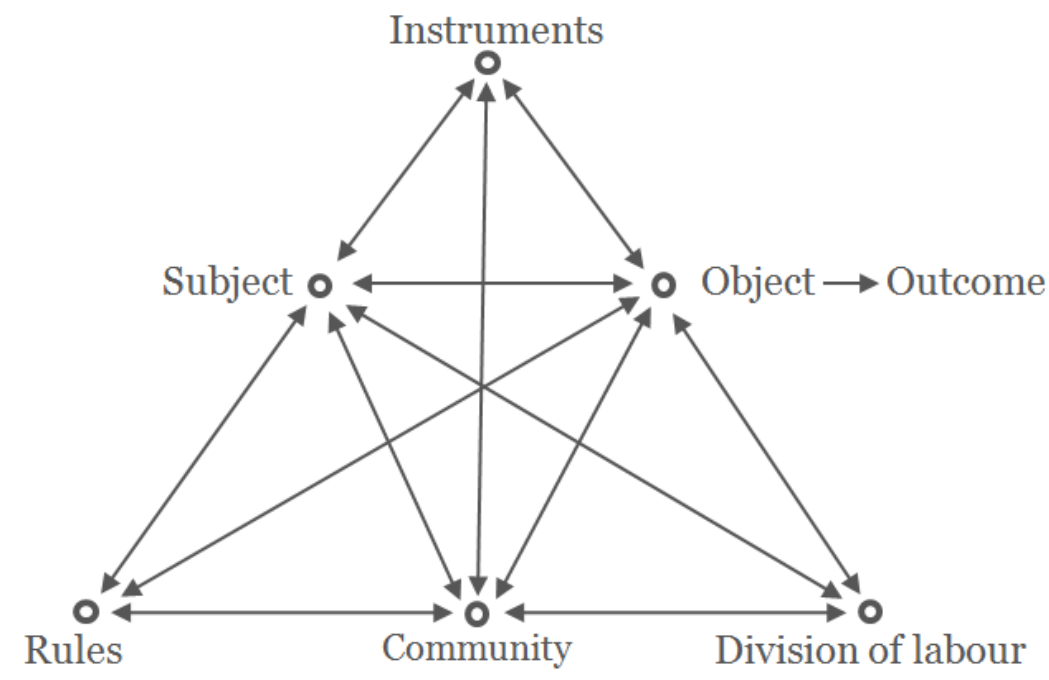

Figure 4. Activity Theory. From Kaptelinin (2015). 
Within the activity theory framework, the outcome is the ultimate goal or motive for the activity system as a whole that the actors hope to accomplish. In the case of this capstone, the ultimate goal is to prepare preservice teachers to assume the professional responsibilities of a teacher and to teach competently. The objects in the system consist of the experiences, knowledge, and physical products that help the actors achieve the outcome. In this case, the objects would consist of the various experiences and assignments within student teaching such as lesson plans, observation videos, and prompts and responses. The instruments, also sometimes referred to as artifacts, are the tools used throughout the process of working to achieve the goal. Within student teaching at Sequoyah University, these tools would include the CLASS® observation system, the MTPTM-P protocol, and Chalk and Wire, the online platform used to store documents and videos. The subjects of the system refer to the people performing the activities. They are the group of the people whose perspective is the focus of the analysis, in this case the triad members. The division of labor refers to how the work of the activity is split up by the subjects and the instruments they use. The community consists of the social group or environment where the activity takes place. In this capstone, the community is represented by the particular schools where student teachers are placed as well as Sequoyah University. Throughout the system, rules influence the activity through social, cultural, or other norms. In this capstone, the rules refer both to the official requirements of student teaching as developed by Sequoyah University and the unofficial norms and practices engaged in by the student teachers, mentor teachers, and university supervisors. All of these actors contribute to the overall outcome. If you remove any of the actors from the system, it either fails to continue or has to function very differently. It is 
important to note that the actors represented by the theory are not fixed and they can change dynamically (Engestrom et al., 1999). In my conceptual framework model (see Figure 5), I will specifically highlight the features of activity theory as they apply to the student teaching experience.

\section{Conceptual Framework}

Systematic study of the university supervisor and role of the post-observation triad conference requires a conceptual framework (Figure 5) to make sense of the complex nature of supervision. Using elements from both Bryk and Schneider's (2002) relational trust theory and Engestrom et al.'s (1999) activity theory, this framework illustrates how this model is used to guide the current study and serves as a basis for this capstone. 


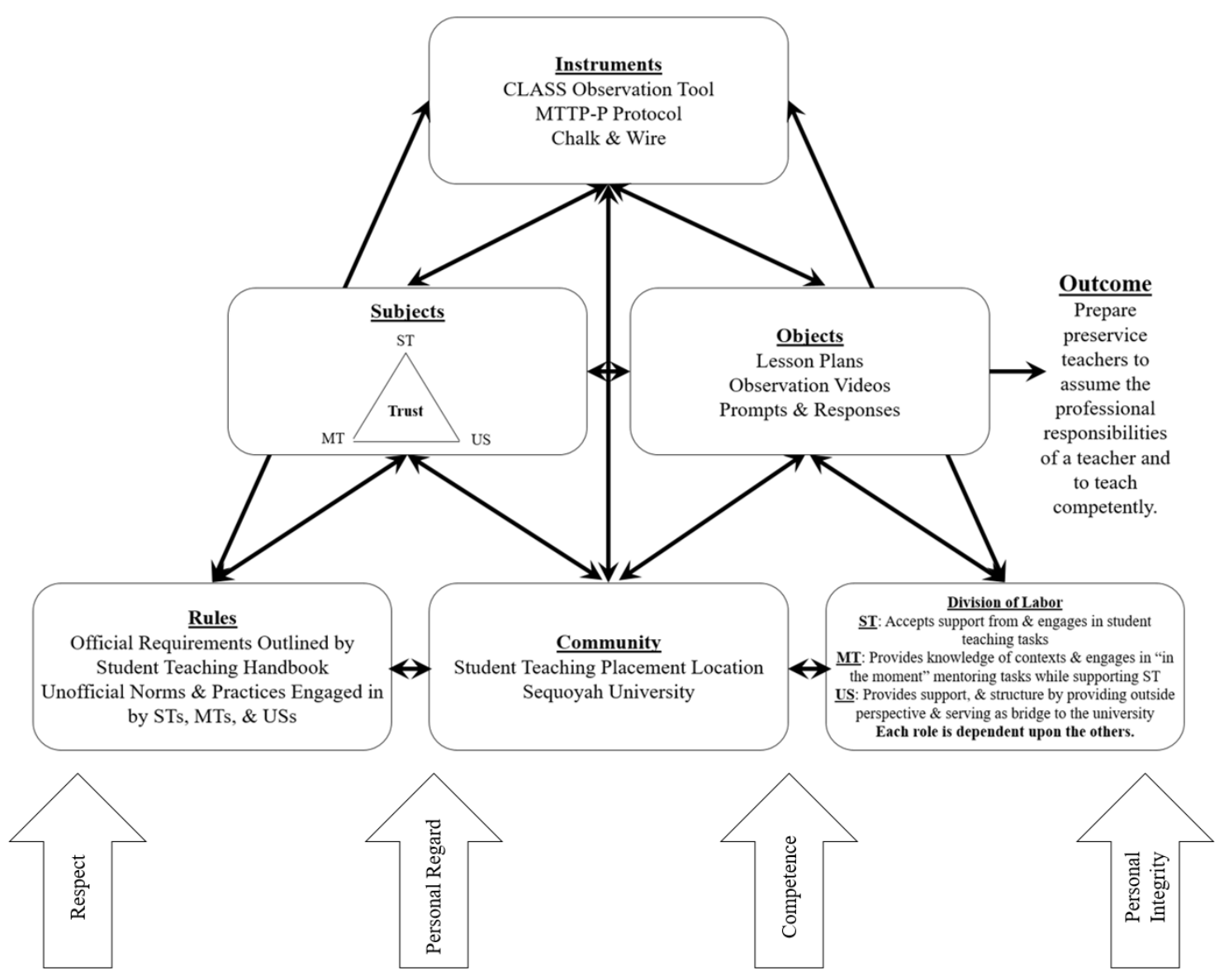

Figure 5. Conceptual framework for this capstone.

The conceptual framework highlights the interactions of each factor within the student teaching experience that contributes to the overall outcome of preparing preservice teachers. It serves as a reminder of the complexity of the student teaching triad, provided a lens through which I viewed and organized the data, and also influenced the specific ways I organized the findings stemming from this study. The primary purpose of this capstone is to provide teacher education faculty at Sequoyah with a better understanding of the specific practices of university supervisors that members of the student teaching triad find to be most helpful as well as the overall usefulness of triad conferences. Because deeper understanding of these supervision practices and triad 
conferences is so dependent on information provided by the three members of the triad, I believe it is important to focus primarily on the trust component of the framework that is heavily influenced by the four considerations upon which relational trust is built. These four factors of respect, personal regard, competence in core role responsibilities, and personal integrity influence the overall model of the activity of the student teaching experience. The work of the triad is not done in isolation from the other factors contributing to the outcome, but the rest of the system cannot function successfully without the components of respect, personal regard, competence, and personal integrity that influence the interactions student teachers, mentor teachers, and university supervisors are able to have. Because of this, the relational trust component of the conceptual framework provides a useful lens through which to analyze each triad members' perceptions of helpful supervision practices and the utility of triad conferences. The methods I used to collect data for this study were influenced by the conceptual framework and the complexity of student teaching it illustrates. Because there are so many factors that influence the overall outcome of whether a student teacher is prepared to assume the professional responsibilities of a teacher and to teach competently, it was necessary to gather data from a variety of sources by interviewing each triad member, watching the observed lesson video, observing the triad conference, and analyzing each of the documents associated with the supervision cycle.

\section{Research Questions}

This study addresses the following research questions:

1. What specific practices do university supervisors engage in that are viewed as helpful by members of the student teaching triad? 
a. What about these practices make them helpful?

b. Are there any practices that are viewed as problematic or unhelpful? How and why are they problematic or unhelpful?

2. How are triad conferences useful in promoting the development of student teachers?

a. How do student teachers, mentor teachers, and university supervisors perceive the triad conferences?

b. Are triad conferences viewed as helpful? In what ways?

c. In what ways, if any, do conferences impact student teachers' future classroom decision-making in their student teaching placements?

d. What specific problems do student teachers, mentor teachers, and university supervisors note about the triad conferences? What is the nature of these problems?

The answers to these questions shed light on particular components of triad conferences that are viewed as helpful by all members of the student teaching triad. 


\section{Chapter 2}

\section{Literature Review}

Increased attention on teacher preparation has led to increased questioning about what works in teacher preparation. There is a lack of updated and relevant work looking at university supervisors and the role they play in the development of student teachers. Many questions remain about the usefulness of university supervisors, the specific practices they engage in, and the utility of post-observation conferences. In this chapter, I will discuss what is known about successful student teaching field experiences and what past research shows us about post-observation triad conferences and the role university supervisors play in the development of student teachers. Particular attention will be paid to the four components that influence relational trust when applicable.

\section{Development of Preservice Teachers}

The preparation of preservice teachers through a student teaching field experience is a widely accepted practice in teacher education (Cuenca, 2011), although it is also possible to become certified in some states through alternative programs without student teaching first. The student teaching experience is considered beneficial because "modern learning theory makes clear that expertise is developed within specific domains and learning is situated within specific contexts where it needs to be developed" (Hammerness \& Darling-Hammond, 2005, p. 403). Practice is a necessary factor of this development. There are also several findings from the field of psychology about how we learn that are applicable to the student teaching experience. One psychological principle 
related to student teaching is that what students already know affects their learning (APA, 2015). Preservice teachers come to the student teaching process with knowledge based on what they have been taught in other settings and in the past. Student teaching allows them to either add to their existing knowledge through conceptual growth or revise their knowledge though conceptual change (APA, 2015). Mentor teachers and university supervisors may foster conceptual growth and change by "engaging students in meaningful, thoughtful interaction with the information to be learned" (APA, 2015, p. 8). A unique feature of teacher education is the fact that student teachers have spent thousands of hours as schoolchildren prior to starting their official education coursework and experiences as student teachers. A consequence of this phenomenon, referred to as “the apprenticeship of observation" by Lortie (1975), is that while people entering other professions are likely to be aware of the limitations of their knowledge, student teachers may be more likely to fail to realize that the aspects of teaching they perceived as students represented only a narrow view of the teacher's full role and job duties. While a student "sees the teacher frontstage and center like an audience viewing a play" (Lortie, 1975 , p. 62), they do not fully see or realize the "backstage" behaviors crucial to a teacher's job such as identifying objectives, creating assessments, planning for instruction, making general preparations, or engaging in reflection. Despite the incomplete nature of the techniques learned in the apprenticeship of observation, the methods still serve as a set of default strategies the student teachers may revert back to in times of indecision or uncertainty as they teach (Tomlinson, 1999). Indeed the central result of this highly influential period of observation is that teacher education courses are viewed by many as having a weak effect on student teachers (Borg, 2004). 
Another relevant psychological principle is that acquiring long-term knowledge and skill is largely dependent on deliberate practice, which involves "attention, rehearsal, and repetition over time and leads to new knowledge of skills that can later be developed into more complex knowledge and skills" (APA, 2015, p. 11). Student teaching provides preservice teachers with this practice by allowing them to test what they have learned through their coursework. Another psychological principle related to student teaching is that interpersonal relationships and communication are critical to the teaching-learning process (APA, 2015).

Knowledge of teaching emerges directly not only from the observation of teaching as students, but also from the activity of engaging in teaching for themselves, so student teaching provides preservice teachers with an opportunity to build their own understandings of teaching based on the practical quandaries they encounter in the field (Cuenca, 2010). To put it another way, "how student teachers learn about the knowledge and skills needed to teach and the situation in which they learn to teach are inextricably linked, shaping how student teachers ultimately understand the work of teaching" (Cuenca, 2011, p. 118).

There is a substantial body of literature addressing the conditions for successful student teaching experiences. These conditions include a field placement that is closely integrated with coursework (Beck \& Kosnik, 2002; Fosnot, 1996; Samaras \& Gismondi, 1998) and a well-trained mentor teacher (Knowles, Cole, \& Presswood, 1994; Zeichner, 1996) with a critical stance toward their own teaching and that of their student teachers (Maynard, 1996; Zeichner, 1996) who supports the student teacher (Williams, 1994), gives a considerable amount of meaningful feedback (Calderhead \& Shorrock, 1997; 
Maynard, 1996), and collaborates with the student teacher through team teaching or other collaborative methods such as co-planning (Ambrosetti \& Dekkers, 2010; FeimanNemser \& Beasley, 1997). University supervisors contribute to the success of a placement by working closely with mentor teachers, supporting student teachers, and visiting school sites (Beck \& Kosnik, 2000; Beck \& Kosnik, 2002). Placements are most helpful when a student teacher gains experiences in a diversity of sites (Beck \& Kosnik, 2002; Butt, 1994; Darling-Hammond, Wise, \& Klein, 1995). Based on Bryk and Schneider's (2002) relational trust theory, it holds that student teaching placements are also more effective when there is a high level of relational trust between the student teacher, mentor teacher, and university supervisor.

In a 2002 study, Beck \& Kosnik surveyed 65 and interviewed eleven randomly selected student teachers in order to identify characteristics of student teaching field placements they found to be most helpful. Their findings include emotional support from mentor teachers, being respected and treated as a teacher by both mentors and students, collaborating with the mentor teacher in terms of planning and finding resources, flexibility in teaching content and method, feedback from the mentor teacher, a sound approach to teaching and learning on the part of the mentor teacher, and systematically and progressively taking over classroom responsibilities, (Beck \& Kosnik, 2002). It should be noted that the interview and survey questions focused largely on the student teacher's relationship with the mentor teacher rather than that of the university supervisor, but it is easy to see how many of these identified factors align with the four components of respect, personal regard, competence, and personal integrity (Bryk \& Schneider, 2002). 
There is a substantial and growing body of literature on the contextual factors that influence student teaching, but some (Clift \& Brady, 2005) still urge researchers to move toward a more complex conceptualization of the interactive and social nature of developing practice in student teaching. Even with the growing body of work, much of the research on student teaching has continued to focus on the perspective of just one or two triad members rather than the interactions between all three (Valencia et al., 2009). Among the researchers who have examined the interplay of triad members within student teaching contexts, most have found the dynamics to be complex and challenging, resulting in mixed outcomes when it comes to the development of student teachers (Borko \& Mayfield, 1995; Bullough \& Draper, 2004; Newell, Gingrich, \& Johnson, 2001; Slick, 1997, 1998a, 1998b; Valencia et al., 2009).

For example, Borko and Mayfield (1995) followed four student teachers through their year-long student teaching experience. The researchers observed fifteen lessons and two post-observation conferences for each student teacher as well as conducted interviews of each mentor teacher and university supervisor. Their findings showed that university supervisors and mentor teachers had limited influence on student teachers' knowledge, teaching strategies, and beliefs about teaching. This could be due partly to the apprenticeship of observation (Lortie, 1975) discussed above given the fact it has been associated with weaker effects of teacher education programs on actual teaching practices (Borg, 2004). They (Borko \& Mayfield, 1995) called for clarification of the roles university supervisors and mentor teachers play as well as additional support and preparation for those fulfilling them. These suggestions align with what Bryk and Shneider (2002) would call competence in core role responsibilities, one of the four 
crucial factors in building relational trust. Calling for a clarification of roles also makes sense given the emphasis placed on the division of labor and importance of mutual dependency in Engestrom et al.’s (1999) activity theory.

Although at a smaller scale, Bullough and Draper (2004) also outlined difficulties in the triad relationship in their examination of a "failed triad" caused by tension between a cooperating teacher and a university supervisor in their views about how a student teacher should approach the teaching of algebra. This tension suggests a breakdown in the component of respect as outlined by Bryk and Schneider (2002). This finding, of course, should be interpreted with caution given the extremely narrow scope of the investigation. Slick (1997, 1998a, 1998b) agreed with previous findings and called for the redefinition of triad members' roles while Newell et al. (2001) suggested that alignment between the student teaching placement and university coursework should be increased if student teachers are expected to adopt methods learned at the university and develop reflective practice.

Valencia et al. (2009) more recently added to this body of work by examining the experiences of nine preservice teachers as they completed their student teaching experiences. Through interviews, observations, and document analysis, Valencia et al. (2009) were able to identify several lost opportunities for learning to teach during the student teaching experience, outlined in more detail throughout this section. One central tension students experienced was the "multiple views of the goal of field experiences, mentoring, and effective language arts instruction" (Valencia et al., 2009, p. 318). This lack of a central goal shared by all community members is not consistent with the concept of personal integrity as outlined by Bryk and Schneider (2002). Student teachers 
felt they were unable to consistently try out new ideas and approaches in the classroom, and that mentor teachers were unavailable or unable to provide feedback (Valencia et al., 2009). Once again, this is inconsistent with Bryk and Shneider's (2002) conception of personal regard, or the willingness to go beyond job requirements to make yourself consistently available by reaching out and offering your services. University supervisors also expressed dissatisfaction with the process, noting they felt unwilling to share valuable perspectives "due to the feedback they had received from the university, the affiliation they felt with the cooperating teachers, and their commitment to preserving harmony" (Valencia et al., 2009, p. 318) between all members of the triad. An issue that has not been explored within the literature is a situation where the university supervisor disagrees with the teacher education program goals. The effects of disagreement between university supervisors and mentor teachers will be discussed later in this capstone.

Finally, some of the mentor teachers noted the complexity of their roles, having to balance classroom and school responsibilities with mentoring student teachers, with "little support or training in how to serve these dual roles" (Valencia et al., 2009, p. 318). What the participants called "harmony" among the triad members is closely related to respect in the relational trust framework (Bryk \& Schneider, 2002) while the complexity of their roles is closely related to competence in core role responsibilities. Valencia et al., 2009, concluded their work by noting that in addition to clarifying and aligning roles of the members of the triad, we must "understand the inherent tensions among the multiple roles each member plays and the need for each person to balance them while participating simultaneously in the triad" (p. 318) in order to have deeper and more authentic discussions of learning to teach. By gaining deeper understanding of the role of the post- 
observation conference and how the position of university supervisor is viewed by all members of the triad, this capstone contributes to this line of research and further helps to clarify the structures that shape the learning and experiences of preservice teachers.

\section{The Role of Feedback in Post-Observation Triad Conferences}

Communicating feedback productively is extremely important to professional learning in many professions, and research shows that student learning can be increased when students receive regular, specific, and timely feedback on their work (APA, 2015; Brookhart, 2008; Hattie, 2008). According to a study of 32 post-observations conferences between 21 pairs of university supervisors and student teachers, supervision of student teachers by engaging in a supervision cycle is essential to student teachers' professional development (Tang \& Chow, 2007). Supervision has normally been conceptualized as consisting of five stages: (1) the pre-observation/planning conference, which may or may not take place in person and usually features lesson plan feedback; (2) observation of the lesson, either in person or through virtual means; (3) analysis and strategy where the supervisor considers notes and developed a plan for the conference; (4) the postobservation conference, once again either conducted in person or virtually; and (5) postconference analysis where the supervisors analyzes her own performance (Goldhammer, 1969). Goldhammer (1969) proposed this model of supervision because he believed it resulted in "more democratic behavior on the part of the supervisor, an improved teacher attitude toward the process of supervision, and genuine interest on the part of the teacher in improving instruction” (Reavis, 1978, p. 581). Goldhammer's (1969) model of clinical supervision is considered the traditional approach still used in universities today (Acheson \& Gall, 2003; Pajak, 2003). As part of this model, post-observation 
conferences establish a process of collaborative reflection, a process which forms a "significant component of the practice teaching through helping student teachers build a bridge between their theoretical knowledge base and their practice experience in schools" (Akcan \& Tatar, 2010, p. 154).

There is some work focusing on the content and nature of post-observation conferences (Lewis, 1998), although the amount of research focusing on this topic has declined in recent years (Clift \& Brady, 2005). According to Fletcher's (2000) handbook on mentoring in schools, giving proper feedback is the most essential part of the university supervisor's role and requires systematic and accurate observation of a student teacher's performance. Fletcher (2000) goes on to note that feedback should facilitate reflection and foster critical thinking skills of student teachers on their own teaching practices. In order for these conversations to take place and to be well-received, it is necessary for members of the triad to perceive strong interpersonal relationships and communication (APA, 2015; Brookhart, 2008; Hattie, 2008).

\section{Post-Observation Conference Dialogue}

Several studies have looked at the conversations held during feedback sessions between student teachers, university supervisors, and mentor teachers (Lopez-Real, Stimpson, \& Burton, 2001; Tang, 2000; Zeichner and Liston, 1985). For example, Zeichner and Liston's (1985) study of conferences held between seven university supervisors and fourteen student teachers found that post-observation conference discussion focused mainly on identifying goals, curriculum materials, students, lessons, and context. In a study conducted at a university in Hong Kong, Tang (2000) recorded post-observation conferences for seven teachers and found that immediate classroom 
practice rather than wider educational or theoretical issues is the primary concern in postobservation conferences. Concern about the lack of theoretical and wider educational issues during post-observation conferences, several teacher education researchers (Tang \& Chow, 2007; Lopez-Real, Stimpson, \& Bunton, 2001; Zeichner \& Liston, 1985) have called for research that will contribute to a better understanding of the basis of supervisor-student teacher conversations. The types of questions being asked in triad conferences is also a focus of study, with Jyrhama (2001) finding that "why" questions asked by university supervisors helped student teachers think more deeply about the components of effective teaching and enabled them to critically discuss their own teaching practices. Although this study (Jyrhama, 2001) took place in a foreign context (Finland), the large sample size of 196 university supervisors and 226 student teachers responding to the survey makes it noteworthy.

\section{Observation Tools and Reflection}

Other work looks at the possible influence of practices and instruments such as observation forms on the content of conversations in post-observation conferences. Instruments like observation forms on which the supervisor records data observed in the lesson have been shown to have substantial impacts on the content of supervisor-student teacher conversations (Tang \& Chow, 2007). In a study of 27 university supervisors' observation notes, Bunton, Stimpson, and Lopez-Real (2002) found that less structured observation forms that allow for more descriptive and questioning comments are more likely to encourage reflection on the part of student teachers. Waring (2013) offers additional suggestions for promoting reflection on the part of student teachers stemming from his detailed analysis of four post-observation conferences. These include talking 
less, being less directive, and asking open-ended questions such as "how do you think the lesson went?" (Waring, 2013). Brandt (2008) analyzed post-teaching feedback by conducting a four-year study on feedback given to TESOL teachers. The study, which included 95 participants in nine different countries, found that withholding value judgments and avoiding unsolicited feedback resulted in more reflection (Brandt, 2008). In her textbook on instructional supervision, Zepeda (2007) echoed the finding about withholding judgments and avoiding unsolicited feedback and also recommended that supervisors make open-ended statements about aspects of teaching observed instead. The practices of asking open-ended questions, withholding judgments and making openended statements are closely related to the concept of respect as outlined by Bryk and Schneider (2002) because they allow participants in the triad to listen to one another and respect each other's opinions. Others have addressed whether the timing of triad conferences in relation to the observation affects the quality of reflection (Williams \& Watson, 2004). Williams and Watson (2004) analyzed and compared six delayed feedback sessions with six immediate feedback sections and found that a higher level of reflective analysis resulted from delayed debriefings.

\section{Post-Observation Conference Topics}

Akcan and Tatar (2010) analyzed the differences in the perceived importance of various topics by university supervisors versus mentor teachers by conducting classroom observations of 52 student teachers as well as post-observation conferences and document analysis. The researchers found that "classroom management was seen as a precondition for effective teaching by a majority of mentor teachers whereas university supervisors frequently made comments on the quality of activities" (p. 165) and content. 
This is related to Acheson and Gall's (1997) assertions in their book of clinical supervision techniques that there may be disagreement between mentor teachers and university supervisors about the relative importance of behaviors that represent good teaching. As previously discussed, disagreements such as these may affect trust between members of a triad if they are not handled in a respectful manner. Although there is a growing body of research on post-observation conferences (Akcan \& Tatar, 2010), little of the available literature on supervisory conferences attempts to explore the perspectives on feedback from all members of the triad. Because quality feedback is so crucial to the development of preservice teachers (Bailey, 2006; Fletcher, 2000; Tang \& Chow, 2007), it is important to know the dynamics and nature of feedback student teachers receive from their university supervisors during post-observation conferences. The capstone contributes to this topic by exploring perspectives on various forms of feedback from each member of the student teaching triad.

\section{Perspectives on University Supervisors and the Student Teaching Triad}

In recent decades, researchers have focused on the student teaching experience from the different perspectives of triad members. Studies have looked at student teaching from the student teacher's perspective on mentor teachers (Glenn, 2006); the mentor teacher's perspective related to university supervisors (Koemer, 1992; Veal \& Rickard, 1998), and the university supervisor's perspective on mentor and student teachers (Bain, 1991). Several studies also focus on relationships between members of the triad (Lemma, 1993; Caires \& Almeida, 2007) and the differing roles that each member performs (Caires et al., 2010; Hyland \& Lo, 2006; Johnson \& Napper-Owen, 2011). 
However, there are far fewer studies looking at the utility of university supervisors from the perspective of all three triad members. Of the studies focusing on triad members' perspectives of the student teaching experience that do exist (Ali \& Khalid, 2015; Caires \& Almeida, 2007; Murphy, 2010; Talvitie, Peltokallio, \& Paivi, 2000; Tjeerdsma, 1998; Veal \& Rikard, 1998), most of them focus on the views of only one triad member (usually the mentor teacher or student teacher), and the majority of them are either dated or were conducted in a foreign country. Several of these studies also focus on student teachers in specific content areas such as physical education rather than provide more general information from a wider and more diverse group of participants. Each of these studies, which involve work closely related to the topics and questions of this capstone, will be addressed beginning with those providing perspectives from mentor teachers, continuing with student teachers, and then perspectives of all three members of the triad as a whole. Methodological flaws and gaps in the literature are addressed as I present ways this capstone will contribute to the body of work focusing on university supervisors and student teaching triads.

\section{Mentor Teachers Perspectives' on Student Teaching and Triads}

In recent decades, several studies have examined the student teaching experience from the perspective of the mentor teacher. Gibbs and Montoya (1994) used a mail survey to gather information from 149 elementary classroom teachers regarding the perceived influence of student teachers on the mentor teachers' classrooms and professional development. Tannehill (1989) interviewed three mentor teachers prior to and after student teaching about their perspectives on the placement while Rikard and Veal (1996) interviewed 23 mentor teachers about their beliefs, practices, and 
preparation. There were inconsistent results in terms of perspectives on student teaching, with some mentor teachers claiming positive experiences while others reported negative experiences. Most of these studies also relied on a single data source such as interviews or surveys.

Tjeerdsma (1998) expanded this line of research by using multiple data sources (interviews, journals, and observations of lessons) to examine the student teaching experience from the perspective of seven elementary physical education mentor teachers. While the primary focus of the study was on the purposes of physical education and the experiences of being a mentor teacher as a whole, some of Tjeerdsma's (1998) findings can inform this capstone. Tjeerdsma (1998) found that mentor teachers viewed the purpose of student teaching as letting the student teacher experience the "real world of teaching" because "college classes were not enough to become a good teacher" (p. 222). It is possible that these beliefs suggest a lack of trust when it comes to competence in core role responsibilities on the part of the university supervisors (Bryk \& Schneider, 2002). Participants in the study identified three primary duties of mentor teachers: (1) to guide and lead the student teacher through the experience; (2) observe the student teacher and provide feedback and ideas; and (3) encourage, support, and make the student teacher feel comfortable. In contrast to the perceived duties of mentor teachers, the teachers in the study reported that the single primary duty of university supervisors was "that of overseer and moderator" (p. 223), which once again suggests a lack of agreement on perceived responsibilities and division of labor. This role of overseer and moderator included helping to keep a good working relationship between the mentor teacher and student teacher and clarifying the university's expectations about the student teaching 
internship for the mentor teacher. Another important finding from the study reveals that the mentor teachers with the most positive experiences were those that said they "received considerable help from the university, appreciated the clear guidelines established by the university, and valued interactions with the university supervisor" ( $p$. 226). These structural attributes are clearly related to the rules and community components of activity theory (Engestrom et al., 1999). Mentor teachers who perceived mostly negative experiences reported few interactions with and little help from the university supervisor.

In the same year that Tjeerdsma's (1998) study took place, Veal and Rikard (1998) also analyzed mentor teachers' perspectives on aspects of student teaching. Focusing more specifically on the student teaching triad, Veal and Rikard (1998) interviewed 23 physical education mentor teachers. The study could have been improved methodologically as the mentor teachers all came from a convenience sample of those willing to respond, and each participant was only interviewed once by inexperienced graduate students. Findings from the study revealed many negative perceptions of university supervisors. For example, mentor teachers indicated they did not usually collaborate with supervisors because of the relatively few visits they made to the school. Several of the respondents also mentioned criticizing university supervisor actions when talking to their student teachers. These criticisms included the beliefs that university supervisors looked only at the negative aspects of a lesson, made the student teachers fearful of observations, and assigned unfair grades. These criticisms point to a lack of respect among members of the triad as defined in relational trust theory (Bryk \& Schneider, 2002). Many mentor teachers also noted that they perceived university 
supervisors as being "out of touch" with the "real world of public schools" (p. 113) and that the mentor teachers themselves knew so much more about what the student teacher has done than a university supervisor that only visited infrequently for a small amount of time. This perceived lack of competence would contribute to lower levels of trust according to Bryk and Schneider's (2002) framework. The mentor teachers interviewed saw university supervisors as outsiders largely because they were "unfamiliar with the context of student teaching and lack knowledge about the pupils that would allow them to relate their comments to specific incidents during the student teacher's lessons" (p. 114). Mentor teachers offered recommendations such as having the university supervisors visit the schools more to both observe and teach so they could have a better understanding of the teaching context. Veal and Rikard (1998) concluded their study with three recommendations for changing the then current model of supervision including shared power between mentor teachers and university supervisors, even distribution of conversation during conferences, and recognition by all parties the "student teacher's need to own the naming and framing of problem areas and strengths" (p. 117). The views mentor teachers expressed in the study were overwhelmingly negative, with not a single positive contribution of university supervisors having been noted. It is difficult to say if these responses were a true reflection of how mentor teachers felt, were a result of the way the interview questions were framed (e.g. "If you could change places with a university supervisor, what changes in student teaching would you make?”, p. 110), or perhaps were due to researchers' biases reflected in presentation of the findings. 


\section{Student Teachers' Perspectives on Student Teaching and Triads}

In addition to studies focusing on perspectives of mentor teachers, work has been done to gather views of student teachers as well. While there are valuable findings from these studies that can help inform how student teachers perceive student teaching and their fellow triad members, it should be noted that all of them come from foreign contexts. Therefore, one gap in literature this capstone addresses is how American student teachers perceive university supervisors and the student teaching triad in general, and comparisons between the multiple contexts will be possible.

Talvitie et al. (2000) investigated student teachers' views about the influence of contributions from university supervisors and mentor teachers on their professional development. A total of 16 students from a professional teacher program at a university in Finland participated. Like the other studies discussed so far, these 16 participants were all from a physical education program. The source of data for the study consisted of journals kept by the student teachers as part of their practicum, and students were instructed to record "those aspects or events in their teaching, classrooms, and teacher education programme that most occupied their thoughts" (Talvitie et al., 2000, p. 82). The structure of journal reporting was left open so that student teachers were not restrained in their responses. Perhaps due to this fact, many of the study's findings were general as well. For example, Talvitie et al. (2000) reported that the majority of participants "reported that their supervisors or cooperating teachers had a strong influence on the changes they experience" (p. 83). Student teachers reported being guided to reflect more and make better instructional decisions, but it is unclear if this was primarily a result of guidance from their mentor teachers or university supervisors. It is 
also unclear how this guidance took place. Student teachers reported seeking the advice of their university supervisors for more general professional development dilemmas while they sought more practical and classroom-level advice from their mentor teachers. Once again, few details are provided regarding the exact nature of these dilemmas. Because of the extremely general, and self-reporting nature of the student teachers' responses, it would be irresponsible to consider the researchers' findings generalizable in any way.

A more recent and applicable study conducted by Caires and Almeida (2007) explored student teachers' perceptions about the most positive aspects of supervision provided during their student teaching experiences. This study involved a group of 224 student teachers in an initial teacher licensing program at a university in Portugal. Unlike the previous research discussed, the participants in this study came from a variety of subject area backgrounds, and researchers chose to divide them into two main groups: those who planned on teaching Arts and those who planned on teaching Sciences. These two groups were not clearly defined. The researchers used the Inventory of Experiences and Perceptions of the Teaching Practice (Caires \& Almeida, 2001) instrument to evaluate student teachers' experiences. The instrument is composed of 61 items organized into five dimensions of teaching practice: (1) Professional and Institutional Socialization; (2) Learning and Professional Development; (3) Socio-Emotional Aspects; (4) Support/Resources/Supervision; and (5) Vocational Aspects. The most applicable of these dimensions, Support/Resources/Supervision, had several items that examined "the degree of satisfaction concerning the support and aid granted by the university and schools supervisors in terms of, for example, emotional encouragement, modeling, or 
logistical back up" (p. 518). Most of these items were rated using a five-point Likert scale ranging from totally disagree to totally agree, but there were also a few qualitative items that allowed for more open responses and explanations. Five Likert scale items and two open-response questions related to supervision were used to present findings about supervision. It is important to note that for the Likert scale items, the student teachers' observations simultaneously consider the university and mentor teachers' performance, therefore making it impossible to determine the amount of nature of influence each of these members had on the perceived development of the student teacher. Data showed that student teachers were generally satisfied with their supervisors' performance with all of the Likert scale items being rated at about a level three in the five-point scale. The two open response questions asked the student teachers to name three positive aspects of supervision provided by their university supervisors and three positive aspects of supervision received from their mentor teachers. Results showed that student teachers particularly valued the structural and organizational aspects of university supervision using terms such as "organized, enlightening, and relevant" (p. 521) to describe the aid they received from supervisors. Student teachers also appreciated their university supervisors' personal attributes such as accessibility, competence, sympathy, attentiveness, flexibility, calmness, and confidence. Interestingly, feedback was only mentioned in $6.1 \%$ of the responses when listing positive aspects of supervision. Overall, the student teachers' responses indicate that the most prized aspects of university supervision during student teaching are "related to the way supervisors act and interact with their trainees in terms of involvement, proximity, respect and support ensured" (p. 524), especially as it pertains to the university supervisors' interpersonal characteristics. 
These are closely related to the components of respect and personal regard as outlined by Bryk and Schneider (2002). This study is clearly more methodologically sound than those previously discussed, but it is important to remember that it also takes place in a foreign context. The quantitative methods used provide us with a wider sample of perspectives, but it also results in less explanation of the how and why of what student teachers view as positive aspects of the support they receive from university supervisors.

A more recent and large-scale study concerning the perceptions of student teachers on supervision was conducted by Ali and Khalid in 2015. This study involved 638 participants from 16 teacher training institutions in Pakistan. Researchers used a questionnaire based on a five-point Likert scale ranging from strongly agree to strongly disagree to obtain the opinions of student teachers "regarding the role/characteristics of university supervisors and cooperating teachers performed during student teaching" (Ali \& Khalid, 2015, p. 428). Results showed that there were not significant differences in perception of availability of mentor teachers and university supervisors, but mentor teachers were viewed as significantly more helpful for student teachers when it came to lesson planning and preparing instructional materials. Other significant differences between university supervisors and mentor teachers included more vigilance in providing lesson plan feedback on the part of university supervisors, more active observation by mentor teachers, more feedback during and after observations by university supervisors, and more encouragement and support throughout the student teaching experience by mentor teachers. University supervisors and mentor teachers were viewed as essentially equal when it came to general problem solving. These differences in the roles that mentor teachers and university supervisors were perceived as performing suggest that there was a 
clear division of labor and that triad members were aware of who was responsible for which roles (Bryk \& Schneider, 2002). Once again, it is important to remember that this study took place in a context that is very different from that of the United States. Although this study provided data from a large sample size, this quantitative data once again failed to provide a more complete picture of how and why mentor teachers and university supervisors were viewed differently by the student teachers.

\section{Triad Members Perspectives on Student Teaching}

The literature I have discussed so far in this review focuses on the perspective of a single member of the student teaching triad. Murphy (2010) conducted a similar study in a college-based educator licensure program in Guam, this time focusing on the perspectives of all three members of the student teaching triad. Murphy (2010) interviewed each of the members of eight distinct triads three separate times during the student teaching experience as the primary method of data collection. In addition to responding to open-ended questions during the interviews, the student teacher participants also completed daily journals in which they reflected on "significant occurrences, problems encountered, possible solutions, effectiveness of solutions, experiences learned in teaching, emotional responses and reflections, and any questions or concerns that arose" (p. 57). Results showed differences in the ways student teachers perceived university supervisors and mentor teachers. Students agreed that university supervisors in general had higher expectations that were more often based on theory or research while expectations from mentor teachers were more realistic and pragmatic. Additional differences included more clear feedback from university supervisors and deeper personal connections and relationships with mentor teachers. Interesting insights 
gathered from the mentor teachers included the fact that many of them felt poorly trained and that they measured the success of their relationships with student teachers based mostly on personal compatibility. Mentor teachers noted the necessity and importance of the student teacher having both a mentor teacher and university supervisor because the presence of two experienced teachers enhanced the student teaching experience by providing a balance between theory and practical knowledge and that supervisors brought their own strengths to help contribute "to the overall growth and professional development of student teachers" (p. 61). Like the mentor teachers, the university supervisors surveyed felt they were poorly trained in the art of supervision and most of their knowledge and skills came from past teaching experience or other sources of information such as interactions with colleagues or attendance at conferences. University supervisors also noted that they would like to communicate more with mentor teachers, and they too noted the importance of complementary views that having both a mentor teacher and university supervisor could offer for the student teachers, thus enhancing their experiences with student teaching. This study had several limitations that significantly lower the generalizability of the results. These include the low sample size, the specific context of student teachers enrolled in a physical education program in Guam, and the self-reporting nature of all of the data.

\section{Connecting the Literature to the Conceptual Framework}

Although I have made several connections between the major findings of the literature on student teaching triads and relational trust, I think it is useful to reorganize these findings and situate them within my conceptual framework more broadly in order to highlight those connections and begin to describe how the four factors of relational trust 
are apparent within student teaching triads. It is important to note that many of the studies cut across the four factors that contribute to relational trust. Because of the intertwined nature of these factors, it is impossible to keep them entirely separate from one another. I will provide justification for why I chose to play each of the studies under its respective factor of relational trust.

\section{Respect}

Recall that Bryk and Schneider (2002) described respect as respecting the input of all members of a community by genuinely listening to what others have to say and taking those views into account as you work with one another. In a respectful environment, community members feel comfortable saying what is on their minds and can still feel valued when disagreements occur as long as it is still clear that others respect their opinions. There is a basic recognition that each member of the community plays an important role in contributing toward the overall goal. Lack of respect within communities can lead to avoidance of interactions with one another or perpetual conflict between members. The concept of respect as described by Bryk and Schneider (2002) applies to student teaching triads in much the same ways it does in other communities. In order for student teachers, mentor teachers, and university supervisors to feel respected within their triads, they have to feel like they are being listened to and that their opinions matter. Common disagreements arising from differences in teaching philosophies, conceptions of roles, preferred teaching methods, and other issues can be mitigated as long as opinions are respected.

Components of respect are visible in the literature across studies. Recall that interpersonal relationships and communication are critical to the teaching-learning 
process and that these factors have significant impact on how feedback is received (APA, 2015). In Bullough and Draper's (2004) study of one student teaching triad, there was tension between the mentor teacher and university supervisor that disagreed on instructional philosophies and methods. This disagreement and tension led to resentment among all members of the triad and resulted in what Bullough and Draper (2004) called "a failed triad". The tension and resentment suggests there was a low level of respect among the mentor teacher and university supervisor and that they were unable to disagree respectfully.

Valencia et al. (2009) noted a related issue in their finding that university supervisors were working hard to preserve harmony within their triads at the expense of sharing valuable perspectives. Some supervisors in the study reported that they were hesitant to share some of their own experiences and practices with teaching because they did not feel like they would be well-received by mentor teachers if they were not in alignment with mentor teachers' own practices. An unwillingness to share your own opinions is a clear sign of lack of respect between members according to Bryk and Schnedier (2002). Valencia et al. (2009) found that the hesitation to share negatively impacted the conversations that triad members were able to have by not allowing participants to have deeper and more authentic conversations about teaching.

Veal and Rikard (1998) also found issues of respect in their study of mentor teachers' views on university supervisors. They found that mentor teachers were critical of university supervisors' few visits to the school setting and reported that they only looked at negative aspects of a lesson, made students fearful of observations, assigned unfair grades, and were "out of touch with the real world of public schools" (p. 113). 
Because some of the complaints focus on interactions with student teachers, it is possible that student teachers had similar feelings. In a respectful environment, mentor teachers and student teachers would have been able to discuss some of these issues with university supervisors in a way where everyone could still feel valued. In the evidence presented in Veal and Rikard's study (1998), there is no evidence of a basic recognition that each member plays an important role in contributing to the overall goal of preparing the student teacher. The mentor teachers' complaints also touch on the competency factor and the personal integrity since it seems like university supervisors were not perceived in having the student teachers' best interests at heart.

\section{Personal Regard for Others}

Bryk and Schneider (2002) describe personal regard as the actions taken by a member of a group with the goal of reducing another group member's sense of vulnerability. It has been called the most powerful dimension of trust discernment and is evident when people see that others care about them and are willing to extend themselves beyond what their role might formally require (Bryk \& Schneider, 2002). Within a student teaching triad, personal regard may be demonstrated by going beyond the steps and requirements as outlined in the student teaching handbooks for each role. A university supervisor, for example, might show personal regard by doing one or more live observations in order to gain a deeper sense of a classroom context, making herself available for live conferences rather than virtual ones via phone or Skype, or even meet a student teacher at a coffee shop outside of the supervision cycles in order to provide advice or serve as a sounding board. 
There is evidence of aspects of personal regard throughout the literature on student teaching. Beck and Kosnik (2002) found that university supervisors were often willing to work very close with mentor teachers in order to support student teachers by visiting school sites and going beyond official requirements in multiple cases. The student teachers in Caires and Almeida's (2007) study shared many personal attributes they valued in their university supervisors such as accessibility, sympathy, attentiveness, and flexibility. In fact, Caires and Almeida (2007) found that the most prized aspects of supervision by student teachers were "related to the way supervisors interact with student teachers based on involvement, proximity, respect, and support ensured" (p. 521). In Valencia et al.'s (2009) work, on the other hand, student teachers reported that their mentor teachers were unavailable or unable to provide feedback. This lack of personal regard as perceived by the student teachers resulted in difficulty in having deeper and more authentic conversations about teaching (Valencia et al., 2009).

\section{Competence in Core Role Responsibilities}

Competence in core role responsibilities centers on the idea that a person is able to perform the duties of their individual role effectively. There is recognition between all members of a community that interdependence of their roles exists in attaining the overall desired outcome (Bryk \& Schneider, 2002). When perceived negligence or incompetence in a person's enactment of their role regularly occurs, it undermines trust between everyone. It is important to note that roles should be clearly defined in order for members of a community to know when someone is not fulfilling their role competently. If there is a lack of clarity regarding which community member is responsible for which tasks, there is a higher chance that incompetence will be perceived and overall levels of trust will be 
diminished (Bryk \& Schneider, 2002). In a student teaching triad, details of each member's role may be outlined in handbooks provided by the teacher education department. University supervisors and mentor teachers may also engage in mandatory training in order to learn the intricacies of fulfilling their roles in supporting student teachers.

Many studies have focused on the roles each member of a student teaching triad plays throughout a student teaching placement. Some studies (Borko \& Mayfield, 2005; Slick 1998b; Tjeerdsma, 1998; Valencia et al., 2009) show a clear disagreement regarding the roles of university supervisors and mentor teachers while other, more recent studies (Ali \& Khalid, 2015; Murphy, 2010) found clear delineation between roles. In the case of Borko and Mayfield (1995), their finding that mentor teachers and university supervisors had limited influence on student teachers' knowledge, strategies, and beliefs led them to call for clarification of the roles of mentor teacher and university supervisor and additional support and preparation for fulfilling those roles. Slick (1998b) echoed these calls for clarification. Tjeerdsma (1998) found some tension in mentor teachers' perceptions of their roles versus university supervisors. They found that mentor teachers believed they represent the "real world of teaching" because "college classes were not good enough to become a good teacher" (p. 222). Additionally, they saw the single primary duty of university supervisors as that of "overseer and moderator" (p. 223). University supervisors were not surveyed as part of this study, but many researchers would disagree with this conception of the role of university supervisor as they have been shown to fulfill many additional duties (Banville, 2006; Coleman \& Mitchell, 2000; Fletcher, 2012; Johnson \& Napper-Owen, 2011; Vuran et al., 2014). Tjeerdsma’s (1998) 
findings, therefore, suggest a lack of agreement among roles, which can lead to difficulty in supporting and preparing student teachers (Valencia et al., 2009).

Unlike previous studies examining roles within triads, Ali and Khalid (2015)

found that there were clearly delineated roles between university supervisors and mentor teachers as perceived by student teachers. This study did not, however, determine whether these clearly defined roles contributed to improved outcomes. Murphy (2010) surveyed all three members of triads and found that members of each role had specific ideas about the roles of others. University supervisors were viewed as having high expectations based on theory and research and provided clear feedback. Mentor teachers, on the other hand, were seen as realistic and pragmatic and had deeper personal connections and relationships with student teachers because of the extra time they spent working together (Murphy, 2010). Mentor teachers thought the university supervisors brought balance between theory and knowledge, ties to university coursework, and their own strengths to the triad that helped contribute to student teachers' growth. This connects well with findings from other studies (Beck \& Kosnick, 2002; Fosnot, 1996; Samaras \& Gismondi, 1998) that field placements were more successful when they were closely integrated with coursework. In addition to this research focusing on the differing roles between mentor teachers and university supervisors, it is also important to note that positive experiences with student teaching have been clearly linked to clear guidelines provided by the university (Tjeerdsma, 1998).

\section{Personal Integrity}

Personal integrity is described as consistency between what a person says and does (Bryk \& Schneider, 2002). This has been closely linked to maintaining a central 
goal that informs a person's decision-making and interactions with others (Bryk \& Schneider, 2002). If members of a community believe that you mean what you say and use the community's ultimate goal as a perspective to guide your work, there will be higher levels of trust within the community. Within a student teacher triad, this is manifested in whether triad members perceive each other as using the ultimate goal of preparing the student teacher to enter the field of teaching as a guide for their actions. Valencia et al. (2009) found that tension exists within a triad when there are multiple views of the ultimate goal of field experiences and this results in difficulty when it comes to having deeper and more authentic conversations about teaching. Another way this can manifest within a student teaching triad is when it comes to providing feedback for student teachers. If mentor teachers and university supervisors are able to withhold value judgments when providing feedback, they are perceived as being more concerned about the student teacher's progress and therefore overall preparation (Brandt, 2008; Zepeda, 2007). This closely ties to the respect element of relational trust as well since people are less likely to feel respected when they feel like they are being judged (Bryk \& Schneider, 2002).

\section{Summary}

The field of teacher preparation is undergoing significant scrutiny and reform. There is a strong push to improve student teaching experiences, and by focusing on university supervision, it is possible to strengthen this component of preservice teacher education.

Several studies have been conducted looking at the student teaching experience in general. Researchers make a strong case for the importance of student teaching and the 
central role of feedback in the development of preservice teachers. Few studies have focused on the role of university supervision and even fewer have specifically addressed the utility of university supervisors and post-observation triad conferences. Of the studies that do address these topics, many are dated, take place in foreign contexts, focus narrowly on student teachers in specific subject areas such as physical education, have methodological flaws, are not widely (if at all) generalizable, and focus on a single triad member's perspective rather than those of all three. This capstone addresses some of these gaps in the literature by conducting a contemporary, United States-based study that takes into account the changing climate of teacher preparation and provides a better understanding of the usefulness of university supervisors and triad conferences by including the perspectives of all three members of the student teaching triad. By focusing on multiple factors that influence components of student teaching by analyzing the triads within a conceptual framework based on relational trust and activity theories, I am able to provide a more complete picture of the factors involved as members of the triad work to achieve the ultimate goal of preparing the student teacher to assume the responsibilities of a teacher and to teach competently. 


\section{Chapter 3}

\section{Research Methodology}

In this chapter, I will discuss the research methods that were used in the study. Specifically, I will address the research approach, the research site and participants, data collection methods, data analysis methods, trustworthiness, ethical considerations, research bias and assumptions, and limitations of the study.

\section{Restatement of the Problem}

Many universities are looking carefully at their teacher education programs and how they can be improved (Asplin \& Marks, 2013). The experiences of preservice teachers in their student teaching placements in particular is a large area of focus. While several studies have focused on student teaching as a whole, far fewer have focused on the university supervisor (Marks, 2002). Of these studies that do exist, many are dated, come from foreign contexts, or are methodologically flawed in some way.

University supervisors are responsible for creating connections between coursework and the student teaching field experience by referencing educational research, central philosophies or the teacher education program, and resources or assignments shared within previous coursework when possible (Caires \& Almeida, 2007). Little is known about the specific practices university supervisors engage in while fulfilling this role, especially those practices that each member of the student teaching triad finds to be particularly useful (Asplin \& Marks, 2013). Within the context of this study, teacher education faculty and staff at Sequoyah University want to better 
understand the value of the student teaching triad conference and the role that university supervisors play in supporting student teachers. Increased understanding of this crucial role could serve to benefit the university teacher education program as a whole by informing future university supervisor training and professional development practices, as well as inform future program evaluation. Beyond the scope of Sequoyah University, isolating specific university supervision practices that are viewed as helpful can allow researchers to later ask additional questions about what makes the practices helpful, under what conditions they are most successful, how they can effectively be taught and encouraged in university supervisor training, how the theories that inform university curriculum can be translated most easily and readily to the practical life of the classroom, and ultimately how they can encourage the further development of student teachers as they become practitioners in the field.

\section{Research Questions}

The purpose of this study is to provide the teacher education faculty at Sequoyah University and teacher educators in general with a deeper understanding of the usefulness of student teaching triad conferences and to identify specific practices of university supervisors that members of the triad find to be most helpful. The following research questions are addressed:

1. What specific practices do university supervisors engage in that are viewed as helpful by members of the student teaching triad?

a. What about these practices makes them helpful?

b. Are there any practices that are viewed as problematic or unhelpful? How and why are they problematic or unhelpful? 
2. How are triad conferences useful in promoting the development of student teachers?

a. How do student teachers, mentor teachers, and university supervisors perceive the triad conferences?

b. Are triad conferences viewed as helpful? In what ways?

c. In what ways, if any, do conferences impact student teachers' future classroom decision-making in their student teaching placements?

d. What specific problems do student teachers, mentor teachers, and university supervisors note about the triad conferences? What is the nature of these problems?

The answers to these questions will shed light on the practices of university supervisors as well as illustrate triad members' perspectives on the post-observation conferences.

\section{Research Approach}

This study was structured as a comparative multiple-case study of three student teaching triads from one teacher education program. Qualitative methods were most appropriate given the need to understand deeper perspectives that can best be captured through qualitative responses, face-to-face interaction, and observation. Other methods, such as a quantitative survey, would not provide a full understanding because people's thoughts, feelings, and beliefs are involved. Compared to other methods, the strength of the case study method is its ability to examine, in-depth, a "case" within its "real-life" context. According to Yin (2014), the case study method is useful when research addresses a descriptive or explanatory question. It can also be helpful when the researcher 
seeks to get an in-depth and first-hand understanding of events and interactions because it helps you make direct observations and collect data in natural settings (Yin, 2014). Case study methodology was the most appropriate approach for this study because of the nature of the research questions being asked and the contextual nature of triad conferences. The research questions focused largely on how conferences are perceived by different members of the triad, which aligns well with Yin's (2014) suggestions for when a case study should be used.

This study used multiple-case study approach, chosen for the purposes of using replication to strengthen the robustness of the findings (Yin, 2014). Each case or a participant was treated first individually as a unique case and then secondly compared with other members fulfilling the same role. Each role was then compared in order to observe trends in the findings. For example, the responses of one university supervisor were analyzed individually as a single case. Next, the data was compared to responses from the other university supervisors that participated in the study. Finally, university supervisors as a group were compared to data from mentor teachers and student teachers to form a more comprehensive picture of student teaching conferences and the benefits of university supervision. Similar steps were repeated for the participating mentor teachers and student teachers.

\section{Research Site, Participants, and Access}

\section{Research Site}

The research site for this proposed study is Sequoyah University, a public university in a Mid-Atlantic state. Sequoyah University has been offering teacher licensing since the 1960s and accepts between 160 and 180 students into their teacher 
education program each year. The majority of these students are enrolled in elementary education endorsement program, but endorsements in secondary English education, secondary math, secondary social studies, secondary science, P-12 foreign language, P-12 health and physical education, and K-12 special education are also offered. Additionally, students may earn add-on endorsements in gifted education, mathematics -Algebra 1, and English as a Second Language (ESL).

University supervisors at Sequoyah University are expected to serve as a liaison between the teacher education office, the clinical experience course that accompanies a student teaching placement, and the mentor teacher. The university supervisor is also encouraged to reference research, assignments, and educational philosophies central to the teacher education program. The university supervisor is responsible for supervision of the student teacher, facilitating effective communication among all stakeholders in the placement, serving as a goodwill ambassador for the teacher education program, and mediating any professional conflicts that may arise. University supervisors at Sequoyah University must have had at least some teaching experience, and they come from a variety of teaching backgrounds and other education-related roles. Some are doctoral students in other education programs while others are retired teachers and principals. All university supervisors at Sequoyah University participate in annual, three-day trainings where they learn the basics of the CLASS observation tool and how to conduct the six supervision cycles for student teachers. More specific information about backgrounds and experiences of the university supervisors that participated in this study will be provided. 


\section{Participants}

Purposive convenience sampling was used to identify the participants. The sample is considered purposive because it featured members of student teaching triads from a variety of programs at Sequoyah University. These included preservice teachers in the elementary, secondary English, and secondary math programs placed at an elementary school, middle school, and high school respectively. By recruiting participants from a variety of program, I was able to gain insight into differing perspectives across Sequoyah's program offerings. The sampling criteria were that each triad featured a mentor teacher, university supervisor, and student teacher in a general education placement that were all willing to participate in the study. I chose to focus specifically on student teachers in general education placements due to the fact that students seeking special education certification participate in two separate field placements. Because they would not necessarily have been in their placements for several weeks at the time of the observation and interview, I thought it was best to avoid students seeking special education certification. I clearly explained the purposes and nature of the study to all participants, and consent to participate in the study was secured using an informed consent form (Appendix H). In order to ensure confidentiality, I have chosen to use pseudonyms when sharing any information provided by the participants.

\section{Access}

In accordance with the University of Virginia's Research Oversight and Compliance requirements, I secured approval from the Institutional Review Board (IRB) for Human Subject Research in order to conduct my study. Once my IRB paperwork was approved, I recruited participants for my study with help from the teacher education 
office at Sequoyah University. I spoke with the field placement coordinator in order to gain insight into which students were placed in which schools, the student teachers that had the same university supervisors, and other relevant information that ensured I was able to recruit participants from across programs with differing university supervisors. I contacted potential participants via email and continued recruitment efforts until I was able to recruit three complete triads.

Because university supervisors at Sequoyah University supervise multiple student teachers, I thought it would be easiest to recruit them first and then ask the other members of their triads if they would be interested in participation. I contacted eight university supervisors during my first round of recruitment efforts. The choices of who I contacted were based on information I was provided by the field placement coordinator. While she did not suggest specific triads, she did provide information regarding school placement locations, grade levels, subject areas, and some demographic factors such as experience in the university supervisor and mentor teacher roles. Of the eight university supervisors I originally contacted, three were willing to participate, and I asked them which of their triads they recommended for participation in the study. Each supervisor provided the names of at least three triads that could work, and these recommendations were based on how far along in the student teaching placement and supervision cycles students were and whether there was regular involvement from the mentor teacher. Because I was primarily interested in which practices of university supervisors are most useful and how members of the triad perceive triad conferences, I thought it was preferable that I only include triads where the mentor teacher was regularly involved in the conferences and overall student teaching experience. Additionally, I only considered 
student teachers that had not yet completed the six supervision cycles as eligible participants because I wanted to be able to observe a conference and collect documents related to a supervision cycle to serve as an additional source of data. Using the information I gained about the triads from the university supervisors, I started a second round of recruitment efforts via email. In order for someone to participate, each member of their triad had to agree to participate in the study. Once I had three full triads that were willing to participate, I ceased my recruitment efforts and began to schedule conference observations and follow-up interviews. I explained my study once more and shared the informed consent form with all nine participants. I also made myself available for questions or concerns that participants may have had related to my study.

\section{Data Collection Methods}

Data sources for the case studies included interviews, observations of student teaching triad conferences, and documents such as lesson plan feedback, collaborative feedback forms, and conference summaries/action plans. Multiple sources of data were used to strengthen the credibility of the findings (Merriam, 2009), which is defined as "confidence in the 'truth' of the findings" (Cohen \& Crabtree, 2006). Credibility can be established by triangulating data, or crosschecking data from multiple sources (Cohen \& Crabtree, 2006; Merriam, 2009). In this study, data collected from the interviews, observations, and documents was triangulated in order to support the credibility of the findings.

\section{Observations}

Observations allow the researcher to observe "a firsthand encounter with a phenomenon of interest rather than a secondhand account of the world obtained in an 
interview" (Merriam, 2009, p. 117). The observations for this study occurred prior to interviews. This allowed me to ask questions about things I noticed in the conference observations as I was interviewing participants. Interviews related to what occurred during observations is considered best practice in qualitative fieldwork (Merriam, 2009). During the observations, I kept field notes focused on the participants and their conversations as they interacted in post-observation triad conferences. Conferences were also audio recorded with permission from the participants in order to allow me to revisit the actual conversations that took place. These audio recordings were transcribed using word processing software within 48 hours after the observation took place so as to ensure the situation was fresh in my mind. Along with these transcripts, I maintained analytic notes and reflections during and after the transcription process. Participants were asked to review and verify the transcripts of the conferences for accuracy. The field notes included data on the setting, participants, activities and interactions, conversation, and subtle factors (Merriam, 2009), as well as my notes and ideas about questions to ask during the subsequent interviews.

The observation protocol (Appendix D) was used to capture field notes for the observed conferences. These field notes provided additional data for triangulation and credibility purposes (Creswell, 2012). My role in the observations was as a participant observer. The field notes were taken by hand and typed the same day while the observation was fresh in my mind. The electronic and written versions of field notes, as well as the transcripts of audio-recorded conversations from the conferences were used for analysis. The field notes, recordings, and transcripts did not include personally identifiable data so as to preserve the confidentiality of all of the participants. 


\section{Interviews}

Interviews are a useful method when it is not possible "to observe behavior, feelings, or how people interpret the world around them" (Merriam, 2009). In this case study, the purpose of the interviews was to gather information on the perceptions of all members of the student teaching triad of how conferences are useful in the development of student teachers and the specific practices of university supervisors that are viewed as helpful. These beliefs and perceptions are not observable, so interviews were necessary. The interviews were focused on gathering data for all of the research questions.

Each participant was interviewed for approximately one hour following the observation of a triad conference. Due to the varying locations and timelines of the student teaching placements, each interview was scheduled individually with the participant. The interviews with mentor teachers and student teachers usually took place directly following a conference observation while interviews with the university supervisors were scheduled sometime within a week of the observations. The observations and interviews all took place during the months of November and December when most student teachers were fully serving as the primary instructor in their classrooms. It happened that two of the triads were on their sixth and final observation cycles while the third was on their fifth cycle. Implications of where the triads were at in their supervision timelines will be discussed in Chapter 4. By conducting the interviews after I observed the conferences, I was able to address or clarify any questions I had resulting from my observations. This allowed me to think of additional interview questions that I had not originally planned to ask, and these were tailored specifically to each individual triad depending on the situation. As an example, it was brought up in one 
of the conferences that one of the university supervisors had previously served as a teaching assistant in one of the student teacher's classes. Learning this in the conference allowed me to think of an additional question for all university supervisors and student teachers about their previous experiences working with one another in settings outside of the conferences. This investigation resulted in an important finding about the ways student teachers perceived their university supervisors. This finding will be discussed more in depth in Chapter 4.

The interviews were semi-structured (see Appendices B, C, and D for the interview guides). The interview questions were structured as open questions when possible so as not to lead the participant in responding a certain way (Patton, 2002). All interviews were conducted in person and were audio recorded and transcribed, which is best practice in qualitative research (Merriam, 2009; Patton, 2002). I used word processing software to type the transcriptions, and all personally identifiable information was removed. Pseudonyms were assigned to participants in order to preserve their confidentiality. The participants were asked to review and verify the transcriptions of the interviews for accuracy. Field notes, focusing on both verbal and nonverbal behaviors and the researcher's personal thoughts and interpretations, will also written following the interviews. Field notes and transcriptions from both the observations and interviews were collected in word processing software.

\section{Document Reviews}

Documents and videos served as the last source of data for this study. For each triad, I requested copies of the student teachers' lesson plans with feedback from the university supervisors, the teaching videos submitted for observation, prompts from 
university supervisors and prompt responses from student teachers associated with the recorded lessons, the most recent collaborative feedback forms between mentor teachers and student teachers, and copies of conferences notes and summaries/action plans that the university supervisor is supposed to send out following the conferences. Any personally identifiable data was removed from all documents that I received in order to preserve confidentiality. Although I requested each of these documents, I will explain in chapter four the reasons why they were not all available for each of the triads. The documents I did receive were dated, digitized, and added to my data files for each of the triads. All data, including field notes, transcripts, and documents, were stored on a password protected laptop and on an external hard drive not connected to the internet. Data analysis was conducted using word processing software on a password protected laptop. Following the data collection and analysis phases, I moved all data to an external hard drive not connected to the internet.

Although I had originally hoped the documents and videos would serve as useful data points in answering my research questions, they did not provide as much insight as I had hoped. In some cases, the documents provide useful support for other findings gathered from observations and interviews. I watched each of the observation videos for all three triads, but these mainly served to provide a useful context for the conferences that I observed. The videos made it easy for me to understand the conversations and feedback that took place within the triad conferences. The conferences themselves helped provide context to better understand the interactions, relationships, and levels of trust within the triads to the degree a single observation can. In my analysis of the data and 
presentation of findings, I will make specific note of cases where documents and videos helped support the findings.

\section{Field Placement Coordinator}

Although I would not consider her an official source of data for the findings I present in this capstone, it is important to discuss the fact that I talked about this project with the field placement coordinator at Sequoyah on multiple occasions. She was used primarily as a means of gaining access to participants and was instrumental in providing context for the issues I discuss throughout the capstone. Rather than discuss her views on any of my research questions, she simply provided contextual information about the structural features of supervision and student teaching at Sequoyah.

\section{Role of the Researcher}

In terms of involvement in my observations of conferences, I had very limited participation. For all observed conferences, I introduced myself to the participants, explained my research project once again, asked if there were any questions and answered any that were asked, received permission to audio record the conferences, and ensured that everyone signed the consent forms. During the conferences, I was an unobtrusive observer and declined taking part in any of the discussion. Since I did not want to directly influence the conference environment, I did not talk or participate once the official conference began. I observed and took notes on participants' behavior in as unobtrusive a manner as possible. In order to minimize the possibility that my notes would be distracting, I chose to take them by hand rather than typing them. Because I knew the conferences were being audio recorded, I focused my notes mainly on facial expressions and body movements. I also made notes of things that I wanted to bring up 
later in the interviews. This included a few clarifying questions about some things that were discussed, things that connected to what I already knew I wanted to ask about, and anything that stood out to me as something I had not considered before in regard to supervision practices and triad interactions. Although I took as many steps as possible to minimize my influence on the meetings, there is still the possibility that my presence as well as the knowledge they were being recorded might have influenced the behavior of the triad members.

During the data collection period, I reflected on my process of observation and note taking. I recorded data about my own research activities and their development using a methodological journal (Rossman \& Rallis, 2012) that I kept using word processing software. This allowed me to keep a record of my data collection, interpretation, and methodological decisions. Writing analytic memos throughout the entire process helped support my decision-making (Rossman \& Rallis, 2012). In these same files, I also documented the specific processes of analysis I used as well as decisions made during the analysis process. As with all of my other documents, all names were de-identified throughout the process. These notes and memos included important details such as the data being analyzed, procedural steps applied, decision rules used, conclusions drawn, connections to literature, associated research comments, and several reflections. Maintaining this methodological journal helped ensure that both the data collection and the analysis process was clear and the decisions I made were logical.

The timeline for data collection was necessarily organized around consideration for time restraints for student teachers, mentor teachers, and university supervisors given their extremely busy schedules. I made every effort to balance this face with my 
responsibility of collecting rich data. Observations, interviews, and document collection took place throughout the months of November and December.

\section{Data Analysis Methods}

I used the methods outlined by Miles, Huberman, and Saldana (2014) in order to analyze the data collected in the study. Miles et al.'s (2014) recommended three stages of analysis include: (a) data condensation, (b) data display, and (c) conclusion drawing/verification. During data collection, I typed my observation notes and analytic memos in which I regularly reflected on the data, searching for themes and emergent ideas. During the data condensation phase, I combined data from multiple sources through "writing summaries, coding, developing themes, generating categories, and writing analytic notes" (Miles et al., 2014, p. 12). This primarily included data from the interview responses and notes I had taken during interviews and conference observations. Next, I created a data display by organizing the data in meaningful ways in order to support drawing and verifying conclusions. This included organizing the interview data in matrices so that I could look at in multiple ways. I was able to look at responses sort by role, meaning I could, for example, see how all three university supervisors responded to the same question. This allowed me to see trends as well as notice differences between each participant that fulfilled each role. I also organized the data in a separate matrix so that I could organize responses by triad in order to compare responses within and across triads. In this step, I also organized data I had collected from the documents I received from the triads. Because I also wanted to keep track of how the different roles informed participants' answers, I color coded the interview responses and analytic notes to correspond with each group. In this way, I was able to keep track of which responses 
came from a university supervisor, which came from a mentor teacher, and which came from a student teacher. This data analysis process was interconnected and took place both throughout and after data collection (see Figure 6).

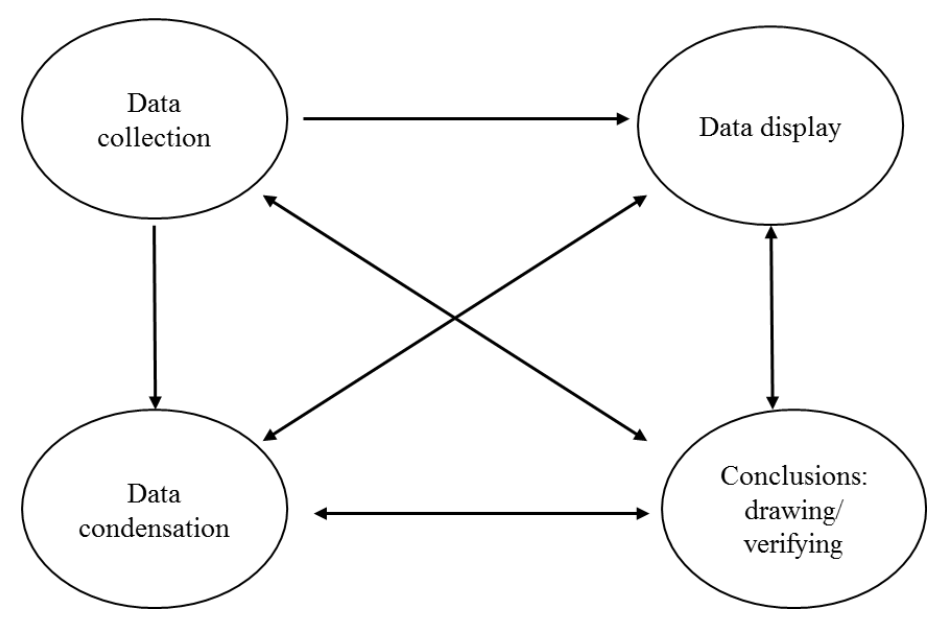

Figure 6. Miles et al. (2014) Interactive Model of Data Analysis. Adapted from Qualitative Data Analysis: A Methods Sourcebook, by M.B. Miles, A.M. Huberman, and J. Saldana. Copyright 2014 by SAGE.

Following data collection period, I engaged in data condensation through coding (Miles et al., 2014). This step began with "first-cycle coding" where preliminary codes were then assigned to the data (Miles et al., 2014). I used a short list of deductive start codes that I had previously identified through the literature review as a starting point for coding my data. I organized these start codes using the relational trust components of my conceptual framework. Throughout this process, I kept a record of the data collection and analysis process in my methodological journal. In addition to my deductive start codes, codes inductively emerged throughout the data collection process through descriptive codes that I assigned. Inductive codes are important to the process in order to allow codes to emerge rather than being forced onto the data from the beginning (Miles et al., 2014). Once I had a set of preliminary codes, based on both the literature and my theoretical 
frameworks, I revisited all data sources in order to analyze the data using both my deductive and inductive codes. This included checking the data from the documents I had collected against the codes stemming from the interview and observation data. At several points throughout my data analysis, I read and re-read my collected data and memos in order to search for emergent themes and possible assertions (Creswell, 2012). Some codes were revised throughout the analysis process while others were abandoned and new ones emerged. Throughout the entire process, I was mindful of how my codes and themes were related to my conceptual framework.

As the second step of coding, I identified pattern codes form the data by inducing them from the first-cycle coding. Pattern codes usually are comprised of categories or themes, causes/explanations, relationships, and/or theoretical constructs (Miles et al., 2014), and these stemmed largely from my conceptual framework and the four components influencing relational trust. The pattern codes were then expanded into analytic memos as a way to document my reflections and thinking processes about the data. Analytic memos are important tools to help organize conceptual thinking during the data analysis process, so I used tables created in word processing software in order to create a database to manage these memos and codes from multiple data sources.

Following all of the data condensation, I revisited my data displays using matrices. These supported drawing and verifying conclusions and were the most appropriate for the cross-case analysis I engaged in (Miles et al., 2014). I revisited the matrices at several points during the analysis phase in order to identify patterns and themes within and across each case, making contrasts and comparisons as I went (Miles et al., 2014). 


\section{Trustworthiness}

The value of qualitative research is based largely on the trustworthiness of the particular study, and this trustworthiness is usually based on credibility, transferability, dependability, and confirmability (Lincoln \& Guba, 1985). I designed this study to maximize trustworthiness by addressing each of these four factors.

\section{Credibility}

Credibility is confidence in the 'truth' of the findings (Lincoln \& Guba, 1985). A common way to increase credibility is triangulation, or to use multiple data sources in an investigation to produce understanding (Lincoln \& Guba, 1985). In this study, data was triangulated by using the multiple sources of interviews, observations, and document review.

Another way to improve credibility is through member checks when the participants are able to review the data that has been gathered or analyzed (Lincoln \& Guba, 1985). Member checks are important because they make it less likely that the researcher has incorrectly recorded, interpreted, or analyzed participants's statements (Lincoln \& Guba, 1985). Member checks were conducted as part of this study by allowing the participants to review both the observation and their individual interview transcripts. Due to the nature of the personal information that I collected in the interviews and conferences, the small number of participants that may have known one another, and the fact that I analyzed the data both individually and across participants, it was impossible to share my preliminary analysis of the data with each participant.

In addition to triangulation and member checking, I also engaged in peer debriefing while I conducted my analysis. Peer debriefing allows the researcher to 
explore "aspects of the inquiry that might otherwise remain only implicit within the inquirer's mind" by engaging in discussion with a peer regarding the analysis of data (Lincoln \& Guba, 1985, p. 308). The debriefer may engage in analytical probing and therefore help uncover biases, perspectives, and assumptions on the researcher's part, as well as allow the researcher to test and defend emergent hypotheses in order to determine if they seem reasonable and plausible to the debriefer (Lincoln \& Guba, 1985).

As a final step of increasing credibility, I will participated in negative case analysis. Negative case analysis may revise or broaden patterns emerging from data analysis (Lincoln \& Guba, 1985). This involved searching for and discussing elements of the data that did not support or possibly contradicted explanations that emerged from data analysis (Lincoln \& Guba, 1985).

\section{Transferability}

Transferability is a way the researcher shows that findings can be applied to other contexts. In qualitative studies, the primary way to establish transferability is by including thick description, or providing enough detail about a phenomenon so that one may evaluate the extent to which conclusions draw may be transferable to other times, settings, situations, and people (Lincoln \& Guba, 1985). For this study, I used thick description for all of my observation notes in order to allow others to determine for themselves if the findings are transferable to a particular context of interest.

\section{Dependability}

Dependability is showing that findings are consistent and could be repeated (Cohen \& Crabtree, 2006). Dependability is often supported through the use of external audits, which involve having a researcher not involved in the research process examine 
the process and product of the research study (Creswell, 2012). The purpose of this audit is to evaluate accuracy and whether or not the interpretations and conclusions of the study are in fact supported by the data (Creswell, 2012). For this study, the capstone committee served as the external auditors as they provided insight into data collection and data analysis and provided feedback on the findings of the proposed study.

\section{Confirmability}

Conformability is the degree to which results of the study could be confirmed or corroborated by others. It is the extent to which the findings of a study are shaped by the respondents and not researcher bias, motivation, or interest (Lincoln \& Guba, 1985). Confirmability of findings is supported through the use of triangulation and external audits, each of which has been previously discussed in terms of how the proposed study will employ their use. A second method of supporting confirmability is through reflexivity, which consists of the researcher engaging in critical reflection and being aware of biases and assumptions (Cohen \& Crabtree, 2006; Merriam, 2009). In order to engage in these processes, the researcher should systematically attend to the context of knowledge construction at each step of the research process (Lincoln \& Guba, 1985). In this study, I kept a methodological journal that documented the research process. This journal included reflexive entries that outlined my decisions, the reasons for them, logistics of the study, and personal reflection on what happened throughout the research process (Lincoln \& Guba, 1985).

\section{Ethical Considerations}

Due to the personal nature of the information I collected as part of interviews and observations, it was necessary to preserve the confidentiality of all participants. 
Therefore, any personally identifiable information from all stages of data collection and analysis was removed and pseudonyms were assigned. The proposal for this study also went through the process of being approved by the University Institutional Review Board. I provided informed consent forms that outline the scope of the study and any associated risks to all of the participants (Appendix $\mathrm{H}$ ).

\section{Researcher Bias and Assumptions}

As a researcher engaging in qualitative research as an observer and interviewer, it is extremely important to acknowledge my own biases and assumptions. My role as a researcher is to interpret the meaning making and interpretation of participants in the study through the lens of my conceptual framework and research questions (SchwartzShea \& Yanow, 2012). Researchers bring their own meaning making and interpretations to the interpretations and meaning making of participants (Schwartz-Shea \& Yanow, 2012). In order to make this study more useful and credible, it is necessary to disclose who I am as a researcher and how the process of data collection and analysis evolved (Rossman \& Rallis, 2012).

My interest in university supervision is a product of previously having been a university supervisor myself. Given this experience, it is possible that my own perspectives may impact this work. I strongly believe that the process of supervision is beneficial to student teachers, but I also believe there is great room for improvement when it comes to making the most of the university supervisor role. I do not believe that traditional, university-based teacher preparation programs are broken or should be abandoned. Instead, I think researchers should continue striving to learn more about student teaching as a whole, and should especially seek more information when it comes 
to the role of university supervisor. By learning more about the specific aspects of conferencing and the specific practices of university supervisors that different members of the triad view as beneficial, we can take the first step toward improvement of university supervisor training and development. This will in turn lead to improvement of the preparation of teachers, resulting in higher quality education for P-12 students throughout the country.

It should also be noted that I knew two of the student teachers, Rachel and Natalie, who participated in this study through my role as a graduate teaching assistant. In a semester prior to her student teaching, I served as Natalie's teaching assistant in a general instructional methods course. I served as a teaching assistant for Rachel's elementary student teaching seminar during the semester she completed her student teaching. I am not aware of any impact that these previous relationships had on the study, but I believe they are nevertheless important to report.

While taking notes and collecting and analyzing data, I was aware of my professional biases that support the use of university supervisors and traditional teacher preparation model. In order to avoid the influence of my biases on the data collection, analysis, and decision-making, I engaged in: (1) systematic reflection on the data collected by keeping a methodological journal (Rossman \& Rallis, 2012); (2) meticulous data collection and analysis that looked for both confirming and disconfirming evidence (Lincoln \& Guba, 1985); and (3) making strong assertions based on clear evidence from the analysis of multiple data sources (Creswell, 2012). 


\section{Chapter 4}

\section{Findings}

In this chapter, I will describe the findings resulting from my data collection as well as the recommendations that stem from these findings. In Chapter 3, I explained that I collected data from three different sources: observations of conferences, interviews of triad members, and document collection. In this chapter, I will restate my research questions, address the contexts in which I collected data, and describe my findings that resulted from data collection within my conceptual framework.

The purpose of this study was to provide the teacher education faculty and staff at Sequoyah University and teacher educators in general with a deeper understanding of the usefulness of student teaching triad conferences and to identify specific practices of university supervisors that members of the triad find to be helpful. Through observations, semi-structured interviews, and document analysis, I attempted to provide answers to the following research questions:

1. What specific practices do university supervisors engage in that are viewed as helpful by members of the student teaching triad?

a. What about these practices make them helpful?

b. Are there any practices that are viewed as problematic or unhelpful?

How and why are they problematic or unhelpful? 
2. How are triad conferences useful in promoting the development of student teachers?

a. How do student teachers, mentor teachers, and university supervisors perceive the triad conferences?

b. Are triad conferences viewed as helpful? In what ways?

c. In what ways, if any, do conferences impact student teachers' future classroom decision-making in their student teaching placements?

d. What specific problems do student teachers, mentor teachers, and university supervisors note about the triad conferences? What is the nature of these problems?

The answers to these questions will shed light on the practices of university supervisors as well as illustrate triad members' perspectives on the post-observation conferences. I will describe the specific contexts of each triad and present the findings as they relate to each of them based on the characteristics of the triad members and their perceptions of supervision practices and post-observation conferences. Following the findings presented within each triad, I will also describe findings that cut across triads and were evident in each case. Although grade level is not central to my findings or their interpretation, it is an easy way to distinguish between the triads as they are discussed. A summary of important characteristics for each triad is included in Table 1. 
Table 1

Student Teaching Triads

\begin{tabular}{|c|c|c|c|c|c|c|}
\hline & $\begin{array}{c}\text { Previous } \\
\text { Relationshi } \\
\text { p }\end{array}$ & $\begin{array}{c}\text { Experienc } \\
\text { e in Roles }\end{array}$ & $\begin{array}{c}\text { US's } \\
\text { Previous } \\
\text { Teaching } \\
\text { Experienc } \\
\text { e }\end{array}$ & $\begin{array}{c}\text { US's } \\
\text { Connectio } \\
\text { n to } \\
\text { Sequoyah }\end{array}$ & $\begin{array}{c}\text { Mentor } \\
\text { Teacher } \\
\text { Engageme } \\
\text { nt }\end{array}$ & $\begin{array}{c}\text { Perceived } \\
\text { Strength } \\
\text { of Student } \\
\text { Teacher }\end{array}$ \\
\hline $\begin{array}{l}\text { Elementar } \\
\text { y Triad } \\
\text { Rachel } \\
\text { (ST) } \\
\text { Alice (MT) } \\
\text { Holly (US) }\end{array}$ & None & $\begin{array}{c}\text { Alice- } \\
\text { mentored } \\
\text { several } \\
\text { STs } \\
\text { Holly-1 } \\
\text { time } \\
\text { supervisor }\end{array}$ & $\begin{array}{l}\text { Matched } \\
\text { with } \\
\text { student } \\
\text { teaching } \\
\text { setting }\end{array}$ & None & $\begin{array}{c}\text { Taped all } \\
\text { observed } \\
\text { lessons and } \\
\text { attended all } \\
\text { conferences }\end{array}$ & $\begin{array}{l}\text { Described } \\
\text { as ready } \\
\text { for the } \\
\text { classroom } \\
\text { by US \& } \\
\text { MT }\end{array}$ \\
\hline \begin{tabular}{l}
\multicolumn{1}{c}{ Middle } \\
School \\
\multicolumn{1}{c}{ Triad } \\
Natalie \\
(ST) \\
Carrie \\
(MT) \\
Erica (US) \\
\end{tabular} & $\begin{array}{c}\text { None, but } \\
\text { Natalie and } \\
\text { Erica met } \\
\text { once }\end{array}$ & $\begin{array}{l}\text { Carrie-1 }^{\text {st }} \\
\text { time } \\
\text { mentor } \\
\text { Erica-1 }^{\text {st }} \\
\text { time } \\
\text { supervisor }\end{array}$ & $\begin{array}{l}\text { High } \\
\text { school- } \\
\text { did not } \\
\text { match }\end{array}$ & $\begin{array}{c}\text { Doctoral } \\
\text { student }\end{array}$ & $\begin{array}{c}\text { Did not } \\
\text { view } \\
\text { observed } \\
\text { lessons and } \\
\text { attended } \\
\text { half of } \\
\text { conferences }\end{array}$ & $\begin{array}{c}\text { Struggling } \\
\text { with } \\
\text { classroom } \\
\text { manageme } \\
\text { nt but } \\
\text { described } \\
\text { as ready by } \\
\text { US \& MT }\end{array}$ \\
\hline \begin{tabular}{l}
\multicolumn{1}{c}{ High } \\
School \\
\multicolumn{1}{c}{ Triad } \\
Molly (ST) \\
Amelia \\
(MT) \\
Joyce (US)
\end{tabular} & $\begin{array}{c}\text { Joyce \& } \\
\text { Amelia (3 } \\
\text { years) } \\
\\
\text { Joyce \& } \\
\text { Molly (TA } \\
+ \\
\text { practicum) }\end{array}$ & $\begin{array}{c}\text { Amelia- } \\
\text { mentored } \\
25+\text { STs } \\
\text { Joyce-4 }^{\text {th }} \\
\text { year } \\
\text { supervisor }\end{array}$ & $\begin{array}{l}\text { Matched } \\
\text { with } \\
\text { student } \\
\text { teaching } \\
\text { setting }\end{array}$ & $\begin{array}{l}\text { Doctoral } \\
\text { student } \\
\text { and } \\
\text { teaching } \\
\text { assistant }\end{array}$ & $\begin{array}{l}\text { Viewed } \\
\text { video of } \\
\text { observed } \\
\text { lessons, } \\
\text { read } \\
\text { prompts } \\
\text { and } \\
\text { responses, } \\
\text { attended all } \\
\text { conferences }\end{array}$ & $\begin{array}{l}\text { Described } \\
\text { as } \\
\text { struggling } \\
\text { by US \& } \\
\text { MT; } \\
\text { expressed a } \\
\text { desire for } \\
\text { more time } \\
\text { with ST }\end{array}$ \\
\hline
\end{tabular}

Elementary Triad: Rachel, Alice, and Holly

\section{Elementary Triad Members}

Rachel is a fifth year student in the elementary combined bachelor's and master's degree program. Prior to this student teaching experience, she worked with kids in many other capacities include through summer camps, the Boys \& Girls Club, a classroom volunteer organization sponsored by Sequoyah, and her previous field placements while in the program. As with all other student teachers, Rachel's previous experience working with the CLASS ${ }^{\circledR}$ observation tool and the MTPTM-P protocol consisted of two full 
observation cycles in the practicum field experience taking place the semester prior to the full-time student teaching in the fall. Rachel's student teaching placement is in a second grade classroom in a low-poverty ( $~ 9 \%$ free or reduced lunch) and largely white $(71 \%)$, homogenous suburban elementary school in the county surrounding the city where Sequoyah University is located.

Rachel's mentor teacher, Alice, is in her fifteenth year of teaching. With a science background and an MBA, she chose to leave a lucrative career in the sciences in order to pursue her true passion of teaching. She's been at her current school for eleven years and worked at another local elementary school before that. Rachel is her fifth full-time student teacher from Sequoyah, and she has also served as a mentor teacher for three practicum students.

Holly is Rachel's university supervisor. She taught fourth, fifth, and sixth grades for five years prior to becoming a university supervisor. In addition to supervising twelve students for Sequoyah, she also serves as a part time consultant for an out-of-state education program. Holly's twelve student teachers are composed of seven students in the elementary program and five students in the secondary social studies program. Other than her role as a supervisor, she is not affiliated with Sequoyah in any way.

\section{Findings Salient to the Elementary School Triad}

Positive relationship. It was clear from both the observed conference and the participants' interview responses that Rachel, Alice, and Holly enjoyed a strong positive relationship with one another. This relationship was based on a variety of factors, but personality characteristics, flexibility, availability, and a feeling that all triad members were working toward the same goal were all presented as factors that contributed to this 
relationship. When asked what she did to build positive relationships within the triad, Holly described the first triad conference where introductions were made between herself, Alice, and Rachel:

The first day I was there during their teacher work week. They were cutting something out and I just kind of picked up scissors and was helping them from the very beginning. So maybe that set the tone a little bit, that I was 'with them.' I also used a lot of language like, 'how can we do this next time or what are we doing for this?' Maybe that set the expectation that I'm part of this with you and we're going on this journey together. I just tried to convey that as much as I could. I didn't want it to be that I was there to critique or judge in any sort of way. I ended every meeting with, 'What else can I do for you or how else can I serve you?' (Holly, personal interview, December 8, 2016)

The steps that Holly took in order to build relationships in her triad did not go unnoticed. Rachel described Holly as very thoughtful and appreciated that Holly met them in person each time for their conferences. She described herself as "feeling lucky" knowing that Holly "has always gone that extra mile" by doing "little things" like popping in and waving when she was in the building. She noted that she felt comfortable and like she "could have gone to Holly with anything" because she "always knew [Holly] was there to meet [her] needs and that it was all about [her] (Rachel, personal interview, November 30, 2016). "She cares a lot. I know she really wants to see me do well. She's supportive and goes beyond just checking the boxes. It's her personality too. She's just very warm and kind," (Rachel, personal interview, November 30, 2016) Rachel noted about Holly. Alice, for her part, also appreciated Holly's willingness to build 
relationships as they impacted the student teacher's willingness to accept feedback and ask for help when necessary. She reported that a positive relationship was absolutely crucial in order to have productive and meaningful conversations within triad conferences.

Mentor teacher engagement. Another relevant feature of the elementary triad was Alice's level of involvement throughout the supervision process. She was present for each of Rachel's observed lessons and even held the camera and followed Rachel as she interacted with students around the classroom. Because of this, she had direct knowledge of the observed lesson that was being discussed in the conference. She made it a priority to attend and participate in each of the triad conferences by contributing her own thoughts and questions about how the lesson went and placement was going in general. Rachel acknowledged that Alice frequently helped her look at things in a new way and appreciated that she helped her celebrate the good that happened in the placement without focusing too much on negative things. Alice's engagement allowed the three triad members to work together throughout the student teaching experience and ensure that Rachel was able to push herself in the placement.

Lessons learned. The elementary school triad provided important insights into the importance of relationships and engagement from all three members of the triad. Although there are various ways to build positive relationships within triads, certain factors can help. These include the supervisor making it a priority to conference face to face and communicating a sense that the triad and the growth of the student teacher is a central priority. The availability of the supervisor and her flexibility when it comes to 
scheduling are important factors in communicating this sense of priority to the other triad members.

Mentor teacher engagement can enhance a student teaching experience because they provide insight that neither student teachers nor university supervisors can. Like the student teachers, they have a full understanding of their classroom context. However, unlike the student teacher, they have experience and expertise in how contextual factors can influence instruction and classroom management. Because of their contextual knowledge and day-to-day interactions with the student teacher, they can provide a different level of insight than that of the university supervisor. University policies and representatives, as well as the university supervisor, can affect mentor teacher engagement by communicating the importance of watching observed lessons and contributing to triad conference discussions.

\section{Middle School Triad: Natalie, Carrie, and Erica}

\section{Middle School Triad Members}

Natalie is a fifth year student in the combined bachelor's and master's degree program in secondary English education. Prior to this student teaching experience, she worked with students through babysitting, serving as a nanny, working at summer camps, and through her previous field placements while at Sequoyah. Natalie's student teaching placement took place in a sixth grade language arts classroom at a low-poverty $(\sim 12$ free or reduced lunch) and largely white $(\sim 73 \%)$, homogenous suburban middle school in the county surrounding the city where Sequoyah University is located.

Carrie, Natalie's mentor teacher, is in her $25^{\text {th }}$ year of teaching. She has a bachelor's degree in education and a master's in counseling. She has served in various 
roles throughout the school system including as a peer counselor, test coordinator, guidance counselor, and classroom teacher. She has been a classroom teacher at the same school for the past ten years. Natalie is her first full-time teacher from Sequoyah, although Carrie has had four practicum students in the past and also a full-time student teacher from another area university.

Erica is Natalie's university supervisor. She is a first year doctoral student in the department of curriculum and instruction at Sequoyah, and this is her first semester supervising full-time student teachers. She has not supervised practicum students in the past, so this is her first experience serving as a university supervisor in any capacity. Erica taught eighth, ninth, eleventh, and twelfth grade language arts for three years at a very rural high school in the state. She also has a part-time job for a different department within the university. Working as a university supervisor was not part of her scholarship funding, so it is considered an additional job where she is paid by the number of students she is supervising. Erica's six student teachers are all in the secondary English education program. Two of them, including Natalie, are placed in middle schools while the other four are in area high schools. Prior to starting the supervision cycles, Erica and other university supervisors were invited by the secondary English seminar instructor to attend a class and meet the students they would be supervising. Erica took advantage of this opportunity and was able to meet Natalie and her other student teachers in a short, informal meet and greet.

\section{Findings Salient to the Middle School Triad}

Perfunctory efforts and relationship. The middle school provides useful insights into triad interactions when the university supervisor and mentor teacher perform 
their job duties in a perfunctory manner. Carrie did not make either her attendance or participation in the triad conferences a priority. Both Natalie and Erica reported that she only showed up to half of the conferences and would sometimes be working in her classroom doing other tasks even if she was there. A possible reason for her lack of participation in the conferences was because she did not watch any of the observed lessons. Carrie would frequently leave the classroom in order to give Natalie more independence and practice working with students as the central authority figure in the classroom. She also frequently served as a substitute for other teachers in the building. Because of these factors, she may not have felt knowledgeable about Natalie's progress within the placement, especially when it came to the specific observed lesson being discussed.

To a lesser extent, Erica also performed her job duties in a perfunctory manner. She completed the required steps for each supervision cycle by providing lesson plan feedback, watching the video and writing prompts, reading Natalie's prompt responses, and attending the triad conferences. However, Erica did not collect or provide any documentation to support these efforts in terms of the collaborative feedback forms and conference summaries/action plans. This may have further exacerbated Carrie's perceived lack of knowledge of the placement as she was neither attending some conferences nor receiving documentation about the conversations that were taking place. The reasons why Erica did not use these documents are unclear, but could possibly be due to a lack of understanding of the purposes or how they should be used to supplement other supervision structures. It is possible she did not have a full understanding of the supervisory relationship and how the documents could be used to help increase 
communication and strengthen relationships among triad members. Of the three triads, Erica discussed the need to build relationships the least.

Previous teaching experience. The middle school triad also highlighted a question about the importance of matched teaching. Matched teaching refers to the alignment between the characteristics of a university supervisor's previous teaching experiences and the characteristics of the current student teaching placement. Erica had previously taught high school and did not have any experience in a middle school setting. Both Natalie and Carrie reported that this affected the feedback and support that Erica was able to provide because she was not viewed as having knowledge of middle school classrooms and the students' unique needs. While this was perceived as an issue by Natalie and Carrie, it is not clear whether or not it affected Erica's supervision in any way. It is possible that this perception is related to the relationship among triad members and the perfunctory nature of some of their actions. The perception of unmatched teaching negatively affecting the triad could simply be a place holder for the relationship among the participants or a lack of knowledge regarding pedagogy, student development, the teacher education program, or something else entirely.

Lessons learned. It is important to consider the various reasons that this triad's relationship was different than the others described in this capstone and how it may have affected Natalie's development as a student teacher. Unlike in the case of the elementary school triad, both Carrie and Erica seemed unwilling to go beyond the minimal requirements of their roles. This is perhaps the main reason that the relationship was viewed as being much more professional than caring or nurturing by Natalie. She 
expressed uncertainty in whether Erica cared for her personally outside of the student teaching context:

I definitely think she wants to see me grow as a better teacher and is really nice. She doesn't know me that well individually, though, because we never met outside of a school context. It's sort of like the way a teaching assistant cares about your participation in class and you becoming a better student. It's more like an impersonal school, professional relationship. So the caring thing is like, like I think she wants me to do well and I think she'd be sad if I disappeared, but it's more professional. (Natalie, personal interview, December 6, 2016)

Whether matched teaching played a significant role in triad members' interactions with one another is unclear, but Sequoyah could take steps to mitigate this perception by matching university supervisors to student teaching settings based on their previous teaching experiences. In the cases where this is not possible, university supervisors could be given instruction on how to present themselves and their differing experiences in a way that are perceived as being beneficial. Additionally, Sequoyah should provide explicit training about how to build relationships within triads. Attention should be given to the specific characteristics that are associated with positive relationships so they may be emphasized, while those associated with negative relationships can be avoided or minimized. This could be done in initial supervisor training as well as continued professional development throughout student teaching placements. 


\section{High School Triad: Molly, Amelia, and Joyce}

\section{High School Triad Members}

Molly is a fifth year student in the combined bachelor's and master's degree program in secondary math education. Prior to this student teaching experience, she had no experience working with children outside of the required field placements as part of Sequoyah's teacher education program. It is also interesting to note that Molly did not have any personal experience in a traditional school setting since she was homeschooled for her entire life. Molly's student teaching placement took place in a secondary math classroom where she taught academic and honors level Algebra 2 and a combined Algebra 3/Trigonometry class with students ranging from ninth to twelfth grades. This placement was at a mid-low poverty ( $44 \%$ free or reduced lunch), diverse ( $\sim 54 \%$ nonwhite) high school in the small urban area where Sequoyah is located.

Molly's mentor teacher, Amelia, is in her $32^{\text {nd }}$ year of teaching. She has a bachelor's degree in math education. Over the course of her career, she has served as a mentor teacher for approximately 25 student teachers from Sequoyah and neighboring universities. She has mentored students in both practicum and full student teaching placements for Sequoyah over the past several years.

Joyce, Molly's university supervisor, is a fourth year doctoral student in the department of curriculum and instruction at Sequoyah. She has supervised both practicum and full student teachers for all four years she's been in the program. She taught an integrated algebra and biology course to ninth and tenth grade students at a progressive school in the Bronx for six years prior to entering her doctoral program. Although she served as a supervisor for an elementary student teacher and secondary social studies 
practicum students in the past, she is currently supervising five secondary math students in various high school settings. As a current doctoral student, Joyce receives funding from the department of curriculum and instruction in exchange for working 20 hours a week. Ten of these hours are dedicated to serving as a research advisor for her advisor while the remaining ten are dedicated to supervision. In addition to these roles, Joyce also serves as a graduate teaching assistant in both semesters of the math methods course for fourth year students and the fall student teaching seminar for current student teachers. Through these roles, she is able to get to know all of the secondary math education students that she will supervise in both practicum and full student teaching placements. It is important to note that she met Molly as a fourth year student in the methods course, served as her supervisor in her practicum placement, and has gotten to know her over the past three semesters. Joyce has also worked with Amelia for the past four years, serving as the university supervisor for all of Amelia's practicum and student teachers over the course of this time period.

\section{Findings Salient to the High School Triad}

Previously established relationships. The high school triad members' unique connections to one another highlighted questions about the effects of previously established relationships on supervision. Joyce and Amelia had been working together in a triad relationship for more than three years, so they had a strong rapport with one another and frequently communicated outside of the traditional means of email and conferences. This may have been in part due to Molly's perceived struggles within the placement. 
Molly and Joyce had also known each other for more than a year and worked together in coursework as well as the previous semester's practicum placement. Because of this relationship, Molly viewed Joyce as a professional with expertise in math pedagogical content knowledge. Joyce knew Molly well and had a strong knowledge of the experiences Molly had had in her math methods courses. Because of this, she was able to provide connections to resources and strategies that created a strong link between coursework at Sequoyah and the field placement, which contributed to Molly's development as a student teacher as perceived by her, Joyce, and Amelia.

Experience and commitment to role. Another factor highlighted by this triad was the role of experience and commitment to mentoring and supervising student teachers. Amelia had mentored over twenty-five student teachers and believed strongly in the importance of the work. She consistently looked for ways to improve the process by communicating with the student teaching seminar instructor who was in charge of setting some policies related to the supervision of secondary math students. Joyce was also experienced in her role as a fourth year supervisor. This is a large amount of experience for a doctoral student because it means she supervised every semester while she was in school. In addition to this time commitment, Joyce reported being very committed to and fulfilled by the experience of supervision overall and expressed a desire to continue the work in her new job as a faculty member at another university. I believe these factors played a role in the interactions Amelia and Joyce had with one another as well as with Molly. Their commitment to their roles meant they were willing to go beyond the basic job duties in order to fully support Molly as needed. Because Molly was struggling within the placement, this commitment manifested itself in several forms including 
outside communication among all triad members, Joyce's commitment to observing lessons live on two occasions, Amelia's desire to know more about other steps of the supervision cycle such as lesson plan feedback and video prompts, and everyone's willingness to have an extended triad conference lasting more than 90 minutes rather than the suggested twenty.

Lessons learned. The features of this triad raise questions about how these characteristics of previously established relationships and experience and commitment to roles could be leveraged in order to provide more effective supervision of student teaching candidates, particularly those that are struggling in a placement. Efforts could be made to allow mentor teachers and university supervisors work with one another for extended periods of time beyond just a semester. This prolonged relationship could build trust between these two members by allowing them to become more familiar with ones another's experiences, strengths, weaknesses, and general ways of doing things. An increased level of trust between the mentor teacher and university supervisor could result in increased trust with the student teacher as well.

In addition to establishing long term relationships, it is important to consider triad members' experience in and commitments to their roles. Mentor teachers are different from the doctoral students that supervise at Sequoyah because the mentor teachers have chosen their roles while the doctoral students are often volunteered for them. While this did not seem to negatively impact Joyce's commitment to providing effective supervision and going beyond her job duties, it may have played a part in Erica's commitment to the middle school triad. How university supervisors are chosen at Sequoyah may need to be 
revisited in order to increase the likelihood that university supervisors enjoy feel efficacious in their roles.

Findings Spanning Across Triads

Careful analysis based on Miles et al.'s (2014) framework for data analysis

yielded the findings described in this chapter. Although some findings are more salient to certain triads given contextual factors, there are also three broad findings that are evident across all triads. In this section, I will focus on presenting these conclusions using three broad assertions (see Table 2).

Table 2

Summary of Findings

Finding 1: Positive relationships, viewed as central to providing effective supervision, can be built by conveying a sense that the triad is a central priority for all members. This is demonstrated through flexibility, availability, and engagement within supervision. Prolonged, cross-contextual relationships can contribute to more positive interactions.

Finding 2: Previous teaching experiences and level of experience within the triad role may affect supervision and how it is perceived by triad members. Supervisors should present themselves in a way that emphasizes the knowledge and experiences they bring to a triad.

Finding 3: The student teaching experience should be perceived as formative in nature. Tools used in providing formative feedback must be used effectively in order to impact student teachers' classroom decision-making.

Finding 1: Positive relationships, viewed as central to providing effective supervision, can be built by conveying a sense that the triad is a central priority for all members. This is demonstrated through flexibility, availability, and engagement within supervision. Prolonged, cross-contextual relationships can contribute to more positive interactions. 
From my analysis of responses, it is clear that relationships within triads matter. All nine participants mentioned positive relationships as something they viewed as helpful, and many noted that positive relationships were necessary in order to provide effective supervision. There are several factors that seem to contribute to building positive relationships.

\section{Making the Triad a Central Priority}

A primary factor is conveying a sense that the triad is a central priority for all members. For university supervisors, this often takes shape in the form of being flexible, available, and willing to make an effort beyond minimal supervision duties. The university supervisor in the elementary triad, Holly, was incredibly successful in building positive relationships with Alice and Rachel. Alice noted the importance of these relationships on conversations they were able to have within the conferences:

You need a relationship to be able to say, 'I need to work on this' or ask 'do you have ideas about that?' instead of feeling shy. The university supervisors that come face to face have a strong relationship with their student teachers, absolutely. Holly worked really hard to provide a support system to scaffold Rachel's learning. It all goes back to relationship building. (Alice, personal interview, November 30, 2016)

One of the ways that Holly was able to build these relationships was by making it a priority to conference life. This was seen as "incredibly important to establish rapport and build the feeling of safety for a student teacher and for [Alice] too" (Alice, personal interview, November 30, 2016). Alice also appreciated Holly's preparation and the sense that "she knows what she's doing. She shows commitment and she's very organized and 
does things in a timely manner. She takes the job very seriously. And I love that she's flexible and accessible when it comes to scheduling and communicating" (Alice personal interview, November 30, 2016).

The willingness to conduct conferences in person versus virtually and being very flexible when it came to scheduling were also noted as being helpful and appreciated by both Carrie and Amelia in the other triads as well. This suggests that virtual conferences were viewed as less helpful when it came to building positive relationships. Alice noted specifically the necessity of the student teacher knowing the university supervisor and having a relationship built with them. "I don't think you can do that as well via Skype, no matter how convenient it may be," Alice noted (personal interview, November 30, 2016). Amelia viewed live observations as a way to build relationships because they provide "more context for the classroom" and give you a bit more of "the whole picture and not just a snippet" (Amelia, personal interview, November 28, 2016). These steps taken to encourage more live interaction were obviously appreciated by both student teachers and mentor teachers, and university supervisors viewed them as very helpful as well.

Some of the university supervisors were perceived and described their own actions as "going beyond" their job duties by providing emotional support for the students teachers. Alice noted the importance of Holly being willing to provide emotional support for Rachel, saying that, "It's really important for Rachel to have another person to talk to" (Alice, personal interview, November 30, 2016). Alice went on to discuss the importance of Holly sending the message that she was completely committed to her role as a university supervisor: 
She showed from the start that she was on top of things. I know everyone has a heavy load, but she knew her stuff, she came prepared, she was all ready to talk about dates of things, and that was really important. I knew from the first moment that things were going to go well with this triad because it wasn't somebody saying they were busy or unsure of what the schedule would be. She was absolutely ready to go and get started, and that gave me confidence in her. You don't have to be perfect, but you have to show me you're committed. And she showed that. Part of this means being accessible, and Holly always says, 'You can read be by email or phone whenever.' Honestly, she's just the best I've ever had. She just comes in and you would think this was her whole job-just me and Rachel. I don't know where she gets that, but you should find out. (Alice, personal interview, November 30, 2016)

Similar to Holly, Joyce prioritized relationships in her provision of supervision. One way she communicated her commitment to triads was by making it a priority to observe lessons live sometimes:

I just found the relationships to be so important that if you are doing supervision, time needs to be made to have something face to face in the six supervision cycles, something to help build those relationships. I remember one year I was supervising a student up in [a community two and a half hours north]. I drove up there for our meetings and to observe a couple of lessons in person because I thought that was so important, having that connection. (Joyce, personal interview, November 30, 2016) 
Joyce placed a high premium on building relationships with both student teachers and mentor teachers and saw it as "the most important aspect of [her] job" because she could not fulfill her other duties without "at least a baseline relationship" established (Joyce, personal interview, November 30, 2016). Joyce believes that "investing so much time building relationships" has made it possible to engage in open dialogue throughout a cycle. She goes on to note, "I'm able to give them a safe space for [student teachers and mentor teachers] to ask questions, ask for opinions, and for me to do the same" (Joyce, personal interview, November 30, 2016).

Of the three university supervisors, Erica discussed the need to build relationships the least. She saw it as important that she provided her phone number and email in case anyone needed anything outside of the scheduled interactions. Although she took advantage of an invitation to get to know her student teachers by visiting the secondary English student teaching seminar during the first week of classes, she self-reported that she made no other efforts to get to know her assigned student teachers or mentor teachers. Unlike with interactions between Joyce, Holly, and their student teachers, none of Erica's student teachers reached out to her outside of the pre-scheduled observations and conferences that were required by the teacher education office. This lack of emphasis on building relationships perhaps contributed to Natalie's feelings that Erica did not care about her beyond their professional supervision relationship as described above.

By not engaging with student teachers outside of the pre-scheduled observations and conferences, Erica did not seem to provide any level of emotional support for the student teachers. Holly and Joyce, on the other hand both, both did. Holly reported going outside of student teaching conferences to help support student teachers emotionally by, 
"having coffee with a few of my student teachers this semester. They mainly wanted to have someone there to listen. And I also helped a few of them with their communication issues with mentor teachers" (Holly, personal interview, December 8, 2016). Molly also reported that Joyce helped support her emotionally, "especially when it came to mediating discussions between me and my mentor teacher" (Molly, personal interview, November 28, 2016).

\section{Mentor Teacher Engagement}

University supervisors communicated a sense that the triads were a priority by being flexible, available, and willing to go beyond their assigned duties. Mentor teachers contributed to a sense of priority by their level of engagement in the supervision structures. As previously noted, the student teachers had differing experiences when it came to the level of mentor teacher involvement in their placements, and the university supervisors described a wide range of level of involvement across the multiple triads they supervised. Both Rachel and Molly benefited from heavy involvement from Alice and Amelia throughout student teaching. "She was always there when I taught, and she's the one that filmed, so she was always able to contribute to the conferences," Rachel noted (Rachel, personal interview, November 30, 2016). Alice was present for all of the triad conferences, and was able to contribute to discussion due to the fact she had seen all of Rachel's observed lessons.

Molly noted that Amelia not only watched the observed lesson videos for the last few cycles, but that she also read the prompts that Joyce wrote and it helped Amelia to "remember the lesson and know what Joyce was talking about and contribute to the conversation when we meet” (Molly, personal interview, November 28, 2016). It was 
clear from the interviews that Amelia had the highest level of involvement of the three mentor teachers. Molly did not share her opinions on this matter beyond the fact that she thought see the lesson and prompts helped Amelia contribute to the conferences more.

The mentor teachers discussed the importance of mentor teacher involvement as well. While Rachel and Erica wished there had been more involvement, Joyce discussed the benefits of having Amelia be so involved throughout the process of working with Molly. In discussing involvement of mentor teachers, Holly did not focus on Alice, possibly because she was already so involved. Instead, Holly discussed the differences in her experiences with other triads where the mentor teacher was not as involved:

I wish the mentor teachers were there every time. It's very different if a mentor teacher isn't involved. There's less to discuss, and I find myself trying harder to think of things to talk about. It's so much more vibrant and effective when the mentor teacher is there to add something and provide insight. They can tell little anecdotes that trigger thinking and help the student teachers think more deeply about their teaching. (Holly, personal interview, December 8, 2016)

Holly also indicated that differences in the level of mentor teacher involvement tended to be influenced by whether they were elementary or secondary and how long they had been mentoring student teachers:

Usually the ones that weren't in the conferences tended to be the secondary teachers that had been doing it for a long time. I always emailed meeting reminders, but it's my understanding that secondary teachers don't have the expectation to be there, which I think is a shame. (Holly, personal interview, December 8, 2016) 
Unlike Rachel and Molly, Natalie did not benefit from high levels of engagement from Carrie. She noted, "I think Carrie actually seeing the observed lessons could have been helpful. Maybe if the format was where she had to watch them too, our discussions would've been better" (Natalie, personal interview, December 6, 2016). It is important to remember that Carrie attended approximately half of the triad conferences and did not view any of Natalie's observed lessons either live or via video.

Erica echoed Holly's concerns about how conferences were different when the mentor teacher was not present, especially when discussing lessons that did not go as well for the student teacher or she felt they needed more support:

I wish the mentor teachers wanted to be more involved. I get that there are scheduling conflicts sometimes, but I'm also coming to them, so they don't even have to go anywhere. There were times when the mentor teacher opted to be there just for the midterm and final evaluation conferences and nothing in between. They just kind of like didn't show any interest. It makes it more difficult for me to have those constructive conversations when the lesson kind of bombed or when a student teacher frequently needs more support in terms of classroom management or her instruction. We try to talk about it and the student teacher is not super comfortable having that conversation, and I kind of feel like I have to be the bad guy because I'm the only one there. But if their mentor teacher was there backing me up, they have this deeper relationship with them and the class, so it's easier to have them there. Having them there is not only beneficial for the growth of the student teacher, but it also allows me to gain insight into their relationship and 
how things are going in general. It's kind of difficult when it's more like two dyads instead of one triad. (Erica, personal interview, December 7, 2016)

It is clear that the both the student teachers and university supervisors wanted more mentor teacher involvement when involvement was low and that they appreciated the involvement in the cases where it was higher. This finding is also supported with Joyce's unique experience of having worked with Amelia for four years and her thoughts on their interactions in supporting Molly. She discussed both her appreciation of having Amelia involved in the process in both conferences and just general communication about the student teacher:

I think it is so beneficial to have all three triad members be involved in both the observed lesson and the conferences. I don't get to see the whole lesson, so I have a different perspective than Molly and Amelia. Amelia is observing with much greater understanding of the students and the overall scope of the class because she's taught for so long. So she has that level of expertise she's bringing to the conference that impacts her perspective too. And then Molly has the perspective of actually have taught it and being the one that felt everything that happened. (Joyce, personal interview, November 30, 2016) In addition to Amelia's involvement in the observed lessons and conferences, Joyce discussed the frequent communication between her and Amelia:

Amelia and I communicated a lot outside of normal meeting times. We've worked together before, and we didn't really communicate outside of the cycles then, but it's different with Molly. She's taken longer to get into the swing of things than some of Amelia's other student teachers have in the past. And for Amelia, this 
was initially a red flag and a reason why we should maybe intervene a little more frequently. So we've been in communication and she's been sending me frequent updates so I have a better sense of what's going on. There is always transparency in terms of the fact we always communicate what's being discussed with Molly, but she might not always be 'cc'ed' in emails or at the meetings if we see each other outside of school. She's definitely shown growth from all of our hard work though. (Joyce, personal interview, November 30, 2016)

It was clear that Joyce had been working very closely with Amelia throughout Molly's placement. The fact that both of them were willing to email each other so frequently and even meet outside of conference times suggests they both felt like they were in a real partnership when it came to supporting Molly. This could be due to a variety of factors such as their commitment to teacher education in general, Joyce's wellestablished relationship with Molly, the relationship Amelia and Joyce had built after having worked together for so long, Molly's difficulty in the placement, or a combination of these and other things. I think it is notable that Joyce mentioned this was the first time she and Amelia had worked so closely though, which suggests their interactions were due primarily to Molly's struggles and need for more support rather than other factors. Once again, more work is needed looking at the factors that would influence the relationship between the mentor teacher and university supervisor and how that relationship would be impacted by working together for extended periods of time.

The high school triad was also unique because of the fact that Amelia, already heavily involved, wanted to be even more so. She expressed a desire to be more involved with the lesson plan feedback, video, prompts, and responses. She felt "left out" when she 
did not see the lesson and thought being involved in every step along the way in supervision would help her contribute to conference discussion more:

I really just want everything. We're all responsible for ensuring Molly is ready to teach, so I like to see all the pieces. I read the lesson plans, but don't see the feedback she gets from Joyce. I think the procedures for sharing lesson plans with mentor teachers should be formalized. Joyce told me at one point that her [Molly's] lesson plans were less detailed than what other students were turning in. Well that's something I need to know about so I can respond as her mentor teacher. But if I don't know, then I can't respond. I think there needs to be a clear set of norms from the beginning about what's going to happen with lesson plans and observations and what's expected. I'm seeing the videos and the prompts now, but I'd like to see Joyce's lesson plan feedback and Molly's prompt responses too. (Amelia, personal interview, November 28, 2016) Once again, it is important to remember the context of Amelia's triad when thinking about her desire for more information and involvement in the supervision process. Because Molly was perceived as needing a lot of support, it makes sense that Amelia would be concerned about receiving enough information to help ensure Molly was getting as much preparation as possible. As previously noted the need for such a high level of support for Molly influenced Amelia's interactions with Joyce as well, and it was clear Amelia recognized this. "We do have to speak outside of the triad from time to time. We [Joyce and Amelia] talk about things we think we need to work on as a team to benefit Molly," Amelia noted (Amelia, personal interview, November 28, 2016). Amelia's comments support my description of their relationship that I discussed earlier, 
which was that both Amelia and Joyce seemed to view themselves as being as strong partnership in their support of Molly.

More research should be conducted that looks at the interactions between mentor teachers and university supervisors and the ways they are influenced by the nature of their relationship and the levels of the support the student teacher needs. Additionally, it is important to know if the level of mentor teacher involvement has demonstrated effects on a student teacher's preparation for the classroom. It is possible that although triad members want more involvement, it would not necessarily lead to better results in terms of student teacher growth. While not the focus of this capstone, there is evidence in the literature, however, that mentor teachers must provide emotional support, collaborate, and provide feedback (Beck \& Kosnik, 2002) in order for a student teaching placement to be perceived as successful by student teachers. Other researchers have also identified communication, authenticity, encouraging gestures, honesty, trust, constructive feedback, and emotional and academic support as necessary qualifications for quality mentoring (Izadinia, 2015; Zanting, Verloop, \& Vermunt, 2001). It makes sense that a mentor teacher would be better able to fulfill these roles with the more involvement they had in a placement by watching the lessons and participating in triad conferences. More work should also be conducted on the factors that influence mentor teacher involvement in the first place, which may include the mentor teacher's conception of the role, training received, steps taken by the university and/or supervisor to encourage active participation, other responsibilities within the school, nature of the relationship between mentor teacher and student, perceived level of support needed by the student teacher, and 
more. By gathering information on these influences, further steps could be taken to encourage this involvement if it was deemed beneficial.

To summarize, the differing views on mentor teacher involvement seem to be influenced by a variety of factors including the level of mentor involvement that was experienced during the student teaching placement, the student teacher's needed level of support, and the nature of the relationships between triad members. Rachel and Molly viewed the fact that their mentor teachers watched the lessons positively because it enabled them to take part in the triad conferences to a greater extent while Natalie, whose mentor teacher had not watched the lessons, wished Carrie had seen the lessons for the same reasons. With the university supervisors, Erica and Holly wanted more mentor teacher involvement because they viewed it as crucial for more productive conversations about teaching, especially in cases where the student teachers needed additional support. Joyce already experienced a high level of involvement with Amelia, and perhaps because of this, did not identify more involvement from mentor teachers as something that was problematic with supervision. The mentor teachers also expressed differing opinions regarding the matter with neither Alice nor Carrie expressing a desire for more involvement with any additional features of supervision. Amelia, although already more heavily involved than the other mentor teachers discussed in this capstone, did express a desire for more involvement across all the mechanisms of supervision in order to provide a deeper level of support for Molly.

\section{Prolonged Cross-Contextual Relationships}

A unique characteristic of Joyce's triads are that she only supervises student teachers within her content area of math, and she has previously established relationships 
with each of her student teachers since she serves as a graduate teaching assistant in their completed math instructional methods course and their current student teaching seminar. Joyce also has a previously established relationship working with mentor teacher Amelia for the previous three years. Joyce believes these relationships have a clear effect on the supervision she provides with student teachers. She described her differing experience during a previous semester where she was assigned an elementary student teacher to supervise:

I've invested so much time building relationships with [secondary math student teachers] before we get to [student teaching]. I noticed a difference in the triad relationship when I was supervising an elementary preservice teacher once. I didn't have that connection with her... They saw me as a resource that could help connect them to the teacher education program, but I don't think they saw my role as being much more than that. (Joyce, personal interview, November 30, 2016) Joyce went on to describe how her previous interactions with her math teachers were markedly different:

Because I invest the time to get to know them very well during their fourth year and seeing them every week [in seminar], they see me as a resource and I'm able to move beyond that observation cycle supervisor role because I'm able to work with them and support them during seminar too. It's a way to give them more feedback and support beyond just the MTPTM-P steps. (Joyce, personal interview, November 30, 2016)

It is difficult to say whether the prolonged relationship of knowing Molly for two years and supervising her through two placements or the fact that Joyce and Molly 
interacted in two different contexts is more important. It is possible that both factors contributed to the fact that Molly really respected Joyce's opinions and knew she was there to support her. My getting to know Joyce as a teaching assistant in the math methods course first, it is possible that she very quickly saw her as very knowledgeable when it came to teaching math. Seeing her as a knowledgeable professional may have made her more open and receptive to Joyce's feedback throughout student teaching. Amelia, having worked with Joyce in different triads over the course of four years, discussed concerns about working with a new university supervisor after only recently working with Joyce:

I really enjoyed getting to work with the same supervisor for multiple years because we were able to communicate well and knew what to expect from one another. Now I have to start all over with someone else, and that's going to take time away we could be dedicating to support for the student teacher. (Amelia, personal interview, November 28, 2016)

Amelia's comments align well with current literature on the topic. There is a growing body of work on prolonged student teaching experiences, and several studies (Beck and Shanks, 2005; Levine, 2006; Rubenstein, 2007) have demonstrated their success. However, it is not yet clear if this success is due to prolonged relationships with mentors and supervisors or has more to do with simply additional hours in the classroom or the opportunity to see how the school year progresses from start to finish. At least one study (Spooner, Flowers, Lambert, \& Algozzine, 2008) comparing the perceptions of student teachers in semester long and yearlong placements found that those in yearlong placements reported better relationships with their mentor teachers. Future research could 
explore the effects of prolonged relationships between mentor teachers and university supervisors to see if these would impact development of student teachers. Work could also be done exploring the effects of having the same university supervisor through both practicum and student teaching field placements for student teachers.

\section{Summary of Finding 1}

It is clear that relationships among triad members matter when it comes to providing effective supervision. Positive relationships are viewed as central to providing effective supervision and can be built by conveying a sense that the triad is a central priority for all members. This is demonstrated through flexibility, availability, and engagement within supervision. Prolonged, cross-contextual relationships can contribute to more positive interactions.

Finding 2: Previous teaching experiences and level of experience within the triad role may affect supervision and how it is perceived by triad members. Supervisors should present themselves in a way that emphasizes the knowledge and experiences they bring to a triad.

\section{Previous Teaching Experiences}

Participants in this study raised many questions about the impacts of the university supervisor's previous teaching experiences on the effectiveness of the supervision they provided. Several participants described feeling that a lack of experience affected the relationships they were able to build. Holly, who supervises both elementary and secondary social studies student teachers, felt that it was more difficult to build relationships with students that were teaching in classrooms outside of what she considered her area of expertise due to a lack of experience with the subject and/or grade level. Holly noted: 
Sometimes it was difficult to build relationships with secondary students. They just didn't really care very much. The stuff wasn't meaningful to them so they would turn things in late and didn't really respect the timing of things. Their mind was in the classroom and they didn't really see me as a key part. I suspect it has a lot to do with the fact they knew I was an elementary teacher previously and maybe didn't trust me as much. (Holly, personal interview, November 30, 2016) Holly suspected that her different relationships with secondary teachers had "a lot to do with the fact they knew [she] was an elementary teacher previously and maybe didn’t trust me as much" (Holly, personal interview, November 30, 2016). Joyce also noted differences in the relationship she had with the one elementary student teacher she supervised in the past. She described her feeling that the student teacher only saw her as a connection to the teacher education program and not much more than that.

Natalie, whose supervisor Erica did not have any experience teaching in a middle school setting, commented:

[Erica's] lack of experience in sixth grade colors her views a little bit. She was very confused at first why I was doing certain things like repeating directions. She didn't understand that's what you have to do with sixth graders because she only taught high school students. Sometimes there were just little things where she wasn't able to connect because of her different experience, you know? (Natalie, personal interview, December 6, 2016)

Carrie echoed this comment, noting that Erica "just didn't fully understand the developmental needs of our sixth graders because she's never taught middle school 
before. And I think that impacts things somewhat (Carrie, personal interview, December 6, 2016).

In the triads where the university supervisors' experiences matched with the student teaching placement, participants were quick to point out how Holly's and Joyce's previous experiences helped them seem more knowledgeable in their supervisory role. Alice saw Holly as "very open and willing to talk about her own personal teaching experiences" and viewed the fact that she based a lot of her feedback on those experiences as a way to build camaraderie and "help us remember she's been in the same boat as us" (Alice, personal interview, November 30, 2016). Rachel had similar views and noted:

It was nice knowing she's been in similar situations. I really appreciate her general knowledge of teaching. She brings a lot of experience and examples. She gets it. She knows how classrooms work and is very understanding about anything crazy that happens. (Rachel, personal interview, November 30, 2016) Whereas Rachel and Alice were appreciative of Holly's experience when it came mostly to behavior and classroom management issues, Molly and Amelia were particularly appreciative of Joyce's pedagogical content knowledge and her experience with teaching secondary math. "She really knows the content," Amelia noted, "how to go about scaffolding it, what questions to ask, what questions the students are going to have, all of that" (Amelia, personal interview, November 28, 2016). Molly echoed very similar views and noted that Joyce's background gave the triad "the advantage that she knows the content and she knows how to teach it. She knows the nuances of the different methods and if they'll work with specific content" (Molly, personal interview, November 
28, 2016). When thinking about Molly's perceptions of Joyce's expertise, it is important to remember that Joyce has served as a graduate teaching assistant in three semesters of Molly's coursework. She also served as Molly's university supervisor during her practicum placement. It is possible that seeing Joyce in these roles also influences Molly's perceptions of Joyce's pedagogical content knowledge.

Although there is not a large body of research on the subject, some work has been done looking at whether or not it matters if university supervisors have experience teaching the subject or grade level that matches with the student teaching placement. Kissau and Algozzine (2013) found that generalist university supervisors who lacked pedagogical content knowledge related to foreign language teaching were unable to provide appropriate feedback to their foreign language student teachers, had lower expectations for their student teachers, and themselves relied more heavily on others such as mentor teachers and methods instructors to provide the student teachers with additional support. In a study comparing twenty physical education university supervisors, researchers (Hunt, Mitchell, Maina, \& Griffin, 2015) found that the supervisors who had previous experience teaching physical education were more adept at using contentspecific technical language to represent what they observed, were better at prioritizing conference discussion topics related to observed strengths and weaknesses of the student teacher's instruction, and were better at gaining a greater amount of contextual information concerning an observed lesson. Although these studies relate specifically to matched content, it is possible that matched grade level has important impacts on university supervision as well. More research is needed looking at this topic. 
Within the context of this capstone, it is difficult to say if matched teaching between the supervisor's previous experience and student teaching setting were really the root cause of the participants' views on the importance of this characteristic. It is clear that participants within this study identified matched teaching as a factor that increased perceptions of competence and unmatched teaching as a far that decreased perceptions of competence. However, it is difficult to say if these characteristics were actually the driving forces behind these statements or if other factors played a role. For example, Joyce was viewed very positively by both Molly and Amelia in terms of the supervision she provided. It is possible that the prolonged relationships and willingness to go beyond her assigned duties affected the positive views and importance they placed on her previous teaching experiences. Joyce was very experienced in her role as a supervisor and placed a large emphasis on helping Molly reflect on her own teaching without providing the answers for her. She saw it as very important that she build positive relationships within her triads by always conferencing live and even observing live when she could.

Erica, on the other hand, placed less of an emphasis on building positive relationships. As previously mentioned, she did not engage with either Natalie or Carrie outside of the scheduled conferences. Natalie noted in her interview that Erica did not understand why she had to repeat directions to the sixth grade students so frequently. Natalie went on to describe this feedback as questioning her methods rather than asking her to reflect on her teaching. Recall that Erica was a first year university supervisor and may not have considered how the questioning was received. The methods she used possibly highlighted the fact that she had never taught middle school and did not realize that sixth graders often need directions multiple times. If she had asked Natalie to reflect 
on this moment in a different way, it is possible that Natalie and Carrie would not have viewed it as a lack of experience on Erica's part, but as an opportunity for Natalie to consider the decisions she was making and ways to improve her techniques. For example, rather than just outright asking Natalie why she was repeating directions so much, she could have chosen a video clip from the observed lesson and asked Natalie what she noticed about the directions she gave. As a second step, she could have asked Natalie to brainstorm additional ways of presenting directions that would ensure students were able to be more autonomous in figuring out what was necessary. This would have focused the feedback for this particular lesson on Natalie's decision-making, justification, and ideas for improvement rather than the fact Erica did not understand that sixth graders often need directions repeated or presented in multiple ways.

It is possible that rather than the previous teaching experiences themselves, triad members perceived university supervisors' competence based on other factors such as the positive relationships they had built, their style of providing feedback, experience in the role, or other factors entirely. However, it is also important to note that perception is reality. Therefore, if triad members are viewing previous experiences as an important factor in the effectiveness of supervision, then this issue needs to be addressed. This issue will be discussed further at the end of this section.

\section{Experience Within Triad Role}

In addition to previous teaching experiences, the experience that a university supervisor has within her role may also be important. Both Joyce and Molly noted that Joyce's feedback she provided in prompts and conference discussions required Molly to really think about her teaching and provide justification for the decisions she made. It is 
possible that Joyce's long term experience in the role as supervisor affected her ability to prompt reflection at a deeper level than novice supervisors such as Erica and Holly. Both Molly and Carrie knew that Joyce had been supervising for four years, and this may have affected the way they received or thought about the questions she asked during conferences. Their perceptions of her competence could also have been related to her experiences with and knowledge of the Sequoyah teacher education program as a whole. Participants identified knowledge of the teacher education program at Sequoyah as something that could affect perceived levels of competence. Holly, Erica, Joyce, though, all viewed knowledge of the courses at Sequoyah as being crucial to their supervision practices. Holly, who had no affiliation with Sequoyah beyond her supervision duties, described her feelings of not being connected to the program as a whole:

I don't have a lot of knowledge about the Sequoyah system, so I feel like I lacked that connection piece with them. Because I didn't know what courses they were taking or what their seminar was like or what sort of assignments they had or what they had already taken. I wish I understood more from the very beginning like what the candidate has done up until this point specifically and what they have going on each semester... I would have been more valuable if I understood the Sequoyah system. If I somehow communicated with the seminar teachers in some way or knew what discussion they had or topics they covered, I might have been able to ask different questions that helped the students make connections and help bridge that gap for them. (Holly, personal interview, December 8, 2016) Joyce's many connections to Sequoyah may have influenced Molly's and Amelia's perceptions of Joyce's ability to create links between the field placement and 
coursework at Sequoyah, the CLASS-S® language, and recent research in the field of education. Amelia cited Joyce's access to current research as a helpful feature of her role as a doctoral student at Sequoyah. She also noted Joyce's ability to use the CLASS-S® language to talk about teaching practices and the fact that she had strong connections to what Molly was learning at Sequoyah since Joyce was in some of her classes (Amelia, personal interview, November 28, 2016). Molly was quick to point out the connections that Joyce was able to make too:

She always does a good job of taking something we're talking about in seminar and asks things like, 'How could you apply that here?' when we're discussing my lessons. She's able to take more of the theoretical stuff and help me focus on how to actually apply those things to my teaching. She's in class with me on a weekly basis, so she increase the connection between Sequoyah and my classroom in lots of ways. It's helpful to have her in seminar because we get to know each other better too. (Molly, personal interview, November 28, 2016)

Molly also discussed Joyce's ability to create connections from ideas she learned at Sequoyah to the CLASS-S language used during her field placements. "Sometimes we use different words in class or during my field placement, but Joyce helps us translate that language so I can see how they're related," (Molly, personal interview, November 28, 2016) Molly noted. In the conference I observed for this triad, Joyce specifically connected a particular CLASS-S ${ }^{\circledR}$ term to the work of a math educator that Molly had read about in her methods course.

Joyce also viewed her connections to Molly's coursework and knowledge of CLASS-S® language and research as particularly helpful in fulfilling her core role 
responsibilities. She reported that she tried to connect what mentor teachers said in the conferences to specific CLASS-S® language as a way to "bridge the gap" between the field placement and Sequoyah. "I want to try and show them even though the language might be different, the actions are the same," she said (Joyce, personal interview, November 30, 2016). Joyce also spent considerable time discussing her role as a graduate teaching assistant and how that role impacted her triad relationships:

The more experiences I have with different courses at Sequoyah, the better it is for supervising relationships. I go to the weekly seminar every week, and then I also TA the math methods class students take during their fourth year. I get to know who I'll be supervising in the methods class and start building relationships with them. They get to know me, and it helps us start the student teaching and supervision process with a very comfortable relationship with one another. And I think it helps them really see me as a person there to support them as opposed to someone who is there to evaluate them. I think it has a huge impact on the triad relationships we have during student teaching. And since I have this sort of teaching role, they also see me as someone who is experienced, knowledgeable, and professional. I'm not just some random person supervising them...I absolutely try to make connections between theory students learn at Sequoyah and what they're doing in their placements. I will often revisit things we did in methods class while they're in the field. If they're teaching a lesson about a specific topic, I will go back to how we talked about it in methods class and just remind them they have resources to look back on. When you're in your placement, it's easy to forget what we did the year before because there's so much 
to keep track of. So I act as sort of a library for them and share resources with them again. (Joyce, personal interview, November 30, 2016)

Although Joyce herself had a deep knowledge of Sequoyah and the coursework her student teachers experienced, she still thought it was important to discuss a trend she recognized with Sequoyah hiring more university supervisors that were not otherwise involved with the university and may not even be able to meet with their student teachers:

I think it would be very hard to supervise preservice teachers without an understanding of their experiences at Sequoyah and what they're teaching. I know that I experienced that having to supervise the elementary student teacher, but I lacked in having in terms of my own teaching experience at that grade level, I think I was able to make up for by having such a thorough understanding of CLASS ${ }^{\circledR}$ and the MTPTM_P observation cycles and those things. So I might not have the pedagogical content knowledge for teaching elementary grades, but I did have a lot I was able to bring to it. So in terms of any questions that came up about the placement structure or the CLASS $®$ dimensions or something like that, I could answer those very comfortably. But as I said, I felt disconnected from that triad because I hadn't worked with the intern at all prior to the triad, prior to the 588 [student teaching] placement starting. The first time I met her was at the first triad meeting, and that was something I hadn't experienced before. (Joyce, personal interview, 2016)

Participants' concerns about the necessity of having knowledge of the teacher education program are supported in the literature with work focusing on the university supervisor's role of bridging the gap between theory and practice (Akcan \& Tatar, 2010; 
Bownman \& McCormick, 2000; Fletcher, 2013). Given the fact that serving as a connection to the university is a central component of the supervisor role (Banville, 2006; Blanton et al., 2001; Fernandez \& Erbilgin, 2009; Freidus 2002; Johnson \& NapperOwen, 2011; LaBoskey \& Richert, 2002; Vuran et al., 2014), it makes sense that knowledge of coursework would be seen as an important component of competence as part of relational trust (Bryk \& Schneider, 2002).

It is unclear why there are differences in the way this knowledge is perceived by the different members of student teaching triads. More research could look at not only details of how different triad members view knowledge of the university and its importance, but how this knowledge affects supervision practices such as providing feedback and resources, and even how high levels of knowledge of coursework and university philosophies could possibly affect university supervisors' abilities to convey competence in their knowledge that might mitigate other factors that led to lower levels of perceived confidence and overall aspects of trust. For example, could a university supervisor that was not supervising in a context similar to their previous experience mitigate this fact with an increased knowledge and understanding of the coursework and philosophies of the university? More work is needed to answer these and other questions.

\section{University Supervisors' Presentation of Themselves as Knowledgeable and}

\section{Experienced}

Although it is not exactly clear the role that previous teaching experiences and experience within the triad role play in perceptions of competence, it is clear that the participants in this study identified these things as being important to the supervision they received or provided. It is possible that these factors were conflated with others such as 
established positive relationships within the triads, styles of feedback, or other characteristics. Still, previous experiences were viewed as important factors in providing effective supervision, and should therefore be considered. When possible, teacher education programs may matched university supervisors to student teachers based on whether their previous teaching experiences match. In situations where this is not possible, university supervisors should be taught how to present themselves in a way that emphasizes the experiences and knowledge they bring to a triad. For example, university supervisors may want to be purposefully vague about the fact they did not teach a certain grade level if they think the mentor teacher and student teacher may discount that expertise after learning this information. Instead, university supervisors could emphasize the number of years they have in the classroom, their commitment to best practices in teaching, their experience within their role as supervisor, knowledge of the teacher education program, or other factors that may strengthen their perceived level of expertise and help them be viewed as professionals within their role. Additionally, university supervisors should be trained specifically on how to ask questions in a way that makes it less about their previous experiences or knowledge of working with certain grade levels and more about the student teacher's justifications and reflection on their classroom decision-making. An example of this was described previously about Natalie's directions to her sixth grade students. University supervisors should also understand the importance of building positive relationships as discussed in the first finding of this capstone. Although it is not possible to determine the root cause of why a university supervisor may not be viewed as competent based on their previous teaching experiences using the data I have gathered within this capstone, it is important that university supervisors 
understand the necessity of building positive relationships as the foundation for providing effective supervision.

\section{Summary of Finding 2}

Previous teaching experiences and the level of experience within the triad role may affect supervision and how it is perceived by triad members. University supervisors should be taught to present themselves in a way that emphasizes the knowledge and experiences they bring to a triad rather than a lack of experience in working with a certain grade level, subject area, or student characteristic. This, combined with a focus on building positive relationships, makes it more likely that other triad members will recognize them as competent professionals.

Finding 3: The student teaching experience should be perceived as formative in nature. Tools used in providing formative feedback must be used effectively in order to impact student teachers' classroom decision-making.

\section{Formative Nature of Student Teaching}

Participants in this capstone believed the central goal of preparing student teachers informed the nature of the feedback shared between triad members and ultimately impacted student teachers' classroom decision-making. An important characteristic of this was the belief that the student teaching experience was formative rather than evaluative in nature. All nine participants seemed to believe in the personal integrity of one another within their personal triads as demonstrated by their beliefs that the central goal of all feedback was to help the student teacher learn throughout her placement so she would be prepared to enter the field upon graduation. Positive and respectful language when giving feedback was viewed as necessary in order for university supervisors to demonstrate their belief in this overall goal. By emphasizing the 
fact that feedback was formative and not evaluative in nature, university supervisors were able to convey the message that they were working primarily toward preparing the student teacher for the field rather than grading or judging them:

It's so easy when you hear you're being observed to immediately think this is something that is going to be evaluative and you're either going to have done a good job a good job or a bad job and it's blank and white. But I think the nature of the observation cycle makes those judgments never happen. It's the idea that instructional decisions need to be purposeful, and the observation cycle is a chance for us to unpack the motivation for the decisions that are made and the interactions that are had in the classroom. (Joyce, personal interview, November $30,2016)$

Regarding Holly's supervision, Alice similarly noted: Rachel knows that there isn't a punitive checklist or anything where she's look at 'oh did you do this' or 'did you do that.' Instead, it's 'we are part of the process to get you ready for the classroom.' And I think that's the single most important job that any university supervisor has, making sure the student teacher is ready to go. (Alice, personal interview, November 30, 2016)

Natalie was also appreciative of the positive feedback Erica gave, noting that she "always couched criticism in a very kind and engaging way" and that "nothing was unhelpful" (Natalie, personal interview, December 6, 2016). She also described Erica telling her, "We're really just trying to help you improve. You're not being graded because it's not what we're trying to do. It's all about you improving and becoming your best self” (Natalie, personal interview, December 6, 2016). Carrie also recognized this 
feature of Erica's feedback by describing her as "very fair" and noting that her feedback was "never punitive" and "always felt helpful" (Carrie, personal interview, December 6, 2016).

From their responses, it is clear that the student teachers really valued this aspect of the feedback they received throughout their placement and that it contributed to their overall feelings of trust within their triads. These findings are consistent with Valencia et al.'s (2009) work that found tension often existed within triads when multiple views of the ultimate goals of field experiences were held. Other researchers (Brandt, 2008; Zepeda, 2007) found that university supervisors were perceived as being more concerned about a student teacher's progress and overall preparation if they were able to withhold value judgments when providing feedback, which is also largely consistent with my findings. These aspects of personal integrity connect well to the respect element of relational trust as well since people are less likely to feel respected when they are being evaluated (Bryk \& Schneider, 2002).

\section{Importance of Conferences}

The post-observation triad conferences played an important role in communicating the student teaching experience as formative. During the interviews, I asked participants to identify which step within the supervision cycle they considered to be the most helpful. All nine participants identified triad conferences as being the most helpful step when it came to preparing the student teachers, but it is interesting to note that the participants in the different roles described the conferences and why they considered them to be beneficial differently. I will first present the participants' responses, and will then discuss the differences that I noticed between them. 
Mentor teachers' perceptions of triad conferences. It is a fairly obvious finding that mentor teachers viewed the conferences as being the most helpful step in preparing student teachers since the conference makes up the bulk of the interactions mentor teachers have with the student teachers and university supervisors within the supervision cycle. Although Carrie and Alice expressed similar views of the conferences, I believe Amelia's comment serves as the best example of the mentor teachers' general perceptions of the conferences:

They give a feeling of comfort and people are more willing to share where they need to grow. The conferences help celebrate the little successes in the classroom because they provide everyone a time to slow down and reflect a little. It's easy to lose sight of what's working well when you're in the middle of the school day, so I appreciate the time with Molly and Joyce to just slow down. The conferences also provide a good time to reflect broadly and narrowly on what's working and what isn't. It helps us address areas of concern. (Amelia, personal interview, November 28, 2016)

It was a common response for mentor teachers to note the importance of having that conference time on a regular basis to talk with their student teacher and work together with their university supervisor in order to provide feedback and help guide the student. Although mentor teachers regularly provided feedback throughout the placement on a day to day basis, they reported that they did not always have the time to sit down together with their student teacher without other classroom topics of focus such as discussing students and lesson planning. Although this will be discussed more in depth later, it is important to note that the three mentor teachers did not participate in the 
conferences equally. Amelia and Alice attended all of the conferences from start to finish throughout their student teachers' placements, but Carrie was unable or unwilling to attend regularly. While they did not provide exact numbers, both Erica and Natalie reported that Carrie had missed about half the conferences. Although participation levels varied, all three mentor teachers still reported that the conferences were extremely important and crucial to the process of preparing their student teachers.

Student teachers' perceptions of triad conferences. The student teachers themselves also appreciated the conferences and viewed them positively overall. All three of them identified conferences as the most important and beneficial part of the supervision cycle. Natalie and Rachel had similar views regarding the supportive nature of the conferences that was associated with the positive feedback that was provided:

A lot of the times it feels more like a conversation than a formal conference. I felt very supported. I was scared at first because I didn't know what to expect really. But I felt so supported, especially when I was being hard on myself. At the beginning of my placement, I was nervous about my role, but they've both been reassuring. They're both just so nice to talk to. (Rachel, personal interview, November 30, 2016)

Although she still found them to be useful, Molly did not have the same change in comfort level that the other student teachers mentioned. She found that her feelings about the conferences tended to depend on how her observed lesson had gone:

It always depends on how I felt the lesson went. I was more nervous if the lesson was 'iffy' or if I knew we had a lot of things to talk about. I'm always kind of nervous going in anyway, but they're generally helpful in letting me see what I 
need to really work on. And I feel like Joyce and Amelia are good at finding the positive too. (Molly, personal interview, November 28, 2016)

Although this issue falls well outside the purview of this particular study, I think it is important to note that Molly seemed to be struggling through her student teaching placement more than the others. Although none of my interview questions focused solely on the student teacher's progress through the placement or perceived effectiveness, both Amelia and Joyce mentioned that they had been very concerned about Molly's teaching early in her placement. Neither of the other mentor teachers or university supervisors mentioned being concerned about their student teacher's progress. I think this information is important to provide with these findings because it is possible that Molly in particular may have experienced more growth-oriented feedback than either Rachel or Natalie. Although all the supervisors provided positive feedback in the conferences, Molly's may have been accompanied by more feedback and questioning that suggested her chosen methods should be adjusted in future teaching. Future research could address this question of whether a student teacher's effectiveness as perceived by university supervisors and/or the nature of feedback they receive influences their feelings about and perceptions of triad conferences. This is an important question to address as it affects the feedback and guidance that a student teacher may be willing to accept in her placement. If the need for a high level of support, for example, negatively impacted a student teacher's feelings about the purposes of the conferences, she may be less will to accept the feedback that she received within those conferences.

University supervisors' perceptions of triad conferences. Perhaps naturally given the fact that conferences make up a significant portion of the ways university 
supervisors engage in preparation of their student teachers, all three supervisors also identified the triad conferences as being the most valuable piece of supervision. Erica appreciated the structure of the CLASS® lens through which she could view lessons and provide feedback:

The conferences are so valuable in part because asking them to look back at something, reflect on what happened, and share their thoughts is what contributes to their growth as professionals. I know they do some reflection and sharing with peers in their seminar course to, but conferences are different because we're there to help guide them and help notice things they might not have otherwise...Use of the CLASS® language is something I think is super important too because I can use it both as a jumping off point for conversation and to narrow conversation. Otherwise, you would just go in there and have a pros and cons talk about everything in the lesson, and there would definitely be too much to talk about for the student teacher to be able to internalize anything. (Erica, personal interview, December 7, 2016)

Erica's response also highlights problems that can occur when members of a triad do not have a common language used to discuss what they notice about a student teacher's practice. When asked about the conferences, Joyce was quick to respond at length as to why she thinks they are so helpful, particularly when it comes to helping student teachers become more reflective, ensuring they do not lose sight of the good things they are accomplishing within their classrooms, and looking at lessons in different ways: 
I love them. Working with student teachers and mentor teachers really helped me realize how much I love having this role and working closely with candidates throughout their program and mentor teachers who are in the community. I think conferences are very productive because they're a space for us to work together to support the student teacher's professional development. Specifically, it helps them develop as reflective practitioners. Over the course of the program, they're able to develop a delicate eye and pinpoint the moments of a lesson that were particularly impactful. I like the structure of the conferences and how they're focused on little moments that we can talk about in depth. It helps build awareness for the student teacher to recognize other moments that are happening in the classroom that they might not have noticed at first. And I love that we always start with something positive that went very well. It's easy to feel like your entire classroom is burning down when something doesn't go the way you want it to in a lesson, and you lose sight of the things you're doing well. And I think that teaching is such an emotionally exhausting profession that if you can't recognize things that went well, you'll burn out very quickly. For some of my student teachers with more difficult classes, this feature has really helped to rejuvenate them and help them recognize the positive impact they're having on students. Another productive thing about the conferences is just having multiple perspectives on a single lesson...We all look at it through a different lens and the debrief is a chance for us to share the way we thought about it and discuss in person those commonalities and some of the things that might be different, not as a means of making judgment, but just sort of sharing the idea that there's a lot of different ways to 
interpret something that happens in the classroom. No one way is right, but it's important to be able to recognize these interpretations. (Joyce, personal interview, November 30, 2016)

Differences in perceptions of triad conferences. Looking across the different ways participants responded to this question, it is interesting to note how members in different roles discussed the conferences and the reasons they were helpful differently. Student teachers were quick to point out that they appreciated the positively-phrased feedback they received and found the conferences mostly comforting, although this also seems to be at least partially influenced by how the placement was going in general and if the student teachers felt successful in their lessons. Mentor teachers, on the other hand, seemed to be most appreciate of just having the time to slow down and really focus on what was or was not working in the placement. They liked being able to sit down with both their student teacher and the university supervisor without other obligations in order to focus specifically on the student teacher's progress. University supervisors focused their descriptions of the conferences on the importance of face to face contact, the guided reflection they were able to provide for student teachers, and helping them recognize multiple viewpoints about lessons and the fact that teachers can go about instruction in many different ways. University supervisors also echoed the importance of positivity within the conferences and reminding the student teachers of the impacts they were having in their classrooms. 


\section{Effective Use of Supervision Tools}

\section{Importance of Video}

As part of the interviews, I asked participants to share a specific example of an instance when a student teacher's decision-making and/or instructional practices were influenced by a conversation held in a conference. I will discuss the differences in how each triad responded to the question and what these responses could possibly tell us about how the conferences and videos are impacting student teachers' practices and decisionmaking.

The elementary school triad. In the elementary triad, Rachel and Holly both identified the same change in practice in their responses while Alice simply gave a very general response of "she adjusts what she does based on feedback from the conferences all the time" (Alice, personal interview, November 30, 2016). Alice did not point to anything specific that Rachel had changed based on feedback, but instead discussed how qualified she thought Rachel was to teach and that she hoped she would find a job within the same school district.

Rachel described the change in practice as something that influenced her awareness throughout the rest of the placement while Holly pointed to an event more specifically:

In one of her first observations, Rachel had been leading a small group lesson and she passed out the materials to all of the students before she gave all of the direction for the activity. After I tagged this portion of the lesson in the video and then we discussed it in the conference, Rachel was able to recognize that giving the materials to students beforehand can lead to distraction and keep them from 
paying attention to her directions. For her next lesson, she specifically waited to hand things out until after the directions. That came directly from the conversations we had. (Holly, personal interview, December 8, 2016)

Rachel also pointed to this situation, but she described it somewhat more generally in terms of how it impacted her awareness in the classroom overall. She noted that the conferences helped her to remember to step back and pay attention to the whole class every once in a while so that she could see the details and notice little things like students being distracted by paper or materials on their desks while she was talking.

It is difficult to analyze this triad's responses to the question, particularly Alice's extremely general claim that Holly made changes based on feedback all the time. I know that Alice was heavily involved throughout Rachel's placement by recording all of her observed lessons for her and attending all of the triad meetings, so I do not think this response is due to a lack of knowledge of Rachel's progress. The change that Holly and Rachel described is very specific and seems like somewhat of a small change when thinking about changes that novice teachers might make in their instruction. Throughout my observation of the final conference and interviews with each member of this triad, it became clear to me that Rachel was perceived as being an extremely effective teacher that both Alice and Holly considered to be ready for the field early on the placement. Rachel herself described feeling ready to enter the classroom well before her student teaching placement was over, and Holly discussed meeting with the field placement coordinator to discuss ways to push Rachel in the placement since she was doing so well with teaching already. Alice described steps she had taken to help ensure Rachel was hired within the district, noting that she had introduced her to several people and thought 
she would make a great fit for the county. It is possible that because Rachel was considered to be so competent in teaching very early on in the placement that it was more difficult to see the progress she was able to make based on discussions held in conferences. If there were not significant concerns with teaching practices, a more minute change in simply waiting to hand out materials before giving directions might have been perceived as one of the very few ways she needed to improve in the first place.

The middle school triad. In the middle school triad, there was not a specific situation identified by two or more of the triad members. Instead, Carrie pointed to one area of teaching that improved while Natalie discussed a specific situation where her actions were impacted and Erica was not able to point to any changes in Natalie's teaching at all. Instead, she provided an example from another student teacher that she was also supervising. Carrie provided a general example and said, “[Natalie’s] gotten better with adding questions into her lesson plan, making sure to break up the lesson with time for questions and short assessments" (Carrie, personal interview, December 6, 2016). She did not expand on this statement or discuss the conversation that took place in a conference to influence Natalie's improvement. In her response, Natalie pointed to changes in her physical movements as she taught:

It helped me see the way I was being perceived by students when I got really frustrated one day. We talked about ways to avoid the frustration, and also ways to hide the frustration if I couldn't prevent it. Seeing myself on video allowed me to notice things that I hadn't in real time, so I gained a deeper understanding of the lesson I had taught. Watching myself helped me notice when I was doing 
weird things like pacing back and forth too. (Natalie, personal interview, December 6)

When prompted with this question in the interview, Erica was unable to think of a specific example for Natalie, so she asked if she could provide an example from another triad instead. Interestingly, similar to Natalie's response, it involved the physical movements of the student teacher as she was teaching. She noted that one teacher was able to see her physicality in the video and why it was difficult for her to command a room. The triad talked about how she was presenting a lack of confidence, and the student teacher was able to make some physical adjustments to ensure she was projecting more confidence in later lessons.

It is difficult to say what should be gathered from this particular triad's responses to the question. It is possible that the strength of the relationships and level of involvement within this triad affected what they were able to notice regarding progress or impacts on decision-making. As previously noted, Carrie was not present at half of the triad conferences. In the conference I observed, she arrived late and worked around her classroom for a portion of the meeting. This level of involvement could perhaps influence the general response she gave about asking more questions. As previously discussed, Natalie considered her relationship with Erica to be very professional rather than personal. It is possible this relationship impacted Erica's inability to think of a specific example of a change in teaching or decision-making that Natalie made based on feedback. There is obviously not enough data to say for certain.

The high school triad. In the high school triad, Molly, Amelia, and Joyce all pointed to improvement in Molly's attention to student engagement as something that 
improved as a direct result of the conversations that took place in their conferences. Amelia pointed to multiple changes she had noticed in Molly's teaching in addition to just the student engagement piece:

She's gotten better at planning. And she's willing to take over more of the planning on her own. She used to really struggle with student engagement, but now she's adjusting her plans based on student questions, input, ideas, etc. That came directly from things we talked about in the conferences. She's definitely started to see things she hadn't noticed before in her teaching. She's reflecting more, thinking more about what she's going to do and then reflecting on what she did. These conferences help her focus more on how she's going about teaching the content and just on all the content itself. (Amelia, personal interview, November 28, 2016)

Molly agreed with Amelia's assessment of her development in teaching and discussed her progress in both reflection and student engagement:

I learned how to open up and ask more questions about my own teaching. And they also reminded me to be aware of student perspectives and let them help guide the lesson by their struggles and questions instead of keeping with my own set agenda all the time. It really helped me with the student engagement piece. (Molly, personal interview, November 28, 2016) Joyce identified student engagement and developing a "teacher eye" as areas where Molly was able to improve her practice based on conference discussions: She has a better awareness of what's happening in the classroom space. She's still working on developing that teacher eye to be able to see and take in everything 
that's happening, but she has definitely improved. Early on, I had the sense that she would teach the lesson the same way regardless of whether or not there were students in the room. And Amelia noticed this too, so we talked about it in the fourth conference. It's not that the students didn't matter to her, but she was dominating conversations, deciding the pace of instruction, and things like that regardless of whether or not students were following along, keeping up, etc. By having the video, she's forced to redirect her attention to specific moments in the lesson. That helps her see what's happening in a way she wouldn't be able to without the video. Since we've drawn her attention to awareness of students, I've seen in her later videos that she is more inclined to ask questions of students and let their responses dictate where the lesson goes. In her last lesson, she actually let a suggestion from a student influence the way she taught that class period and for the rest of the day. That's a huge example of growth because I don't think she would have been as comfortable doing that prior to our conferences. (Joyce, personal interview, November 30, 2016)

It is interesting that members of the high school triad in particular were able to identify multiple areas of growth that were influenced by the triad conferences. As previously discussed, Molly was presented by the other members of her triad as the only student teacher that was having difficulty in her placement. Molly alluded to this herself as she described her feelings of nervousness as she went into the conferences depending on whether her lesson was "iffy" or not (Molly, personal interview, November 28, 2016). It is perhaps because Molly was struggling that the members of her triad were able to provide so many examples of ways that conferences influenced her decision-making 
within her student teaching classroom. It makes sense that the student who was having the most difficulty from the beginning of the placement would also have the most opportunity to learn and improve based on the feedback she received. Combined with the fact that Rachel's triad members picked out a very simple change, this could suggest that recognition of the impacts of conferences on decision-making is influenced by how well the student is doing in the placement and their perceived effectiveness in teaching. More research is needed on this topic of the factors that influence triad members' abilities to recognize changes in teaching or decision-making that were impacted by discussions held in conferences.

Use of video on impacts of classroom decision-making. In analyzing all of the responses to this question across triads, I noticed that all three of the university supervisors mentioned the videos as influencing what the student teachers were able to notice about their own teaching. While this study does not focus on the utility of observation videos, it is important to remember that the videos helped inform the discussions that were held in the triad conferences. The power of video as a tool for enhancing student teachers' reflective and analytical skills is now widely acknowledged (Fadde, Aud, \& Gilbert, 2009; Savas, 2012; Whitehead \& Fitzgerald, 2007).

A number of studies have concluded that the incorporation of video in teacher education fosters productive discussions and leads to the enhancement of preservice teachers' professional development, lesson planning, and reflective skills (Glazer, Hannafin, \& Song, 2005; Harford \& MacRuairc, 2008; Kuter, Gazi, \& Aksal, 2012). Reflection through video analysis has also been shown to be more effective than traditional forms of reflection from memory or alternative forms of reflection such as 
watching videos of other teachers when it comes to developing reflective abilities (Borko, Jacobs, Eiteljorg, \& Pittman, 2008; Robinson \& Kelley, 2007; Seidel, Sturmer, Blomberg, Kobarg, \& Schwindt, 2011). One feature of video reflection that may contribute to its effectiveness is that it allows student teachers to re-watch a single lesson multiple times in order to develop the ability to identify effective instruction and classroom management during "in the moment" classroom situations without having to simultaneously teach (Martin \& Ertzberger, 2013; McDuffie et al., 2014; Sherin \& van Es, 2005; Wang \& Hartley, 2003). Future studies could look more deeply into the impacts of video on changing student teachers' decision-making and practices within both their student teaching placements and into their beginning years of teaching.

\section{Prompts and Reflection}

It is clear from participants' responses that video was being used effectively in order to create change in student teachers' classroom decision-making. In describing features of supervision that were problematic, all of the student teachers and university supervisors pointed to the video prompts and responses as an area where improvement was needed. Prompt responses were used as a means of evaluating competence for student teachers while the prompts themselves were related to student teachers' perceptions of competence and trust with their supervisors. Both student teachers and university supervisors had strong feelings when it came to their thoughts on the prompt structures. The CLASS $®$ system provides specific guidelines for how video prompts should be worded, and university supervisors spend a significant portion of their initial training on learning how to write these prompts. For each supervision cycle, there is usually two dimensions of focus. The general structure of the prompt calls for defining 
the dimension of focus that corresponds with the specific clip that is tagged in the video. Following the description of the dimension, the supervisor relates the dimension to what is seen in the clip and points to a specific moment the student teacher should be focusing on. Recall that these prompts are written in the order of "nice work", "enacting a plan", "consider this", and "making the most of instructional support" (see statement of the problem for more information). It is common that the first two prompts end with a single question asking the student teacher to identify a behavior she sees or aspect of planning she engaged in and how it affects the interaction. For the last two prompts, this first question is usually followed by an additional one that asks the student to describe how the interaction affected the classroom as a whole or how they might have done things differently if they had the chance.

Student teachers discussed feelings about the amount of time spent discussing prompts in the triad conferences. University supervisors identified the length, the restrictive nature of the prompts, and the variety in the level of prompt responses as problematic aspects of this particular component of university supervision. All three student teachers described wanting the prompts to be written more clearly: It's weird that they're so scripted. It seems a little artificial if that makes sense. I never read the beginning of a prompt because they're so repetitive. I just skip down to the actual question. They do sound weird, though, and you just kind of have to get over it. (Rachel, personal interview, November 30, 2016) Natalie discussed her negative opinions about the prompts at two separate points during our interview: 
Sometimes the prompts on the videos are just kind of silly. I would prefer Erica being more straightforward and saying, 'This is a place where you might not have done that great. Why do you think that?' instead of all the formal language. It just felt impersonal. I know it's how they're taught to write them or whatever because they've always looked like that, but it's weird sometimes. It might be evidencebased or something, but I don't really like it. Honestly, I think the commenting is a little dumb.... I would change the wording of the prompts for sure. And I think she [Erica] could've had more opinions or be more opinionated. She tended to be very 'third party' and maybe that's supposed to be the role. But she's also the only person watching the video besides me, so I wouldn't have minded a little less professionalism and a little more personal feedback. (Natalie, personal interview, December 6, 2016)

Recall that Natalie had also commented about the professional nature of her relationship with Erica, noting that it was less caring and "more like an impersonal school, professional relationship" (Natalie, personal interview, December 6, 2016). Looking at these comments together, it is important to consider the possibility that Natalie simply preferred less formal and more informal interactions with her university supervisor on the whole. This desire may have impacted her views on her relationship with Erica. It is also possible that the structure of the prompts contributed to Natalie's views on that relationship and seeing it as more professional than caring. It is possible that Erica's feedback was even more important to Natalie given the fact that her mentor teacher had not been watching her observed lessons and therefore could not provide a lot of feedback on them. This is an important question that should be explored further. 
Future research could look at different structures and tones of feedback provided by university supervisors, how this feedback was perceived by student teachers, and how the feedback may have influenced how student teachers viewed their relationships with university supervisors. An additional question could explore whether some student teachers benefited more from certain types of feedback than others depending on the level of mentor teacher involvement.

Molly also described a negative perception of the prompt language and structure, noting that she found the prompts confusing and wished less time were spent discussing the prompts in conferences:

I don't feel like I ever got anything out of responding to the prompts honestly. I wish we could just talk about those moments [identified in the video by Joyce] in the conferences instead. Sometimes I didn't know what she was asking, so we talked about it in the conference anyway. The structure of the prompts actually confused me. Like there's this whole paragraph, but where's the question in there? I feel like it would be more helpful to not explain the dimensions and just ask the question. I get lost in the paragraph. It would be more helpful to have more direct and straightforward questions for the prompts. I don't think the commenting back and forth is really necessary since we always talked about the prompts in the conferences anyway... I would like to have more time in the conference to talk about general improvements in my teaching by spending less time on prompts. I want to know how I'm doing overall I guess. I would replace that prompt time with more space to talk about the lesson in general and to kind of assess where I am with teaching. I would like to take the time to look at the lesson 
in a broader scale of things instead of just that lesson. Like where we are in the content, where the students are, stuff like that. (Molly, personal interview, November 28, 2016)

Although they each expressed an appreciation of the structure of prompts progressing from "nice work" to "making the most of instructional support," the university supervisors also listed several negative perceptions of the prompt structures as well such as feeling constricted by the prompt language rules, wondering if they were writing them correctly, and the varying levels of prompt responses they received from student teachers.

I think having the four categories [nice work, enacting a plan, consider this, and making the most of instructional support] is helpful, but also constricting. It forces you to look for both positive aspects of the lesson and things to work on, and it also forces you to look at different aspects of the lesson. But I find the prompts themselves to be super constricting and boring. I hate how they repeat the same language, and I feel like the student teachers just skip through the text to get to the question anyway. I think it results in weaker responses because they're so formulaic....It's very puzzling that some of the prompt responses are so bad because they are all getting the same question essentially, so you would think they would all presume the same amount of response is needed. But they are very different people. I don't know what training they were given on it. I know they used the system in their previous placement...I think a lot of it is personality because some give like five word answers and others give you fifty. I think they need to be explicitly told that 'this is really about reflection and is not about a 
right or wrong answer.' I think some students respond with very short answers because they are just trying to answer a question. But we don't really care what they saw in their answers because we are more interested in just seeing the thought processes I guess. At least that's how I interpret it. (Erica, personal interview, December 7, 2016)

Joyce also noted her appreciation of the prompt sequencing and described how she felt about writing the prompts:

I do notice myself feeling very concerned that the way I write my prompts aren't correct. There's a clear way in which the prompts are supposed to be structured based on all of the training. I understand that you start with an explanation of the dimension itself, direct attention to a specific moments, and then ask a question or two. But I found myself struggling with wording my questions and making sure the questions are specific enough for the student teacher to answer without being too specific that I'm giving them the answer. I worry if I make them too specific that I'm telling them how I think they should be interpreting the moment, and I don't want to do that. And then I also wonder how much flexibility I have to deviate slightly from the recommended structure of the prompts. I feel like people in the teacher ed[ucation] office read through the prompts sometimes. I'm sure it's to make sure we're maintaining fidelity to the MTP'M-P process. (Joyce, personal interview, November 30, 2016)

It is important to recall that Joyce was by far the most experienced of the three university supervisors in her fourth year of supervision while both Erica and Rachel were in their first semesters. It is difficult to know how to interpret the fact that the most 
experienced supervisor was also the only one to mention personal insecurity in if she was writing the prompts correctly. Since it is not a large topic of focus for this capstone, and my research methods are not well-suited for addressing it, I will not make any conclusions regarding why this might be the case.

Joyce went on to describe the varying levels of responses she received from students and her views on what caused the discrepancies:

There's definitely a wide range in terms of the amount of detail in responses. I think the student teacher's thoughts about the purpose of the observation cycles influences their prompt responses. So if the prompt responses are thought of as just another thing to do on their checklist, then I think the responses tend to be more curt and not as thorough. But for many of them, they see the observation prompts as a chance to help them grow as teachers, so they're more inclined to think more deeply about the prompt questions and then write more thorough responses. (Joyce, personal interview, November 30, 2016)

Holly also expressed dissatisfaction in the types of responses she received from students and the steps she took in order to address the depth of prompt responses among her student teachers:

There were wide differences in prompt responses. Some would give very short answers while others were really thoughtful. And it was very clear-the ones who did put time into responding, their instruction was better. Plain and simple. They seemed to be more effective, and our conversations were more vibrant, our conversations were more engaging, we had more to talk about, and they had more questions than the ones who just gave very simple answers.... n noticed that 
students didn't seem to have the same knowledge of the dimensions that I did. Sending them the [student teaching] handbook seemed really monotonous, so I ended up giving them all a copy of the outline pages I use to simplify things. Once I did that, it seemed like things changed, like they started to really see what I was trying to say. And then they knew how to plan or what to show me in their lesson because it was just outlined more clearly for them. I think one of the problems with their responses in the beginning was that they didn't relate to them the same way I did because I was looking at a chart and they were reading sentences and paragraphs in the handbook. So there was a disconnect. And once we had the same thing to look at, it got easier to pick out the dimensions they wanted to focus on and their prompt responses were clearer. (Holly, personal interview, December 8, 2016)

Both the students teachers' and university supervisors' perceptions and comments about the prompts bring up a really interesting point about the purpose of the feedback provided and the reflection taking part in the CLASS ${ }^{\circledR}$ system and MTP'м protocol. An analysis of prompts and responses previously conducted by Sequoyah teacher education staff and doctoral students yielded the finding that different types of questions asked by supervisors in the prompts yielded different levels of analysis on the part of the student teacher (Hoffman, McGraw, \& McCool, 2016). More open-ended questions made it more difficult for student teachers to deconstruct their specific classroom interactions while observational, closed questions prompted observational skill development and greater reflection. The researchers believed these observations suggested an inverse relationship 
between a prompt that was vaguely understood by the student teacher and the ability to articulate and deconstruct teaching practice (Hoffman, et al., 2016).

In another analysis of prompts and responses, McCool et al. (2017) found that university supervisors were providing too much information in the part of the prompts where they directed the student teacher's attention to a specific moment in the video. By including too much information, they were doing the observation for the student teacher rather than allowing them to express what they saw for themselves (McCool et al., 2017). A recommendation stemming from McCool et al.'s (2017) work was that student teachers should be trained specifically in what good reflection looks like and how to respond to the prompts. Although not the central focus of this capstone, these findings suggest that more work is needed regarding the characteristics of prompts and other factors that contribute to the varying depths of responses written by student teachers. It is possible that more straightforward and easily understood language would yield deeper reflection from student teachers because of their ability to better understand the questions that were being asked. It is important to note that it has not been demonstrated that university supervisors' fidelity to maintaining prompt structure as they were trained is correlated with the strength of student teachers' prompt responses or depth reflection.

How student teachers interpret the prompts is particularly important given the fact that the CLASS $®$ was originally developed for early childhood research on the interactions between inservice teachers and their students. The MTP ${ }^{\mathrm{TM}}$ system was also originally conceived for inservice professional development. The systems have both since been adapted for use with preservice teachers in the Sequoyah teacher education program. While reliability of the CLASS ${ }^{\circledR}$ observation tool was demonstrated in 
inservice classrooms (Hafen, Hamre, Allen, Bell, Gitomer, \& Pianta, 2015), neither it nor the MTPTM-Preservice model as adapted for use at Sequoyah have been rigorously tested.

I viewed the set of prompts and responses that corresponded to the observed supervision cycle for each of the triads in this study. Although an analysis of their language and structure is not a central focus of this capstone, the prompts and responses supported the perceptions that participants shared. This is a very simplistic view of the content of the prompts, but they ranged in length from 242 words from Holly to 630 words from Joyce with 329 words from Erica in between. The responses from student teachers ranged from 227 words from Molly to 739 words from Rachel with 288 words from Natalie in between. Although much more could be said about the content of the prompts and responses, this is not a central focus of this study. The numbers of words provided in each of the prompts and responses just serve as an additional data point that supports the level of difference described by university supervisors in the depth of responses by their student teachers.

The importance of reflection in student teaching placements is well-documented in the literature because it allows student teachers to recognize their own strengths and limits, explore new ways of managing their classroom, and developing competence in instructional decision-making (Bunton et al., 2002; Calandra, Brantley-Dias, \& Dias, 2006; Calandra, Brantley-Dias, Lee, \& Fox, 2009; Crawford, O'Reilly, \& Lattrell, 2012; Fletcher, 2000; Waring, 2013), so student teachers' negative perceptions of the prompts and the varying levels of reflection as reported by the university supervisors are potentially causes for concern. The Interstate Teacher Assessment and Support Consortium (InTASC) has professional teaching standards that focus on lifelong learning 
through reflection of one's own teaching practices (Council of Chief State School Officers, 2011), so it is important to ensure student teachers are building a solid foundation of knowledge of how to engage in meaningful reflection that may impact their teaching practices.

One potential factor leading to shallow responses is the translation of MTP'M and CLASS $®$ from an inservice professional development model to a preservice one. Future work could investigate levels of effectiveness in coaching models when translated from inservice programs to preservice programs. Specific methods for providing instruction about the process of reflection and what good responses would look like could also be tested to see which methods of teaching student teachers how to reflect are effective and what results deeper reflection could have on teaching effectiveness. Nagro, deBettencourt, Rosenber, Carran, and Weiss (2017) recently conducted a quasiexperimental study looking at the effects of providing guidance and feedback to student teachers in order to supplement video analysis procedures. The researchers (Nagro et al., 2017) found that, while both groups self-reported significant improvements in their teaching ability, only the group of students receiving the extra guidance and feedback on their reflection demonstrated significant growth in reflective ability and instructional skills over time.

Despite negative views regarding writing the prompts and the levels of reflection in the responses to them from student teachers, each of the university supervisors still worked to follow the procedures outlined by the CLASS $®$ and MTPTM-P systems as they were trained by teacher education staff at Sequoyah. In a professional development series on using classroom observation systems, researchers (Stuhlman, Hamre, Downer, \& 
Pianta, 2016) noted the importance of being "very clear that the standard procedures outlined by the system should be followed without exception." Because of this, it is especially important that the structures and language called for in the supervision systems used at Sequoyah allow student teachers to reflect deeply and purposefully.

\section{Use of Supervision Documents}

Supervision tools must be used effectively in order to impact student teachers' classroom decision-making. Video tools, prompts, and responses have been discussed so far as part of this finding, and their importance as perceived by participants is clear. However, the use of documents within supervision is much less clear. There were widely differing opinions regarding the different uses and perceptions of importance of the collaborative feedback forms and summaries and action plans. Some participants referenced them and used them regularly while others did not find them to useful. Holly and Erica both noted that many of their mentor teachers simply did not fill out the collaborative feedback forms. Joyce, on the other hand, found that almost all of her mentor teachers maintained them regularly. She believed that they kept up with them because it was an expectation that all of her student teachers upload them to Chalk and Wire each week (Joyce, personal interview, November 30, 2016). Amelia believed it was important to note that although she completed them, she did not find the collaborative feedback forms to be very helpful "because they were too structured" and she did not "always like to focus on specific domains and would like to give more general feedback instead like 'what's working, not working, and what's the focus or something"' (Amelia, personal interview, November 28, 2016). Amelia did sincerely appreciate the summaries and action plans and even frequently referred back to them though. Carrie did not receive 
summaries and action plans from Erica, but she expressed a desire to see them on a regular basis so she could stay more involved in Natalie's progress. These differences did not go unnoticed by the mentor teachers and student teachers, and their implementation seems to have affected the ways the supervisors are perceived by the other triad members. By maintaining open lines of communication and going beyond assigned supervision duties, Joyce and Holly were clearly able to build trust within their triads, as evidenced by their triad members' comments about their communication and support practices. Erica's methods of just making sure the mentor teachers and student teachers knew she was there as a resource if needed did seem to impact how she was viewed by both Natalie and Carrie.

While the mentor teachers viewed the documents as being a somewhat helpful part of supervision, the three student teachers were less enthusiastic. Natalie had never received one from Erica and did not consider it a loss, while Rachel and Molly dismissed the importance of them except for thinking about the CLASS-S® dimensions that would be used for the next supervision cycle. Molly said she, "sometimes looked at them, but only to figure out the next dimension. I sometimes skim them, but it's really just a summary of something I experienced. I don't necessarily need to go back and revisit that since I was there” (Molly, personal interview, November 28, 2016). Interestingly, despite Molly's admission that she only sometimes skimmed them and did not find them to be particularly useful, her supervisor, Joyce, identified them as a meaningful part of the supervision cycle:

The summary is a way to highlight key components of our conversation and find commonalities across the things we discussed. It allows me to process our 
conversation, and I try to bring everything back together as I'm writing them, tying it back to the CLASS-S® dimension itself and then linking that to the prompts and give something for the student teacher and mentor teacher to look back at to think about the conference and remember what we discussed. Listing the next dimensions on the action plan portion is a great way to help them anticipate what's coming up for the next observation. (Joyce, personal interview, November 30, 2016)

Despite her own beliefs of the importance of the summaries, Joyce also suspected that others did not hold the same views:

I don't know with how much detail they're actually read though. I really hope the student teacher reads them because I write them with the student teacher in mind. I want them to internalize our discussion and takeaways from the observation, and I think the summaries are a great way to do that. But I don't know if they actually do. (Joyce, personal interview, November 30, 2016)

As part of my document collection as a source of data for this capstone, I requested that university supervisors provide all supplementary documents they used in their practice for the supervision cycle that I observed. Of the three triads, Joyce was the only supervisor that provided a summary of the conference to me. This may have been influenced by the fact that Joyce was conducting a fifth cycle conference while both Erica and Holly were conducting final sixth conferences.

Aside from the conference summaries, university supervisors are also tasked with encouraging mentor teachers and student teachers to maintain collaborative feedback forms on a weekly basis (see Appendix $\mathrm{C}$ for an example). Joyce viewed these forms as a 
way to help her "stay in the loop" of what was happening in the placement between supervision cycles, and she had all of her student teachers upload them to Chalk and Wire once a week (Joyce, personal interview, November 30, 2016). Neither Holly nor Erica required their student teachers to use the forms, and both found that, unsurprisingly to them, not many of them did. Holly also discussed her perception that relationships between mentor teachers and student teachers influenced their use of the collaborative feedback forms:

They tended to be the ones that had a weaker relationship because it was a structured way for them to communicate. The ones who meshed and jived really well were communicating so much that they didn't really feel the need to do them. (Holly, personal interview, December 8, 2016)

Given the varying opinions and use of documents from participants in this study, it is difficult to make conclusions about their importance in providing effective supervision. More information is needed regarding their use and the factors that influence that as well as participants' views on them.

\section{Summary of Finding 3}

It is important for the student teaching experience to be perceived as formative in nature. Conferences play a large part in influencing this perception. The tools used in providing formative feedback, especially the use of video in prompt and conference discussions, must be used effectively in order to impact student teachers' classroom decision-making. Less is known about the use and perception of supervision documents, so more work is needed. 
Careful analysis based on Miles et al.'s (2014) framework for data analysis yielded the findings described in this chapter. In chapter five, I will discuss these findings as they relate specifically to the Sequoyah teacher education program and will also make recommendations for actions that teacher education faculty and staff may take based on the findings. Barriers to implementation of the recommendations and suggestions for future research will also be considered.

\section{Limitations}

Several limitations shape the nature and interpretation of both the results and conclusions provided by this study. In this section, I will detail the limitations of the chosen participants, data collection, and data analysis that might affect the interpretations of the recommendations and implications. This multiple-case study focused on just three student teaching triads at a single university, meaning this is a very small sample size. Although in different content areas, each of the student teacher participants completed the same teacher education program. Similarly, each of the university supervisors and mentor teachers received the same training as preparation for their respective roles. Although other factors contributed to the diversity of the participants, these similarities between them and the unique programmatic features of teacher education at Sequoyah provide a very narrow sample of student teaching triads. The participants were also chosen based on convenience. I received information about potential triads from the field placement coordinator. Although she did not provide specific suggestions for which triads I should recruit for participation, she did not provide neutral information about all of the triad possibilities. Therefore, it is possible that my recruitment of participants for the study were influenced based on biased information. 
Although I had originally hoped to recruit participants based on a variety of diverse factors, my participants ended up being eight white females and one mixed-race female. It is very likely that different demographic factors such as culture, ethnicity, age, or gender may have provided new insights and understandings about triad relationships and the factors that influence them. More work is needed looking at these as well as other factors. Given these facts about the participants, it is difficult to transfer the results to wider contexts.

Although multiple data sources were used for this study, the primary source of data comes from the self-reporting of perspectives during semi-structured interviews. These were conducted under the assumption that participants provided accurate and honest responses to the questions, but this cannot be guaranteed. Participants may have had selective memory of events or may have not even been aware of influences when it comes to some of my questions about ways the conferences affected their teaching, the supervisor practices they found to be most helpful, and what they could change about the supervision process. It is possible that the perspectives provided by participants do not accurately represent the participants' true beliefs or perceptions.

My previous relationship with two of the student teachers may have also affected the responses that were given. Although participants were informed of the steps I took in order to keep their participation and data anonymous and confidential, it is possible they were concerned that their answers may be reported to the teacher education office. Additionally, my presence during the observed conferences may have affected the discussions that took place. 
Another consideration to take into account is the timing of the observations in the student teaching placements. As previously mentioned, each student teacher at Sequoyah participates in six supervision cycles throughout their student teaching semester. At the time this study was conducted, each of the recruited triads were starting either their fifth or sixth cycles. While a benefit of this fact is that the triads were well-established and had been working together for several months, a limitation is that some of the triads were wrapping up their time together and the discussions and content of their conferences were influenced by this timing. For two of the triads, student teachers were completing the sixth and final observed lessons. The conferences that took place after these lessons did not focus solely on the sixth observation and instead incorporated discussion about the final evaluations to be conducted by each member of the triad and a general wrap-up or closure of the student teaching experience as a whole. Therefore, these conferences may not be considered "typical" in terms of the discussion that usually occurs for the conferences of earlier supervision cycles. It should also be noted that the timing of the research limited the pool from which I could participants since I wanted to be able to observe and collect material from one full cycle. Since some triads at Sequoyah had already completed their sixth observation cycle, these potential participants were eliminated from my recruitment population. These characteristics of the study necessitate a high level of caution when interpreting any results stemming from this project.

\section{Implications for Future Research}

Keeping in mind the limitations of this work, the findings of this capstone suggest that several factors contributed to levels of trust within student teaching triads, and these influenced the characteristics and practices that participants identified as either helpful or 
problematic. However, in addition to the three broad findings summarized in Table 2, many questions remain. This study aimed to understand student teaching triad members' perspectives on triad conferences and the practices of university supervisors they felt contributed or detracted from to supervision and the student teaching placement as a whole. Throughout the presentation of findings, I identified several areas of future research. Due to the limitation of this particular study, it is important to conduct similar work on a much broader and long term scale, using randomly identified participants if possible. Although this study was aimed at the practices of university supervisors and perceptions of triad conferences specifically, participants spoke about a wide range of issues and perceptions dealing with supervision and student teaching on a much broader scale. Additional efforts could be made to help participants distinguish between practices and characteristics unique to university supervisors as opposed to the overall processes of supervision. On the other hand, studies with a broad scale in mind from the start may be able to capture additional insight by asking new interview questions and engaging in more long term analysis of the triad conferences and changes in student teachers' decision-making by conducting observations of both conferences and classroom teaching over time. Additional methods of data collection and analysis may also be considered and should include more in depth analysis of the video prompts and responses, detailed document analysis, feedback provided by both university supervisors and mentor teachers, and more. More specifically, possible research projects focused on triad relationships could look at the factors surrounding the building of trust within triads by analyzing specific language and actions that build or undermine trust, determining the effects of matching triad members based on previous experience and placement context, 
exploring differences in relationships by comparing live and virtual conferencing, identifying the factors that influence mentor teacher involvement and how a mentor teacher's involvement influences the dynamics of a triad overall, and exploring the effects of prolonged relationships between triad members. Another broad category of research could further explore the influence of different methods of feedback and reflection and how they affect a student teacher's decision-making by exploring the use of supplementary feedback documents in the student teaching placement, the importance of video in reflection, how the structures and tones of feedback influence a student teacher's ability to reflect, ways to ensure student teachers are able to reflect on their teaching at an appropriate depth, whether deeper reflection impacts teaching outcomes, and how a student teacher's needed level of support interacts with these questions. Finally, a large question that remains from this work is whether or not certain supervision methods have different levels of effectiveness between inservice and preservice teachers and how the needs of the two groups may be different. 


\section{Chapter 5}

\section{Conclusions and Recommendations}

Recall that many universities are looking carefully at their teacher education programs and how they can be improved in light of recent policy changes (Asplin \& Marks, 2013). The experiences of preservice teachers in their student teaching placements in particular is a large area of focus, and while several studies have focused on different components of these experiences, far fewer have focused on the university supervisor (Marks, 2002). Of these studies that do exist, many are outdated, come from foreign contexts, or are methodologically flawed in some way.

University supervisors are responsible for creating connections between coursework and the student teaching field experience (Caires \& Almeida, 2007), but little is known about the specific practices university supervisors engage in while fulfilling this role, especially those practices that each member of the student teaching triad finds to be particularly useful (Asplin \& Marks, 2013). Within the context of this study, teacher education faculty and staff at Sequoyah University wanted to better understand the value of the student teaching triad conference and the role that university supervisors play in supporting student teachers. Increased understanding of this crucial role could serve to benefit the university teacher education program as a whole by informing future university supervisor training and professional development practices. Beyond the scope of Sequoyah University, isolating specific supervision practices that triad members view as helpful will allow researchers to ask additional questions about what makes the 
practices helpful, under what conditions they are most successful, how they can be effectively taught and encouraged among triads, and how they encourage the further development of student teachers as they become practitioners in the field.

The central purpose of this study is to provide the teacher education faculty and staff at Sequoyah University with a deeper understanding of the usefulness of student teaching triad conferences and to identify specific practices of university supervisors that members of the triad find to be most helpful within the context of their program. This includes looking at the characteristics of university supervisors and the specific tools and practices of supervision that are or are not being utilized by triad members. The following research questions guided this research:

1. What specific practices do university supervisors engage in that are viewed as helpful by members of the student teaching triad?

a. What about these practices makes them helpful?

b. Are there any practices that are viewed as problematic or unhelpful? How and why are they problematic or unhelpful?

2. How are triad conferences useful in promoting the development of student teachers?

a. How do student teachers, mentor teachers, and university supervisors perceive the triad conferences?

b. Are triad conferences viewed as helpful? In what ways?

c. In what ways, if any, do conferences impact student teachers' future classroom decision-making in their student teaching placements? 
d. What specific problems do student teachers, mentor teachers, and university supervisors note about the triad conferences? What is the nature of these problems?

The answers to these questions were discussed thoroughly in chapter four. These three broad findings paint a complex picture of the relationships between triad members in the triad conferences and how these are influenced by supervision practices they find to be helpful and unhelpful. In this chapter, I will present the recommendations based on the findings described above. Table 3 summarizes the findings and resulting recommendations. Each of these recommendations will be further discussed below, and attention will be given to how these recommendations stem directly from my findings.

Table 3

Findings and Recommendations for Sequoyah Teacher Education Office

Finding 1: Positive relationships, viewed as central to providing effective supervision, can be built by conveying a sense that the triad is a central priority for all members. This is demonstrated through flexibility, availability, and engagement within supervision. Prolonged, cross-contextual relationships can contribute to more positive interactions.
Recommendation 1: Place a heavy emphasis on building relationships among university supervisors, mentor teachers, and student teachers by providing triad members with policies, resources, and structures directed at increasing perceptions of competence and maintaining high levels of engagement among all triad members.
Finding 2: Previous teaching experiences and level of experience within the triad role may affect supervision and how it is perceived by triad members. Supervisors should present themselves in a way that emphasizes the knowledge and experiences they bring to a triad.
Recommendation 2: Evaluate the aspects of supervision that participants identified as problematic by conducting a review of various structures and policies in light of the goals of the program and accreditation requirements. Supervisors should be instructed on how to present themselves in a way that emphasizes the knowledge and experiences they bring to a triad. 
Finding 3: The student teaching experience should be perceived as formative in nature. Tools used in providing formative feedback must be used effectively in order to impact student teachers' classroom decisionmaking.
Recommendation 3: Continue emphasizing the central goal of preparing student teachers and the structures of university supervision that are viewed positively, especially as they relate to using video to guide the provision of positive, formative feedback in order to impact student teachers' classroom decisionmaking.

\section{Recommendation 1}

My first recommendation stemming from my findings is for Sequoyah teacher education faculty and staff to place a heavy emphasis on building relationships among university supervisors, mentor teachers, and student teachers by providing triad members with policies, resources, and structures directed at increasing perceptions of competence, providing targeted support for student teachers based on their individual needs, and maintaining high levels of engagement among all triad members. This recommendation is heavily influenced by my first broad finding that positive relationships, viewed as central to providing effective supervision, can be built by conveying a sense that the triad is a central priority for all members. This is demonstrated through flexibility, availability, and engagement within supervision. Prolonged, cross-contextual relationships can contribute to more positive interactions.

Although the importance of relationships is already emphasized in current training of university supervisors, I believe more work could be done regarding specific ways to build trust within the triads. Recall that while two of the triads discussed having very strong relationships, the relationships in Natalie's, Carrie's, and Erica's triad could have been strengthened to move beyond the professional in order for Natalie to feel more emotionally and personally supported. The field placement coordinator, primarily in 
charge of training university supervisors, may even consider using the theory of relational trust as a framework for discussing the importance of trusting relationships within triads in the training sessions.

One specific way supervisors may increase levels of trust is by conferencing live when possible. All supervisors are required to meet live at least three times during the supervision cycles for each of their student teachers. Although it is yet to be determined if live conferencing results in greater teaching outcomes, participants in this study clearly expressed a preference for meeting live. With this recommendation, it is important to consider the fact that live conferences are not always possible due to funding and location, and for at least some triads, virtual conferencing is preferred. In these cases, it is important for teacher education staff to share effective methods of building and maintaining relationships via technology with triad members. These could include, but are definitely not limited to choosing a time that works for everyone, making sure there's a solid connection and technology is working, having a quiet place to go in order minimize distractions, and remembering to be polite just like you would in a live conference by greeting everyone at the beginning. The information could be included in the online "toolbox" of training materials provided by the teacher education office already.

Another way to encourage relationship building is to emphasize the need for active mentor teacher engagement. Both Erica and Holly expressed a clear desire to have higher levels of mentor teacher involvement within their triads in order to strengthen the conversations they were able to have in conferences. Joyce did not talk about the need for involvement, but she described various ways that working as a partner with Amelia was 
really helpful in terms of Molly's development and progress throughout the placement. Natalie, whose mentor teacher was not always present for observed lessons or conferences, also wanted more mentor teacher involvement because she thought it would also Carrie to provide more insight into their conference discussions. All of these facts, combined with the fact that some of the mentor teachers wanted to be more involved in the processes of lesson plan feedback, video prompts, and responses, make it clear that additional emphasis on mentor teacher engagement is needed.

The teaching internship handbook outlines several specific actions and responsibilities of the mentor teacher which include systematically observing the student teacher and providing written feedback at least once a week; planning deadlines of the student teaching experience with the university supervisor; observing at least one lesson daily to promote oral and/or written feedback on lessons; meeting with the university supervisor and student teacher to share observational data, target observations, and plan next steps for the student teacher; and maintaining regular contact with the university supervisor to discuss the student teacher's performance and progress (“Teaching Internship Handbook," 2015). It is clear from participants' responses that many of these things were not happening within Natalie's triad and other triads described by Holly and Erica. The teacher education office currently allows for each triad member to evaluate one another in terms of how they performed their job duties at the end of a placement. Although this is valuable data, the teacher education office might consider gathering feedback at various points throughout the placement to encourage more engagement from all members. This is a complicated issue since the teacher education office must balance 
the need for gathering as many willing mentor teachers that are needed with ensuring the mentor teachers are fully engaged with the experience.

\section{Recommendation 2}

The second recommendation stemming from my findings is for the teacher education faculty and staff to evaluate the aspects of supervision that participants identified as problematic by conducting a review of various structures and policies in light of the goals of the program and accreditation requirements. Supervisors should be instructed on how to present themselves in a way that emphasizes the knowledge and experiences they bring to a triad. This recommendation stems directly from the finding that previous teaching experiences and level of experience within the triad role may affect supervision and how it is perceived by triad members. Supervisors should present themselves in a way that emphasizes the knowledge and experiences they bring to a triad. Previous teaching experiences and level of experience within the triad role may affect supervision and how it is perceived by triad members. Supervisors should present themselves in a way that emphasizes the knowledge and experiences they bring to a triad.

Positive relationships among triad members could also be encouraged by matching the university supervisor and student teacher based on the supervisor's previous teaching experience matching with the student teaching placement as close as possible in terms of grade level, subject, and possibly even student population. Participants in the study that experienced differences in previous teaching experiences noted that it lowered perceptions of competence amongst all three triad roles. Matching done in this way will not always be possible given the number of teaching candidates at Sequoyah and the variety of their placements. But this should still be considered an important factor as triads are formed. Another factor that may be considered when forming triads is the 
possibility of prolonged relationships among triad members. Joyce, Amelia, and Molly were the only participants to have experienced getting to work with at least one other triad member prior to the current student teaching placement, and each of them expressed being very pleased with having the opportunity. The field placement coordinator noted that she is going to try to encourage continuity in relationships next year by having university supervisors work with their practicum students in the full student teaching placement too. Feedback could be gathered from triad members in order to learn more about the effects of such an arrangement. Given the number of factors that may influence relationships such as matched experiences, previous relationships, and prolonged relationships, it is difficult to know which of these should be prioritized when making placement and triad decisions. Gathering additional feedback from a variety of triads to which these particular scenarios apply could potentially influence the decision-making that goes into forming triads.

Participants identified knowledge of the Sequoyah teacher education program as being beneficial for relationship-building and fulfilling the supervisor role of serving as a connection to the university. This is an important finding in light of the fact that, due to a new budget model, Sequoyah is moving away from having doctoral students supervise. Instead, more and more university supervisors are coming from outside the university. There are of course benefits to this. The field placement coordinator found, for example, that incoming doctoral students really struggled with supervising their first semester at the university because they were going through orientation, taking a full course load, serving as teaching or researching assistants, and even moving to a new city in some cases at the same time they were learning the necessary role responsibilities of being a 
supervisor (Field placement coordinator, personal conversation, April 13, 2017). This made it difficult for them to fulfill their duties in a way that conveyed availability and flexibility to their mentor teachers and student teachers, an issue which Alice clearly described in her interview responses. Many of these challenges were simply not a factor for non-doctoral student supervisors (Field placement coordinator, personal conversation, April 13, 2017).

One downside of having people without any other connections to the university supervise student teachers is that they do not have a full understanding of the teacher education program context. They are less likely than doctoral students to know the student teachers' professors, core philosophies of the program, course objectives, and the overall course sequence that student teachers progress through in order to complete the program. In order to strengthen knowledge of the program, I recommend that the teacher education department create a document that provides a basic framework for the various programs. This could contain the course sequence, course syllabi or at least an outline of the central objectives for each course, and information related to major planning and teaching philosophies used throughout the programs such as backward design and culturally responsive teaching. Additionally, it should be an expectation that university supervisors and mentor teachers are invited to at least one class of the student teaching seminar in order to learn more about how the course supports the learning that takes place within the student teaching placement. Although this is currently an option that all seminar instructors are encouraged to enact, making it a department-wide expectation would encourage more participation. 
In the specific cases where university supervisors cannot be matched based on previous teaching experiences or do not have a high level of experience in the supervisor role, they should be taught to minimize these facts while emphasizing others that may increase perceptions of competence within their triad. This may include emphasizing years of teaching experience, knowledge of the Sequoyah teacher education program, pedagogical content knowledge for their subject area, and other factors that could increase the likelihood that mentor teachers and student teachers view them as experienced, knowledgeable professionals that can provide useful insight into the student teaching experience regardless of whether they taught the same grade level or not. Perhaps one way to increase this perception is to build a foundation of a strong, positive relationship in the first place.

\section{Recommendation 3}

The third and final recommendation for the teacher education department at Sequoyah is to continue emphasizing the central goal of preparing student teachers and the structures of university supervision that are viewed positively, especially as they relate to using video to guide the provision of positive, formative feedback in order to impact student teachers' classroom decision-making. This recommendation stems directly from the finding that the student teaching experience should be perceived as formative in nature. Tools used in providing formative feedback must be used effectively in order to impact student teachers' classroom decision-making.

It was clear from participants' responses that they appreciated the emphasis that was placed on the formative nature of the student teaching experience. Participants were confident that university supervisors used the goal of preparing student teachers to 
assume the responsibilities of a classroom teacher and to teach competently to inform the feedback and support they provided during triad conferences and throughout the supervision cycles. Part of communicating this emphasis on the central goal was providing positive, formative feedback on a regular basis. Participants viewed this as being very important in not only building relationships within the triads, but also contributing to the professional growth of the student teachers.

In addition to emphasizing the positive, formative nature of feedback and keeping sight of the overall goal of student teaching, the teacher education department should continue to use video in lesson observations in order to inform feedback, reflection, and discussion throughout the supervision cycles. It was clear from participants' responses that the use of video was crucial in impacting the student teachers' changes in classroom decision-making. Several participants pointed specifically to video impacting teaching when it came to the physical presence and movements of the student teacher and the engagement of students. As previously mentioned, the positive effects of video reflection in the professional development of teachers are extremely well-documented in the literature (Borko et al., 2008; Fadde, et al., 2009; Glazer et al., 2005; Harford \& MacRuairc, 2008; Kuter, et al., 2012; Martin \& Ertzberger, 2013; McDuffie et al., 2014; Robinson \& Kelley, 2007; Savas, 2012; Seidel et al., 2011; Sherin \& van Es, 2005; Wang \& Hartley, 2003; Whitehead \& Fitzgerald, 2007) and therefore there is a strong basis to support this final recommendation.

There are several additional steps that can be taken in order to enact this recommendation. It is clear from participants' interview responses and the documents they provided during this study that there was highly variable use of documents within 
the triads. Some reported the documents such as conference summaries and collaborative feedback forms were highly useful while others did not even use them. Therefore, it is important to learn more about the use of these documents and to evaluate how they align with the program goals and the documentation requirements of the accreditation body. Information should be gathered from various triads about their use of the documents and how they affected the development of student teachers. For those that did not use the documents, it would be important to know the factors that influenced their lack of use and whether different types of documentation would be more useful instead. Additional information about the perceived usefulness of the documents is also necessary for determining how their use could be encouraged.

The varied use of documents is possibly related to the finding that some of the participants had difficulty identifying specific instances where a student teachers' decision-making was directly impacted by feedback and conversations that took place in triad conferences. Recall that while some participants were able to pinpoint exact instances of change influenced by conferences, others only provided general descriptions of growth. The summaries/actions plans and conference feedback forms are meant to help the university supervisor stay abreast of events taking place within the student teaching experience and to also serve as touch points for all of the triad members to track the progress that is being made in the placement. The goal of tracking growth in the placement is made somewhat more difficult by the fact that the MTPTM-P protocol calls for switching the CLASS® dimensions of focus for each conference. So if you focus on the dimension of Student Engagement for one of the cycles, there is a chance there will not be time to revisit this particular dimension within the placement unless it is a 
particular priority for the student teacher. This can make it difficult to track progress made in certain dimensions if participants are not keeping track of the dimensions outside of the conferences by using the collaborative feedback forms. It is clear that more information about the factors surrounding the use of these documents is needed.

Another suggestion for enacting this recommendation is to evaluate the specific features of MTPTM and CLASS ${ }^{\mathrm{T}}$ that may work differently with preservice teacher populations as opposed to inservice groups. Recall that while participants acknowledged the importance of reflection, they were often frustrated by the language and structures of the prompts and the varying depths of response they elicited. It is important to consider the possibility that some student teachers are not familiar enough with the CLASS $®$ language to fully comprehend the prompts and the questions they ask. It is also possible that even with a solid understanding of the language, some student teachers are simply not able to reflect at the expected level at this stage in their development. Nagro et al. (2017) found that teacher candidates, new to the work of teaching, needed more guidance in learning to reflect on their instructional decision-making.

Although different analyses of the prompts and their responses have already been conducted (Hoffman et al., 2016; McCool, et al., 2017) more information is needed regarding the factors that elicit certain responses from student teachers. It has not been conclusively demonstrated that high fidelity to the CLASS $®$ prompt-writing guidelines results in increased likelihood that the prompt responses will meet expectations in terms of their depth of analysis and reflection.

Regardless of the outcome of conducting additional prompt analyses, the teacher education office should consider taking steps to provide student teachers with instruction 
about the purposes of the prompts and the indicators of strong, meaningful analysis and reflection. Nagro et al.'s (2017) finding that feedback and guidance in reflection yielded deeper reflection and better teaching supports this recommendation. The work of teaching the student teachers what meaningful analysis and reflection looks like could either be enacted in the general methods courses each candidate takes or through direct instructional and continuous feedback provided by mentor teachers and university supervisors within the triad conferences. University supervisors could take time in the first triad conference to explain the structure and purposes of the prompts and provide examples of strong responses. Time could be dedicated within subsequent conferences to look at the student teacher's prompt responses and to provide feedback. A scaffolding tool in the form of a reflection checklist (see Nagro et al., 2017) could also be used to enhance triad members' ability to evaluate and provide feedback on prompt responses. Throughout the process of encouraging deeper reflection, the central goal of reflection should be emphasized. It is important for student teachers to remember that deeper reflection has been linked to increased growth in teaching practices (Wang \& Hartley, 2003) and that responding to prompts is not just "ticking another box" along the student teaching journey.

\section{Reflection}

I originally chose this area of research based on my previous experiences as a novice university supervisor struggling to understand her role and provide effective supervision. While I had a solid understanding of many of the factors affecting supervision, I have learned much more about the goals and challenges of providing 
effective supervision from this project. I will outline two broad conclusions that I reached as part of my work with this capstone.

As with any activity system, supervision relies on a network of people, documents, tools, settings, policies, and a division of labor that contribute to the central goal of preparing teachers to assume the professional responsibilities of a teacher and to teach competently. Underlying these factors are the four components that influence relational trust: respect, personal regard for others, competence in core role responsibilities, and personal integrity. Each factor and component of trust within the system is extremely intertwined with the others and it's impossible to separate factors such as how documents are used, the nature of relationships among triad members, and the language and structure of feedback from other factors such as the perceived level of ability of the student teacher, experiences in roles, and how feedback is received.

The interactions that take place within student teaching triads are not unlike those that take place in K-12 classrooms. Teaching is a messy endeavor, and it is extremely difficult to isolate specific factors that either strengthen or detract from effective teaching. Similarly, due to the many factors involved in supervision, it is difficult to see how each is influencing the outcome and overall goal. It can be impossible to isolate the variables that strengthen and detract from effective supervision.

Because each of these factors work together and impact one another in a variety of ways, it becomes extremely important to very explicitly articulate the ultimate goals of supervision, the student teaching experience, and the teacher education program as a whole. Specific consideration should be given to the importance of instructional decisionmaking and reflection on practice. In the case of Sequoyah, the central goals of the 
teacher education program are clearly defined in the student teaching handbook. The Sequoyah teacher education program is grounded in the belief that teachers who make appropriate decisions are ones who demonstrate effective clinical and pedagogical practices and reflect on the outcomes of their actions. The program aims to prepare teachers who exemplify best practices in connecting content, practice, and research in order to inform instructional decision-making that allows them to foster academic, social, and emotional development in students with diverse backgrounds and diverse needs.

Goals such as those outlined by Sequoyah are common across teacher education programs and can influence the supervision process and the student teaching experience in a variety of ways. These include the tools and documents that are used and the discussions that are had among triad members throughout the supervision cycles. Because programmatic goals form the framework for the policies, tools, and structures that are used, it is important to consistently check alignment between these and the goals themselves. Despite having clearly defined goals, it is hard to ensure that everyone involved in supervision and the student teaching experience have the same understanding of priorities, best practices, and philosophies when it comes to teaching and teacher education. Due to this fact, feedback should be regularly gathered from stakeholders in order to gauge how policies, tools, and structures are affecting actual supervision practices and student teaching experiences. Finally, steps should be taken to revise, eliminate, or mitigate factors that detract from programmatic goals while emphasizing the factors that support them.

In addition to being very complicated because of the number of factors involved in supervision, it can be a challenge for universities to ensure that they create a program 
that meets the needs of all of their students. Once again, this is very similar to what takes place within K-12 classrooms. A very difficult aspect of teaching is ensuring you differentiate your approaches in order to best meet the needs of your individual students. Similar to K-12 students, student teachers arrive in teacher education programs with a variety of needs, experiences, and levels of preparation. Teacher education programs strive to create experiences that are within student teachers' zone of proximal development while at the same time pushing their classroom decision-making and helping them make connections between coursework and field experiences and helping them implement theory into practice.

In this capstone, several factors and constructs were shown to both positively and negatively impact student teaching triads. Factors that contributed positively to perceptions of effective supervision included strong relationships among triad members, matched teaching experiences, connections to the teacher education program, active engagement from all members, previously established and long term relationships, the use of video to guide reflection and conference discussion, and the use of positive language that emphasized the formative rather than evaluative nature of feedback. Factors that contributed negatively to perceptions of effective supervision included unmatched teaching experiences, low levels of mentor teacher engagement, and the negatively viewed language and structure of reflection prompts and responses. It is possible that the negatively viewed prompt language and structure is related to the student teachers' zone of proximal development. The language and structures used in providing feedback should not impede reflection or the understanding or implementation of effective teaching practices. In order for this to happen, the formative nature of the student teaching 
experience has to be emphasized. Student teachers should understand the importance of supervision structures and realize that they are not just ticking a series of boxes. The way they view these structures colors how they view certain elements of supervision such as the prompts, reflections, and questions they are asked during post-observation conferences. Ultimately, they should believe that the ultimate goal of preparing them to be effective teachers is the central driving force of their experiences in order for them to be willing to take risks and grow.

Once their goals are clearly defined, teacher education programs can use these factors as a starting point for their own analysis of programmatic policies, tools, and structures associated with their supervision processes. This will serve as the next step toward checking alignment, and determinations can be made about characteristics of the program that are determined to have either positive or negative impacts on effective supervision. Positive characteristics should be emphasized in program documents, trainings, and policies. Negative characteristics can be revised to make them more effective when possible. The characteristics that are perceived negatively but cannot be changed due to cost, accreditation, or other restrictions could be mitigated by reframing and emphasizing their purposes to stakeholders. Negative characteristics that cannot be revised or mitigated should be eliminated. 


\section{Chapter 6}

\section{Action Communications}

To: Sequoyah University Teacher Education Department Faculty and Staff

From: Katie Loftin, M.Ed.

Doctoral Candidate

University of Virginia

405 Emmet St. South

Charlottesville, VA 22904

\section{Dear Sequoyah University Teacher Education Department:}

I am reporting findings and recommendations based on an investigation of the perceptions of student teaching triad members on the practices of university supervisors and the utility of post-observation triad conferences. Along with observing triad conferences and conducting video and document analysis, I also interviewed nine triad members from three student teaching triads. This qualitative comparative multiple-case study was exploratory, and these findings and recommendations are meant to be used as a starting point for further investigation of university supervision.

The findings of the study are as follows:

1. Positive relationships, viewed as central to providing effective supervision, can be built by conveying a sense that the triad is a central priority for all members. This is demonstrated through flexibility, availability, and engagement within supervision.

2. Previous teaching experiences and level of experience within the triad role my affect supervision and how it is perceived by triad members. Supervisors should present themselves in a way that emphasizes the knowledge and experiences they bring to a triad.

3. The student teaching experience should be perceived as formative in nature. Tools used in providing formative feedback must be used effectively in order to impact student teachers' classroom decision-making.

Based on these findings, I present the following recommendations to support your work: 
Recommendation 1: Place a heavy emphasis on building relationships among university supervisors, mentor teachers, and student teachers by providing triad members with policies, resources, and structures directed at increasing perceptions of competence, providing targeted support for student teachers based on their individual needs, and maintaining high levels of engagement among all triad members.

Several steps can be taken toward enacting this recommendation. Although the importance of relationships is already emphasized in the current training of university supervisors, I believe more work could be done regarding specific ways to build trust within triads. Based on the findings of this study, university supervisors could work toward this goal by conferencing live when possible. In situations where live conferencing is not always possible, effective methods of building and maintain relationships via virtual communication should be shared with triad members. In addition to this action, efforts should be made to match university supervisors to specific student teachers based on the supervisor's previous teaching experience and how well it aligns with the student teaching placement. Participants that experienced differences in previous teaching experiences noted that lack of experience within the grade level or subject affected perceptions of competence. When forming triads, consideration should also be given to the possibility of prolonged relationships among triad members. Participants that experienced working with at least one other triad member prior to the student teaching placement expressed being very pleased with the opportunity to build strong, long term relationships with one another.

An additional way to encourage relationship building is to emphasize the need for active mentor teacher engagement. Although there are several expectations outlined in the teaching internship handbook, participants found that many of them were not being adhered to and that less participation from the mentor teacher had negative impacts on the conversations that were able to happen within triad conferences. One potential way to increase mentor teacher engagement is to provide a mechanism for providing feedback on all triad members throughout a placement rather than just at the end.

Recommendation 2: Evaluate the aspects of supervision that participants identified as problematic by conducting a review of various structures and policies in light of the goals of the program and accreditation requirements. Supervisors should be instructed on how to present themselves in a way that emphasizes the knowledge and experiences they bring to a triad.

Positive relationships among triad members could also be encouraged by matching the university supervisor and student teacher based on the supervisor's previous teaching experience matching with the student teaching placement as close as possible in terms of grade level, subject, and possibly even student population. Participants in the study that experienced differences in previous teaching experiences noted that it lowered perceptions of competence amongst all three triad roles. Matching done in this way will not always be possible given the number of teaching candidates at Sequoyah and the variety of their placements. But this should still be considered an important factor as 
triads are formed. Another factor that may be considered when forming triads is the possibility of prolonged relationships among triad members. Those participants that experienced getting to work with at least one other triad member prior to the current student teaching placement expressed being very pleased with having the opportunity. Supervisors could continue working with practicum students in the full student teaching placement while they could also work with mentor teachers for multiple years. Feedback could be gathered from triad members in order to learn more about the effects of such arrangements. Gathering additional feedback from a variety of triads to which these particular scenarios apply could potentially influence the decision-making that goes into forming triads.

Participants identified knowledge of the teacher education program as being beneficial for relationship building and fulfilling the supervisor role of serving as a connection to the university. As you continue to hire more university supervisors that are not affiliated with the university, it will be important to provide supervisors with basic information about the program such as the typical course sequence, course syllabi or at least an outline of the central objectives for each course, and information related to major planning and teaching philosophies used throughout the program such as backward design and culturally responsive teaching.

In the specific cases where university supervisors cannot be matched based on previous teaching experiences or do not have a high level of experience in the supervisor role, they should be taught to minimize these facts while emphasizing others that may increase perceptions of competence within their triad. This may include emphasizing years of teaching experience, knowledge of the Sequoyah teacher education program, pedagogical content knowledge for their subject area, and other factors that could increase the likelihood that mentor teachers and student teachers view them as experienced, knowledgeable professionals that can provide useful insight into the student teaching experience regardless of whether they taught the same grade level or not. Perhaps one way to increase this perception is to build a foundation of a strong, positive relationship in the first place.

\section{Recommendation 3: Continue emphasizing the central goal of preparing student teachers and the structures of university supervision that are viewed positively, especially as they relate to using video to guide the provision of positive, formative feedback in order to impact student teachers' classroom decision-making.}

It was clear from participants' responses that they greatly appreciated the emphasis that was placed on the formative nature of the student teaching experience. Participants were confident that university supervisors used the goal of preparing student teachers to assume the responsibilities of a classroom teacher and to teach competently to inform the feedback and support they provided during triad conferences and throughout the supervision cycles. Part of communicating this emphasis on the central goal was providing positive, formative feedback on a regular basis. Participants viewed this as being very important in not only building relationships within the triads, but also contributing to the professional growth of the student teachers.

Once again, several specific steps can be taken in order to enact this recommendation. This study makes it clear that there is highly variable use of documents 
such as collaborative feedback forms and summaries/action plans within the triads. Information could be gathered from additional triads about their use of the documents and how they affected the development of student teachers. For those that did not use the documents, it would be important to know the factors that influenced their lack of use and whether different types of documentation would be more useful instead. This could also provide insight into how further use of the documents could be encouraged. The varied use of documents is important to investigate further because it is possibly related to triad members' abilities to identify specific instances of growth in student teachers. When the documents are not used, there are very few other ways of tracking progress within the placement, which could be problematic in the same way that a lack of assessment within a classroom would be.

In order to address this issue, the teacher education office should consider taking steps to provide student teachers with instruction about the purposes of the prompts and the indicators of strong, meaningful analysis and reflection. The work of teaching the student teachers what meaningful analysis and reflection looks like could either be enacted in the general methods courses or through direct instructional and continuous feedback provided by mentor teachers and university supervisors within the triad conferences. University supervisors could take time in the first triad conference to explain the structure and purposes of the prompts and provide examples of strong responses. Time could be dedicated within subsequent conferences to look at the student teacher's prompt responses and to provide feedback. A scaffolding tool in the form of a reflection checklist (see Nagro et al., 2017) could also be used to enhance triad members' ability to evaluate and provide feedback on prompt responses. Throughout the process of encouraging deeper reflection, the central goal of reflection should be emphasized. It is important for student teachers to remember that deeper reflection has been linked to increased growth in teaching practices (Wang \& Hartley, 2003) and that responding to prompts is not just "ticking another box" along the student teaching journey.

In addition to emphasizing the positive, formative nature of feedback and keeping sight of the overall goal of student teaching, the teacher education department should continue to use video in lesson observations in order to inform feedback, reflection, and discussion throughout the supervision cycles. It was clear from participants' responses that the use of video was crucial in impacting the student teachers' changes in classroom decision-making. Several participants pointed specifically to video impacting teaching when it came to the physical presence and movements of the student teacher and the engagement of students. As you well know, the positive effects of video reflection in the professional development of teachers are extremely well-documented in the literature (Borko et al., 2008; Fadde, et al., 2009; Glazer et al., 2005; Harford \& MacRuairc, 2008; Kuter, et al., 2012; Martin \& Ertzberger, 2013; McDuffie et al., 2014; Robinson \& Kelley, 2007; Savas, 2012; Seidel et al., 2011; Sherin \& van Es, 2005; Wang \& Hartley, 2003; Whitehead \& Fitzgerald, 2007) and therefore there is a strong basis to support this final recommendation.

Another suggestion for enacting this recommendation is to evaluate the specific features of MTP'M and CLASS ${ }^{\mathrm{T}}$ that may work differently with preservice teacher populations. Participants were often frustrated by the language and structures of the prompts and the varying depths of response they elicited. It is important to consider the possibility that some student teachers are not familiar enough with the CLASS $®$ 
language to fully comprehend the prompts and the questions supervisors ask. It is also possible that even with a solid understanding of the language, some student teachers are simply not able to reflect at the expected level at this stage in their development. Nagro et al. (2017), for example, found that teacher candidates, new to the work of teaching, needed more guidance in learning to reflect on their instructional decision-making.

I hope these findings and recommendations will be useful to you as you continue to improve university supervision practices and the student teaching experience overall. Please do not hesitate to contact me if you have any questions or concerns.

Sincerely,

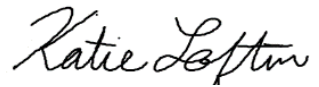

Katie Loftin 


\section{References}

AACTE (2013). The changing teacher preparation profession: A report from AACTE's professional education data system. Washington, D.C.

AACTE (2013a, June 18). NCTQ review of nation's education schools deceives, misinforms public. Washington, D.C.: Author. Retrieved from http://aacte.org/news-room/press-releases/nctq-review-of-nations-educationschools-deceives-misinforms-public.html

Acheson, K. A., \& Gall, M. D. (2003). Clinical supervision and teacher development: Preservice and inservice applications. New York, NY: Wiley.

Acheson, K.A., \& Gall, M. D. (1997). Techniques in the clinical supervision of teachers: Preservice and inservice applications. $4^{\text {th }}$ ed. New York, NY: Longman.

Adamson, F., \& Darling-Hammond, L. (2011). Addressing the inequitable distribution of teachers: What it will take to get qualified, effective teachers in all communities. Stanford Center for Opportunity Policy in Education. Retrieved from https://edpolicy.stanford.edu/sites/default/files/publications/addressinginequitable-distribution-teachers-what-it-will-take-get-qualified-effectiveteachers-all-_1.pdf

Akcan, S., \& Tatar, S. (2010). An investigation of the nature of feedback given to preservice English teachers during their practice teaching experience. Teacher Development, 14(2), 153-72. 
Ali, S., \& Khalid, M.I. (2015). Assessment of teaching practice: Perceptions of pupil teachers towards supervisors and cooperating teacher's practices. The Dialogue, $10(4), 424-433$.

Ambrosetti, A., \& Dekkers, J. (2010). The interconnectedness of the roles of mentors and mentees in pre-service teacher education mentoring relationships. Australian Journal of Teacher Education, 35(6), 42-55.

American Psychological Association (APA), Coalition for Psychology in School and Education. (2015). Top 20 principles from psychology for preK-12 teaching and learning. Retrieved May 31, 2016 from http://www.apa.org/ed/schools/cpse/toptwenty-principles.pdf

Anderson, D. (2007). The role of cooperating teachers' power in student teaching. Education, 128, 307-323.

Anderson, N. \& Radencich, M. (2001). The value of feedback in an early field experience: Peer, teacher, and supervisor coaching. Action in Teacher Education, 23(3), 66-74.

Asplin, K.N., \& Marks, M.J. (2013). Increasing the effectiveness of university supervisors during student teaching. Professional Educator, 3, 1-10.

Baecher, L., \& McCormack, B. (2015). The impact of video review on supervisory conferencing. Language and Education, 29(2), 153-173.

Bailey, K. (2006). Language teacher supervision: A case-based approach. New York, NY: Cambridge University Press. 
Bain, C. (1991, October). Student teaching triads: Perceptions of participant roles. Paper presented at the annual meeting of the North Rocky Mountain Educational Association, North Dakota.

Ball, D.L., \& Forzani, F.M. (2009). The work of teaching and the challenge for teacher education. Journal of Teacher Education, 60(5), 497-511.

Banville, D. (2006). Analysis of exchanges between novice and cooperating teachers during internships using the NCATE/NASPE standards for teacher preparation in physical education as guidelines. Research Quarterly for Exercise and Sport, 77, 208-221.

Bates, A.J., \& Burbank, M.D. (2008). Effective student teacher supervision in the era of No Child Left Behind. The Professional Educator, 32(2). Retrieved from http://www.theprofessionaleducator.org/articles/combined\%20fall_08.pdf

Beck, C., \& Kosnik, C. (2000). Associate teachers in preservice education: Clarifying and enhancing their role. Journal of Education for Teaching, 26(3), 207-224.

Beck, C., \& Kosnik, C. (2002). Components of a good practicum placement: Student teacher perceptions. Teacher Education Quarterly, 29(2), 81-98.

Beck, J., \& Shanks, J. (2005). A case study of teacher education reform: Issues and challenges. The New Educator, 1, 333-343.

Berliner, D.C., \& Glass, G.V. (Eds.). (2014). 50 myths and lies that threaten America's public schools: The real crisis in education. New York: Teachers College Press.

Bestor, A.E. (1953). Educational wastelands: The retreat from learning in our public schools. Urbana, IL: University of Illinois Press. 
Betts, J.R., Zau, A.C., \& Rice, L.A. (2003). Determinants of student achievement: New evidence from San Diego. San Francisco, CA: Public Policy Institute of California.

Blanton, M.L., Berenson, S.B., \& Norwood, K.S. (2001). Exploring a pedagogy for the supervision of prospective mathematics teachers. Journal of Mathematics Teacher Education, 4, 1770294.

Borg, M. (2004). The apprenticeship of observation. English Language Teaching Journal, 58(3), 274-276.

Borko, H., Jacobs, J., Eiteljorg, E., \& Pittman, M. (2008). Video as a tool for fostering productive discussions in mathematics professional development. Teaching and Teacher Education, 24, 417-436.

Borko, H., \& Mayfield, V. (1995). The roles of the cooperating teacher and university supervisor in learning to teach. Teaching and Teacher Education, 11, 501-518.

Bowman, C. \& McCormick, S. (2000). Comparison of peer teaching versus traditional supervision effects. The Journal of Educational Research, 93(4), 256-271.

Brandt, C. (2008). Integrating feedback and reflection in teacher preparation. ELT Journal, 62(1), 37-46.

Brookhart, S.M. (2008). How to give effective feedback to your students. Alexandria, VA: ASCD.

Bryk, A., \& Schneider, B. (2002). Trust in schools: A core resource for improvement. Russell Sage Foundation. 
Bullough, R. V. J., \& Draper, R. J., (2004). Making sense of a failed triad: Mentors, university supervisors, and positioning theory. Journal of Teacher Education, 55, 407-420.

Bunton, D., Stimpson, P., \& Lopez-Real, F. (2002). University tutors' practicum observation notes: Format and content. Mentoring and Tutoring, 10(3), 232-252.

Butt, G. (1994). The role of the higher education tutor. In A. Williams (Ed.), Perspectives on partnership: Secondary initial teacher training (pp. 118-133). London: Falmer.

Caires, S., \& Almeida, L.S. (2001). Inventario de Vivencias e Percep^oes de Estagio (I.V.P.E.): Versao adaptada as Licenciaturas em Ensino. In B.D. Silva \& L.S. Almeida (Orgs.), Actas do VI congresso Galaico-PortuguSs de psicopedagogia (vol. II, pp. 999-1014). Braga: Universidade do Minho, Centro de Estudos em Educa9ao e Psicologia.

Caires, S., \& Almeida, L.S. (2007). Positive aspects of the teacher training supervision: The student teachers' perspective. European Journal of Psychology of Education, $22,515-528$.

Caires, S., Almeida, L.S., \& Martins, C. (2010). The socio-emotional experiences of student teachers during practicum: A case of reality shock? The Journal of Educational Research, 103, 17-27.

Calandra, B., Brantley-Dias, L., \& Dias, M. (2006). Using digital video for professional development in urban schools: A teacher candidate's experience with reflection. Journal of Computing in Teacher Education, 22, 137-145. 
Calandra, B., Brantley-Dias, L., Lee, J.K., \& Fox, D.L. (2009). Using video editing to cultivate novice teachers' practice. Journal of Research on Technology in Education, 42, 73-94.

Calderhead, J., \& Shorrock, S. (1997). Understanding teacher education. London: Falmer.

Clift, R. T., \& Brady, P. (2005). Research on methods courses and field experiences. In M. Cochran-Smith \& K.M. Zeichner (Eds.), Studying teacher education: The report of the AERA Panel on Research and Teacher Education (pp. 309-424). Mahwah, NJ: Lawrence Erlbaum.

Civic Impulse. (2016). S. $1177-114^{\text {th }}$ Congress: Every Student Succeeds Act. Retrieved from https://www.govtrack.us/congress/bills/114/s1177

Cohen, D., \& Crabtree, B. (2006). Qualitative research guidelines project. Retrieved from http://www.qualres.org/HomeLinc-3684

Coleman, M.M., \& Mitchell, M. (2000). Assessing observation focus and conference targets of cooperating teachers. Journal of Teaching in Physical Education, 20, 40-54.

Council for the Accreditation of Educator Preparation (2013, June 11). Standard 3:

Candidate quality, recruitment, and selectivity. Retrieved from http://educationnext.org/gains-in-teacher-quality/

Council of Chief State School Officers. (2011, April). Interstate teacher assessment and support consortium (inTASC) model core teaching standards: A resource for state dialogue. Washington, DC: Author. 
Crawford, S., O'Reilly, R., \& Luttrell, S. (2012). Assessing the effects of integrating the reflective framework for teaching in physical education (RFTPE) on the teaching and learning of undergraduate sport studies and physical education students.

Reflective Practices, 13, 115-129. doi:10.1080/14623943.2011.626025

Creswell, J.W. (2012) Educational research: Planning, conducting, and evaluating quantitative and qualitative research ( $4^{\text {th }}$ ed.). Boston: Pearson.

Cuenca, A. (2010). Care, thoughtfulness, and tact: A conceptual framework for university supervisors. Teaching Education, 21(3), 263-278.

Cuenca, A. (2011). The role of legitimacy in student teaching: Learning to "feel" like a teacher. Teacher Education Quarterly, 38(2), 117-130.

Darling-Hammond, L. (2000). Teacher quality and student achievement: A review of state policy evidence. Education Policy Analysis Archives, 8(1). Retrieved from http://epaa.asu.edu/ojs/article/view/392/515

Darling-Hammond, L. (2006). Powerful teacher education. San Francisco, CA: JosseyBass

Darling-Hammond, L. (2013, June 18). Why the NCTQ teacher prep ratings are nonsense. The Washington Post. Retrieved from https://www.washingtonpost.com/news/answer-sheet/wp/2013/06/18/why-thenctq-teacher-prep-ratings-are-nonsense/

Darling-Hammond, L., Chung, R., \& Frelow, F. (2002). Variation in teacher preparation: How well do different pathways prepare teachers to teach? Journal of Teacher Education, 53(4), 285-302. 
Darling-Hammond, L., Wise, A., \& Klein, S. (1995). A license to teacher: Building a profession for $21^{\text {st }}$ century schools. Boulder, CO: Westview.

Devlin-Scherer, R., Mitchel, L.Z., \& Mueller, M. (2007). Lesson study in a professional development school. Journal of Education for Teaching: International Research and Pedagogy, 33, 119-120.

Dimyan-Ehrenfeld, J. (2013, July 18). Teaching training programs need a reboot. The Washington Post. Retrieved from https://www.washingtonpost.com/opinions/teacher-training-programs-need-a$\underline{\text { reboot/2013/07/18/3d359e5a-eb47-11e2-a301-ea5a8116d211_story.html }}$

Duncan, A. (2014, January 13). Parent voices for world-class education: Remarks of U.S. Secretary of Education Arne Duncan to the National Assessment Governing Board Education Summit for Parent Leaders. Retrieved from http://www.ed.gov/news/speeches/parent-voices-world-class-education

Education Commission of the States. (2016). Mitigating teacher shortages: Alternative teacher certification. Retrieved from http://www.ecs.org/eccontent/uploads/Mitigating-Teacher-Shortages-Alternative-Certification.pdf

Educational Testing Service (2005). General test percentage distribution of scores within intended broad graduate major field based on seniors and non-enrolled college graduates: July 1, 2001-June 30, 2004. Princeton, NJ: Educational Testing Service. Retrieved from http://www.ets.org/Media/Tests/GRE/pdf/5_01738_table_4.pdf 
Elliot, P. (2013, June 18). Too many teachers, too little quality. Yahoo News. Retrieved from https://www.yahoo.com/news/report-too-many-teachers-too-little-quality040423815.html?ref=gs

Engestrom, Y., Miettinen, R., \& Punamaki, R.L. (Eds.) (1999). Perspectives on activity theory. Cambridge: Cambridge University Press.

Fadde, P.J., Aud, S., \& Gilbert, S. (2009). Incorporating video-editing activity in a reflective teaching course for pre-service teachers. Action in Teacher Education, 31(1), 75-86. http://dx.doi.org/10.1080/01626620.2009.10463512

Feiman-Nemser, S. \& Beasley, K. (1997). Mentoring as assisted performance: A case of coplanning. In V. Richardson (Ed.), Constructivist teacher education (pp. 108126). London: Falmer.

Fernandez, M.L. \& Erbilgin, E. (2009). Examining the supervision of mathematics student teachers through analysis of conference communications. Educational Studies in Mathematics, 72, 93-110.

Fletcher Jr., E.C. (2012). Business education university supervisors' challenges in fulfilling their supervisory roles and responsibilities. Delta Pi Epsilon Journal, $54(2), 1-15$.

Fletcher Jr., E.C. (2013). Investigating the challenges of developing business education student teachers: Perspectives from university supervisors. Career and Technical Education Research, 38(2), 87-103.

Fletcher, S. (2000). Mentoring in schools: A handbook of good practice. London: Kogan Page. 
Fosnot, C.T. (1996). Teachers construct constructivism: The centre for constructivist teaching/teacher education project. In C.T. Fosnot (Ed.), Constructivism: theory, perspectives, and practice (pp. 205-216). New York, NY: Teachers College Press.

Fraser, J.W. (2014). Considering the future of university-based teacher education.

Woodrow Wilson National Fellowship Foundation. Retrieved from

http://woodrow.org/wp/wp-

content/uploads/2014/04/WoodrowWilson_Fraser_UnivBasedTeacherEd_April20

14_FINAL.pdf

Freidus, H. (2002). Teacher education faculty as supervisors/advisors/facilitators: Playing multiple roles in the construction of field work experiences. Teacher Education Quarterly, 29(2), 65-76.

Fuller, E.J. (2014). Shaky methods, shaky motives: A critique of the National Council of Teacher Quality’s review of teacher preparation programs. Journal of Teacher Education, 65(1), 63-77.

Gastic, B. (2014). Closing the opportunity gap: Preparing the next generation of effective teachers. In R. Hess \& M. McShane (Eds.). Teacher quality 2.0. Cambridge, (pp. 91-108). Cambridge, MA: Harvard Education Press.

Gibbs, L.J., \& Montoya, A.L. (1994). The student teaching experience: Are student teachers the only ones to benefit? Paper presented at the annual meeting of the Association of Teacher Educators, Atlanta (ERIC Document Reproduction Service No. ED 373 025). 
Gimbert, B. \& Nolan, J. (2003). The influence of the professional development school context on supervisory practice: A university supervisor's and interns' perspectives. Journal of Curriculum and Supervision, 18(4), 353-379.

Glazer, E., Hannafin, M.J., \& Song, L. (2005). Promoting technology integration through collaborative apprenticeship. Educational Technology Research and Development, 53(4), 57-67. http://dx.doi.org/10.1007/BF02504685

Glenn. W.J. (2006). Model versus mentor: Defining the necessary qualities of the effective cooperating teacher. Teacher Education Quarterly, 33, 85-95.

Goldhaber, D. \& Walch, J. (2013). Reality versus rhetoric: Is the academic caliber of the teacher workforce changing? CEDR Working paper 2013-4

Goldhammer, R. (1969). Clinical supervision: Special methods for the supervision of teachers. New York, NY: Holt, Rinehart and Winston.

Goldstein, D. (2014). The teacher wars: A history of America's most embattled profession. New York, NY: Anchor.

Goodlad, J. (1990). Teachers for our nation's schools. San Francisco, CA: Jossey-Bass

Griffin, L.M., \& Combs, C.S. (2000). Student teachers' perceptions of the role of the physical educator. Journal of Physical Education, Recreation, and Dance, 71(4), $42-45$.

Grimmett, P.P., \& Ratzlaff, H.C. (1986). Expectations for the cooperating teacher role. Journal of Teacher Education, 37(6), 41-50.

Grossman, P. (2011). Framework for teaching practice: Brief history of an idea. Teachers College Record, 113(12), 2836-2843. 
Grossman, P., Compton, C., Igra, D., Ronfeldt, M., Shahan, E., \& Williamson, P. (2009). Teaching practice: A cross-professional perspective. Teachers College Record, 111(9), 2055-2100.

Hafen, C. A., Hamre, B.K., Allen, J.P., Bell, C.A., Gitomer, D.H., \& Pianta, R.C. (2015). Teaching thought interactions in secondary school classrooms: Revisiting the factor structure and practical application of the classroom assessment scoring system-secondary. The Journal of Early Adolescence, 35(5-6), 651-680. doi: $10.1177 / 0272431614537117$

Hammerness, K., \& Darling-Hammond, L. (2005). The design of teacher education programs. In L. Darling-Hammond \& J. Bransford (Eds.), Preparing teachers for a changing world: What teachers should learn and be able to do (pp. 390-441). San Francisco: Jossey Bass.

Harford, J., \& MacRuairc, G. (2008). Engaging student teachers in meaningful reflective practice. Teaching and Teacher Education, 24, 1884-1892. http://dx.doi.org/10.1016/j.tate.2008.02.010

Hattie, J. (2008). Visible learning: A synthesis of over 800 meta-analyses relating to achievement. New York, NY: Routledge.

Herman, E. (2015, January 18). Why so many teachers feel so bad so much of the time. The Washington Post. Retrieved from https://www.washingtonpost.com/news/answer-sheet/wp/2015/01/18/why-somany-teachers-feel-so-bad-so-much-of-the-time/

Hightower, A.M., Delgado, R.C., Lloyd, S.C., Wittenstein, R., Sellers, K., \& Swanson, C.B. (2011). Improving student learning by supporting quality teaching: Key 
issues, effective strategies. Retrieved from

http://www.edweek.org/media/eperc_qualityteaching_12.11.pdf

Hoffman, A., McGraw, J., \& McCool, M. (April, 2016). Using a video based protocol to prompt pre-service teachers' self-analysis and change in pedagogical practice. Paper presented at the American Educational Research Association annual meeting, Washington, DC.

Hollins, E. (2016) (Ed). Rethinking field experiences in preservice teacher education: Meeting new challenges for accountability. New York, NY: Routledge

Holmes Partnership (2007). The Holmes Partnership trilogy: Tomorrow's teachers, tomorrow's schools, and tomorrow's schools of education. New York, NY: Peter Lang

Hunt, K., Mitchell, M., Maina, M., \& Griffin, L. (2015). A comparison of selected supervisory skills of content specialist and non-content specialist university supervisors. The Physical Educator, 72, 215-235.

Hyland, F., \& Lo, M.M. (2006). Examining interaction in the teaching practicum: Issues of language, power, and control. Mentoring \& Tutoring, 14(2), 163-186.

Izadinia, M. (2015). Student teachers' and mentor teachers' perceptions and expectations of a mentoring relationship: Do they match or clash? Professional Development in Education, 387-402. http://dx.doi.org/10.1080/19415257.2014-994136

Johnson, I.L., \& Napper-Owen, G. (2011). The importance of role perceptions in the student teaching triad. Physical Educator, 68, 44-56.

Jyrhama, R. (2001). What are the 'right' questions and what are the 'right' answers in teaching practice supervision? Paper presented at the Annual Meeting of the 
International Study Association on Teachers and Teaching, September 21-25, in Faro, Portugal.

Kaptelinin, V. (2015). Activity Theory. In M. Soegaard \& R.F. Dam (Eds.), The encyclopedia of human-computer interaction. ( $2^{\text {nd }}$ ed.) Retrieved from https://www.interaction-design.org/literature/book/the-encyclopedia-of-humancomputer-interaction-2nd-ed/activity-theory

Kent, S. (2001). Supervision of student teachers: Practices of cooperating teachers prepared in a clinical supervision course. Journal of Curriculum and Supervision, $16(3), 228-244$.

Kissua, S. P., \& Algozzine, B. (2013). Foreign language student teaching: Do supervisor qualifications really matter? Foreign Language Annals, 46(2), 175-190.

Knowles, J.G., Cole, A., \& Presswood, C. (1994). Through preservice teachers' eyes. New York, NY: Merrill.

Koemer, M.E. (1992). The cooperating teacher: An ambivalent participant in student teaching. Journal of Teacher Education, 43(1), 46-57.

Koskela, R. \& Ganser, T. (1998). The cooperating teacher role and career development. Education, 119(1), 106-114.

Kramer, R. (1991). Ed school follies: The miseducation of America's teachers. New York, NY: Free Press.

Kuter, S., Gazi, Z.A., \& Aksal, F.A. (2012). Examination of co-construction of knowledge in videotaped simulated instruction. Educational Technology \& Society, 15(1), 174-184.

Labaree, D. (2004). The trouble with ed schools. New Haven, CT: Yale University Press. 
LaBoskey, V.K., \& Richert, A.E. (2002). Identifying good student teaching placements: A programmatic perspective. Teacher Education Quarterly, 29(2), 7-34.

Lankford, H., Loeb, S., McEachin, A., Miller, L.C., \& Wyckoff, J. (2014). Who enters teaching? Encouraging evidence that the status of teaching is improving. Educational Research, 43, 444-453.

Latham, N.I., \& Vogt, W.P. (2007) Do professional development schools reduce teacher attrition? Evidence from a longitudinal study of 1,000 graduates. Journal of Teacher Education, 58, 153-167.

Leef, G. (2013, July 23). A credible critique of teacher education. Pope Center for Higher Education Policy. Retrieved from http://www.popecenter.org/commentaries/article.html?id=2877

Lemma, P. (1993) The cooperating teacher as supervisor: A case study. Journal of Curriculum and Supervision, 8(4), 329-342.

Levine, A. (2006). Educating school teachers. Washington, DC: Education Schools Project. Retrieved from http://www.edschools.org/pdf/Educating_Teachers_Report.pdf

Lewis, M. (1998). A study of feedback to language teachers. Prospect, A Journal of Australian TESOL, 13(1), 68-83.

Lincoln, Y.S., \& Guba, E.G. (1985). Naturalistic inquiry. Newbury Park, CA: Sage. Lopez-Real, F., Stimpson, P., \& Bunton, D. (2001). Supervisory conferences: An exploration of some difficult topics. Journal of Education for Teaching, 27(1), $161-173$. 
Lortie, D. (1975). Schoolteacher: A sociological study. London: University of Chicago Press.

Marks, M.J. (2002). From coursework to classroom: A qualitative study on the influences of preservice teacher socialization. (Doctoral Dissertation). University of Cincinnati, $\mathrm{OH}$.

Martin, F., \& Ertzberger, J. (2013). Here and now mobile learning: An experimental study on the use of mobile technology. Computers \& Education, 68, 76-85.

Match Education (2015). Match teacher residency. Retrieved from http://www.matcheducation.org/join/match-teacher-residency/

Maynard, T. (1996). The limits of mentoring: The contribution of the higher education tutor to primary student teachers' school-based learning. In J. Furlong \& R. Smith (Eds.), The role of higher education in initial teacher training (pp.101-118). London: Kogan Page.

McCool, M., McGraw, J., \& Hoffman, A. (March, 2017). Detangling nuance and fidelity: Text analysis of university supervisors ' prompts and teacher candidates' responses to a video-based protocol. Presented at the American Association of Colleges for Teacher Education annual meeting, Tampa, FL.

McDuffe, A.R., Foote, M.Q., Bolson, C., Turner, E.E., Aguirre, J.M., Bartell, T.G., \& Land, T. (2014). Using video analysis to support prospective K-8 teachers' noticing of students' multiple mathematical knowledge bases. Journal of Mathematics Teacher Education, 17, 245-270. doi:10.1007/s10857-013-9257-0 
McKinney, S.E., Haberman, M., Stafford-Johnson, D., \& Robinson, J. (2008).

Developing teachers for high-poverty schools: The role of the internship experience. Urban Education, 43, 68-82.

McKinsey \& Company. (2010). Closing the talent gap: Attracting and retaining top-third graduates to careers in teaching. Retrieved from http://www.mckinseyonsociety.com/downloads/reports/Education/Closing the ta lent_gap.pdf

Merriam, S.B. (2009). Qualitative research: A guide to design and implementation. San Francisco, CA: Jossey-Bass.

Metzler, M.W. (2011). Instructional models for physical education ( $3^{\text {rd }}$ ed.). Scottsdale, AZ: Holcomb Hathaway.

Miles, M.B., Huberman, A.M., \& Saldana, J. (2014). Qualitative data analysis: A methods sourcebook ( $3^{\text {rd }}$ ed.). Thousand Oaks, CA: Sage.

Murphy, K. L. (2010). Perceptions of the student teaching triad: An inquiry into relationships and supervision. Asian Journal of Physical Education \& Recreation, 16(1), 53-66.

Nagro, S.A., deBettencourse, L.U., Rosenberg, M.S., Carran, D.T., \& Weiss, M.P. (2017). The effects of guided video analysis on teacher candidates' reflective ability and instructional skills. Teacher Education and Special Education, 40, 725.

National Council on Teacher Quality (NCTQ) (2013). Teacher prep review. Washington, DC: Author. Retrieved from http://www.nctq.org/dmsView/Teacher_Prep_Review_2013_Report 
Newell, G. E., Gingrich, R.S., \& Johnson, A. (2001). Considering the contexts for appropriating theoretical and practical tools for teaching middle and secondary English. Research in the Teaching of English, 33, 302-343.

Ongel, S., Capa, Y., \& Vellom, R.P. (2002, April). A study of the effectiveness of a preservice teacher education scheme. Paper presented at the annual meeting of the National Association for Research in Science Teaching, New Orleans, LA.

Otterman, S. (2011, July 21). Ed schools' pedagogical puzzle. The New York Times. Retrieved from http://www.nytimes.com/2011/07/24/education/edlife/edl$\underline{24 \text { teacher-t.html? r=0 }}$

Pajak, E. (2003). Honoring diverse teaching styles: A guide for supervisors. Alexandria, VA: Association for Supervision and Curriculum Development.

Patton, M.Q. (2002). Qualitative research and evaluation methods ( $3^{\text {rd }}$ ed.). Thousand Oaks, CA: Sage.

Popham, W.J., \& Greenberg, S.W. (1958). Teacher education: A decade of criticism. The Phi Delta Kappan, 40(3), 118-120.

Reavis, C. (1978). Research in review/Clinical supervision: A review of the research. Educational Leadership, 35(7), 580-584.

Relay Teacher Pathways (n.d.). Relay teaching residency graduate programs. Retrieved from http://www.teacherpathways.org/graduate-programs/

Rikard, G.L., \& Veal, M.S. (1996). Cooperating teachers: Insight into their preparation, beliefs, and practices. Journal of Teaching in Physical Education, 15, 279-296. 
Robinson, V., Hohepa, M., \& Lloyd, C. (2009). School leadership and student outcomes: Identifying what works and why best evidence synthesis. Wellington: Ministry of Education.

Robinson, L., \& Kelley, B. (2007). Developing reflective thought in preservice educators: Utilizing role-plays and digital video. Journal of Special Education Technology, 22(2), 31-43.

Rockoff, J.E., Jacob, B.A., Kane, T.J., \& Staiger, D.O. (2011). Can you recognize an effective teacher when you recruit one? Education Finance and Policy, 6, 43-74.

Rose, M. (2013, December 16). What's right—and very wrong—with the teacher education debate. The Washington Post. Retrieved from https://www.washingtonpost.com/news/answer-sheet/wp/2013/12/16/whats-rightand-very-wrong-with-the-teacher-education-debate/

Rossman, G.B., \& Rallis, S.F. (2012). Learning in the field: An introduction to qualitative research ( $3^{\text {rd }}$ ed.). Thousand Oaks, CA: SAGE.

Rubenstein, G. (2007). Boston teacher residency: Real-world training and cost incentives keep teachers teaching. Retrieved March 27, 2017 from http://www.edutopia.org/schools-of-education-boston

Samaras, A., Gismondi, S. (1998). Scaffolds in the field: Vygotskian interpretation in a teacher education program. Teaching and Teacher Education, 14(7), 715-733.

Sanchez, C. (2013, June 18). Study: Teacher prep programs get failing marks. National Public Radio. Retrieved from http://www.npr.org/2013/06/18/192765776/studyteacher-prep-programs-get-failing-marks 
Savas, P. (2012). Use of digital video recording in the preparation stage of pre-service foreign language teachers' microteachings. International journal on new trends in education and their implications, 3(3), 107-116.

Schalock, D. (1979). Research on teacher selection. In D.C. Berliner (Ed.), Review of research in education, Vol. 7, Washington, D.C.: American Educational Research Association.

Schwartz-Shea, P \& Yanow, D. (2012). Interpretive research design: Concepts and processes. New York, NY: Routledge.

Seidel, T., Sturmer, K., Blomberg, G., Kobarg, M., \& Schwindt, K. (2011). Teachers learning from analysis of videotaped classroom situations: Does it make a difference whether teachers observe their own teaching or that of others? Teaching and Teacher Education, 27, 259-267.

Sherin, M.G., \& van Es, E.A. (2005). Using video to support teachers' ability to notice classroom interactions. Journal of Technology and Teacher Education, 13(3), 475-491.

Sherin, M.G., \& van Es, E.A. (2009). Effects of video club participation on teachers' professional vision. Journal of Teacher Education, 60(1), 20-37.

Silva, D.Y. (2000, April). Triad journaling as a tool for reconceptualizing supervision in the professional development school. Paper presented at the annual meeting of the National Association for Research in Science Teaching, New Orleans, LA.

Slick, S. K. (1997). Assessing versus assisting: The supervisor's role in the complex dynamics of the student teaching triad. Teaching and Teacher Education, 13, 713726. 
Slick, S. K. (1998a). The university supervisor: A disenfranchised outsider. Teaching and Teacher Education, 14, 821-834.

Slick, S. K. (1998b). A university supervisor negotiates territory and status. Journal of Teacher Education, 49, 306-315.

Spooner, M., Flowers, C., Lambert, R., \& Algozzine, B. (2008). Is more really better? Examining perceived benefits of an extended student teaching experience. Clearing House: A Journal of Educational Strategies, 81(6), 263-270.

Soar, R.S., Medley, D.M., \& Coker, H. (1983). Teacher evaluation: A critique of currently used methods. Phi Delta Kappan, 65(4), 239-246.

Steadman, S., \& Brown, S. (2011). Defining the job of university supervisor: A department-wide study of university supervisors' practices. Issues in Teacher Education, 20(1), 51-68.

Stuhlman, M. W., Hamre, B.K., Downer, J.T., \& Pianta, R.C. (2016). How to use classroom observation most effectively, part 4 of a 5 part series entitled A practitioner's guide to conducting classroom observations: What the research tells us about choosing and using observational systems to assess and improve teacher effectiveness. Retrieved March 15, 2017 from $\underline{\text { http://curry.virginia.edu/uploads/resourcesLibrary/CASTL_practitioner_Part4_sin }}$ gle.pdf

Talvitie, U., Peltokallio, L, \& Paivi, M. (2000). Student teachers' views about their relationships with university supervisors, cooperating teachers, and peer student teachers. Scandinavian Journal of Educational Research, 44(1), 79-88. 
Tang, S.Y.F. (2000, September). Supervision in the field experience of initial teacher education. Paper presented at the European Educational Research Association Annual Conference, Edinburgh, U.K.

Tang, S.Y.F., \& Chow, A.W.K. (2007). Communicating feedback in teaching practice supervision in a learning-oriented field experience assessment framework. Teaching and Teacher Education, 23(7), 1066-1085.

Tannehill, D. (1989). Student teaching: A view from the other side. Journal of Teaching in Physical Education, 8, 243-253.

Teaching Internship Handbook (2015) Retrieved from http://curry.virginia.edu/teachereducation/teaching-internship-handbook

Tjeerdsma, B.L. (1998). Cooperating teacher perceptions of and experiences in the student teaching practicum. Journal of Teaching in Physical Education, 17, 214230.

Tomlinson, P. (1999). Conscious reflection and implicit learning in teacher preparation: 11 implications for a balanced approach. Oxford Review of Education, 25(4), 533544.

Tripp, T., \& Rich, P. (2012). The influence of video analysis on the process of teacher change. Teaching and Teacher Education, 28(5), 728-739.

Tsui, A.B., Lopez-Real, F., Law, Y.K., Tang, R., \& Shum, M.S.K. (2001). Roles and relationships in tripartite supervisory conferencing processes. Journal of Curriculum and Supervision, 16, 322-344.

Tucker, P.D., \& Stronge, J.H. (2005). Linking teacher evaluation and student learning. Alexandria, VA: ASCD. 
Unver, G. (2014). Connecting theory and practice in teacher education: A case study. Educational Sciences: Theory \& Practice, 14(4), 1402-1407.

U.S. Department of Education (2015). Pathways to teaching. Office of Postsecondary Education, Higher Education Act Title II Reporting System. Washington, D.C. Retrieved from https://title2.ed.gov/Public/42653_Title_II_Infographic_Booklet.pdf

Valencia, S., Martin, S., Place, N., \& Grossman, P. (2009). Complex interactions in student teaching: Lost opportunities for learning. Journal of Teacher Education, 60(3), 304-322.

Veal, M.L., \& Rikard, L. (1998) Cooperating teachers' perspectives on the student teaching triad. Journal of Teacher Education, 49(2), 108-119.

Vuran, S., Ergenekon, Y, \& Unlu, E. (2014). Training process cycles for special education teachers and university supervisors: A Turkish context. Educational Sciences: Theory \& Practice, 14(1), 282-295.

Wang, J., \& Hartley, K. (2003). Video technology as a support for teacher education reform. Journal of Technology and Teacher Education, 11, 105-138.

Whitehead, J., \& Fitzgerald, B. (2007). Experiencing and evidencing learning through self-study: New ways of working with mentors and trainees in a training school partnership. Teaching and Teacher Education, 23(1), 1-12. http://dx.doi.org/10.1016/j.tate.2006.04.007

Wilder, A., \& Croker, D.L. (1999). How can we better train our student teachers? English Journal, 88, 17-21. 
Williams, A. (1994). The mentor. In A. Williams (Ed.) Perspectives on partnership: Secondary initial teacher training (pp. 134-150). London: Falmer.

Williams, J., \& Watson, T. (2004). Post-lesson debriefing: Immediate or delayed? An investigation of student-teacher talk. Journal of Education for Teaching, 30(2), 85-96.

Wrenn, J., \& Wrenn, B. (2009) Enhancing learning by integrating theory and practice. International Journal of Teaching and Learning in Higher Education, 21(2), 258265.

Yin, R. K. (2014). Case study research: Design and methods ( ${ }^{\text {th }}$ ed.). Thousand Oaks, CA: SAGE Publications, Inc.

Zanting, A., Verloop, N., \& Vermunt, J.D. (2001). Student teachers' beliefs about mentoring and learning to teach during teaching practice. British Journal of Educational Psychology, 71(1), 57-80.

Zeichner, K. (1996). Designing educative practicum experiences for prospective teachers. In K. Zeichner, S. Melnick, \& M.L. Gomez (Eds.), Currents of reform in preservice teacher education (pp. 215-234). New York, NY: Teachers College Press.

Zeichner, K. (2016). Independent teacher education programs: Apocryphal claims, illusory evidence. Boulder, CO: National Education Policy Center. Retrieved from $\underline{\text { http://nepc.colorado.edu/publication/teacher-education }}$

Zeichner, K., \& Liston, D. (1990). Traditions of reform in U.S. teacher education. Journal of Teacher Education, 41(2), 3-20. 
Zeichner, K.M., \& Liston, D. (1985). Varieties of discourse in supervisory conferences. Teaching and Teacher Education, 1(2), 155-174.

Zeichner, K.M, \& Conklin, H.G. (in press). Beyond knowledge ventriloquism and echo chambers: Raising the quality of the debate on teacher education. Teachers College Record.

Zepeda, S. J. (2007). Instructional supervision: Applying tools and concepts. Larchmont, NY: Eye on Education.

Zheng, B., \& Webb, L. (2000, November). A new model of student teacher supervision: Perceptions of supervising teachers. Paper presented at the annual meeting of the Mid-South Educational Research Association, Bowling Green, KY. 


\section{Appendix A}

\section{Example Video Prompts Written by Erica for Natalie}

Title

Nice Work

Enacting a

Plan

Consider

This

\section{Prompt Text}

\begin{tabular}{|c|c|}
\hline Nice Work & $\begin{array}{l}\text { Student Engagement is intended to capture the degree to which all } \\
\text { students in the class are focused and participating in the learning } \\
\text { activity presented or facilitated by the teacher. The difference } \\
\text { between passive engagement and active engagement is of note in this } \\
\text { rating. One indicator of high level student engagement is when } \\
\text { students respond and volunteer ideas. In this clip, you are } \\
\text { determining what students already know about onomatopoeia and } \\
\text { reviewing prior knowledge. What do you hear that demonstrates that } \\
\text { students are on task and actively engaged? }\end{array}$ \\
\hline $\begin{array}{l}\text { Enacting a } \\
\text { Plan }\end{array}$ & $\begin{array}{l}\text { We're going to continue our discussion of Student Engagement. High } \\
\text { levels of engagement are indicated by students volunteering, sharing } \\
\text { ideas, and responding to questions. You planned for students to } \\
\text { develop figurative language skills. In this clip, students are discussing } \\
\text { figurative language they are learning. What do you hear or see that } \\
\text { demonstrates on-task behavior? }\end{array}$ \\
\hline $\begin{array}{l}\text { Consider } \\
\text { This }\end{array}$ & $\begin{array}{l}\text { Let's look again at Student Engagement. Classrooms that lack off- } \\
\text { task behavior are examples of engaged students. In this clip, you are } \\
\text { discussing the rap and students' behavior. Look and listen for } \\
\text { evidence of student engagement. What do you hear or see that } \\
\text { demonstrates the students are actively engaged with being off-task? If } \\
\text { you could reteach this lesson, how could you promote more on-task } \\
\text { behavior? }\end{array}$ \\
\hline $\begin{array}{l}\text { Making the } \\
\text { Most of } \\
\text { Instructional }\end{array}$ & $\begin{array}{l}\text { Instructional Dialogue captures the purposeful use of content-focused } \\
\text { discussion among teachers and students that is cumulative, with the } \\
\text { teacher supporting the student to chain ideas together in ways that }\end{array}$ \\
\hline Support & $\begin{array}{l}\text { lead to a deeper understanding of content. Students take an active } \\
\text { role in these dialogues and both the teacher and students use }\end{array}$ \\
\hline
\end{tabular}


strategies that facilitate extended dialogue. One of the ways students learn about figurative language is when the teacher is facilitating content-driven discussions that build depth of knowledge through active participation and listening. In this clip, you are going over a note sheet. What do you hear or see that demonstrates content-driven exchanges? What do you hear students saying that demonstrate their understanding of figurative language? 


\section{Appendix $B$}

November 28, 2016

\section{Summary and Action Plan Example}

Dear Molly and Amelia,

Thank you both for taking the time this morning to debrief Molly's fifth observation. I always enjoy our conversations! I'm so happy to hear that Molly is continuing to progress, but I have a hard time believing that we're discussing her plans for transitioning out of the lead teacher role. It feels like this entire placement has gone by so quickly! Amelia shared that she's identified several teachers at CHS that she would like Molly to observe to give Molly the opportunity to see a variety of different instructional strategies and classroom management techniques. She also shared that Molly will be shadowing one of your students for an entire day; this will be a great experience! I remember doing this during my teacher education program and I loved it. I'm excited to hear all about Molly's "day in the life" adventures at our next observation debrief.

For the fifth and sixth observation cycles, we are focusing on the dimensions in the Instructional Support domain. For this observation, we explored Content Understanding. Both of you shared some of the ways that you design your classroom instruction to support your students' understanding of content. Molly spoke about how she wants students to understand the concepts behind the algorithms, using completing the square as an example. By utilizing several different methods for completing the square and integrating new information with students' prior knowledge (e.g., what to do with a Ineq 1), Molly hopes that students will be able to connect the procedures with the bigger picture. Amelia spoke about the importance of making algorithms and processes accessible to students beyond procedural fluency. She spoke about how she utilizes multiple representations in her teaching to help students help her students develop depth in their understanding. Amelia also spoke about the importance of connecting new content with prior knowledge and how this can be used to motivate students when they are challenged with tasks where their prior knowledge is not sufficient.

We also spent some time discussing the lesson itself, further exploring the "Let's Look" and "Enacting a Plan" prompts. In the video clip for the "Let's Look" prompt, we see one of your students attempting to generate a pattern for how to complete the square when a Ineq 1. Her initially observed "pattern" was: (1) write the equation in vertex form, (2) find the actual vertex using the graphing calculator, (3) put the coefficient (a) into the new equation. While her "pattern" was summarizing the steps that were completed for that first example, the fact that she is attempting to abstract concrete exercises is something to be recognized and praised. What a wonderful moment for you as her teacher!

When exploring the "Enacting a Plan" prompt, we spent some time discussing the importance of taking the time to reflect on a lesson's success after teaching. Both of you shared with me that the way you utilized the graphing calculator in this lesson was not something that was initially planned. Using the calculator to find the vertex of the 
original quadratic function and then transforming the equation in vertex form so that it was identical to the original graph was something that was suggested by one of your students in class. As an observer, the way that you used the technology seemed so natural and purposeful that I would have never guessed that this was not part of your original plan! Molly, after seeing how well this went in your lesson, I strongly encourage you to make note of this somewhere. That way, when you do teach this concept again, you will have these notes to remind yourself of how you used the graphing calculator and how well it worked.

As we prepare for our next (and final) observation cycle, please take some time to review the other dimensions within the Instructional Support domain in the CLASS Dimensions Guide on the Curry Teaching Internship Handbook website. As a reminder, our sixth observation debrief will coincide with our final triad meeting. Please make sure to have your final evaluations completed before we meet for our sixth observation debrief, which is scheduled for next Monday, December $5^{\text {th }}$, at 8:45 am. In the meantime, please let me know if there's anything that you need from me to better support the two of you during the last few weeks of the internship.

Thanks again,

- Joyce 


\section{Appendix $C$}

\section{Collaborative Feedback Form}

Instructions: Beside each dimension, place a check in the appropriate box to indicate if the dimension is an area of strength, an area that requires growth, or if you did not yet have the opportunity to observe or discuss this dimension. After completing this checklist, use it as a reference while completing the open-ended prompts.

\begin{tabular}{|c|l|l|l|}
\hline Dimension & Strength & Challenge & $\frac{\text { No Opportunity }}{\text { to Observe }}$ \\
\hline Positive Climate & & & \\
\hline Teacher Sensitivity & & & \\
\hline Regard for Student Perspectives & & & \\
\hline Behavior Management & & & \\
\hline Productivity & & & \\
\hline Negative Climate & & & \\
\hline Instructional Learning Formats & & & \\
\hline Content Understanding & & & \\
\hline Analysis \& Inquiry & & & \\
\hline Quality of Feedback & & & \\
\hline Instructional Dialogue & & & \\
\hline Student Engagement & & & \\
\hline
\end{tabular}

1. What is going well?

2. What is an area of challenge or concern?

3. What are the teacher candidate's next steps?

4. What are the CI's next steps? 
Appendix D

\section{Observation Protocol}

Date:

Setting:

Start Time:

End Time:

Student Teacher Pseudonym:

Mentor Teacher Pseudonym:

University Supervisor Pseudonym:

\begin{tabular}{|l|l|}
\hline Observation & Reflection \\
\hline & \\
& \\
& \\
\hline
\end{tabular}




\section{Appendix E}

\section{Student Teacher Interview Questions}

Thank you very much for your time today. I sincerely appreciate your willingness to be here. Please remember that what we discuss today will be confidential. Feel free to not answer any questions that you are uncomfortable with. If you have any questions about a question I have asked, please do not hesitate to ask for clarification. Do I have consent to conduct and record this interview?

\section{Probes (will be used as needed)}

Please tell me more about that.

Can you give me an example?

Why do you say that?

Could you expand on that a little bit more?

Can you tell me more about that?

I am not sure I understand what you are saying.

What do you mean by that?

What would that look like?

It sounds like you are saying, “...” Is that a fair summary?

Yes.

Mm hmm.

\section{Topic: Triad Conferences}

Question 1: First, I would like to gather some demographic information. Please tell me a little about yourself. Have you had any previous experience as a classroom teacher? And can you tell me a little about your placement - grade, subjects, etc.?

Question 2: Walk me through a typical triad conference. What is your role during the conference? What do you usually talk about? And your mentor teacher and university supervisor?

Question 3: How do you feel about the conferences in general? Would you characterize your feelings about the conferences as mostly positive or negative? 
Question 4: Do you view the conferences as helpful in your development as a preservice teacher? In what ways?

Question 5: What influence do the conferences have on your future instructional practices or decision-making? Do you have any examples of this?

Question 6: Is there anything about the conferences that you would characterize as problematic?

Question 7: If you had two suggestions for improvement for how the conferences could be more beneficial to you as a student teacher, what would they be?

Question 8: Tell me about the summary/action plan that you receive after your conference. What do you find to be helpful or unhelpful about it?

Question 9: In the conference I observed, I noticed Can you tell me a little more about that, please?

\section{Topic: University Supervisor Practices}

Question 10: Let's switch gears a little to talk specifically about your US. What are some specific things your supervisor does that you think are helpful? What about these practices make them helpful?

Question 11: Are there any practices that you think are problematic or view as unhelpful? How and why are they problematic or unhelpful?

Question 12: If you had two suggestions for improvement for your university supervisor, what would they be?

Question 13: If you had two suggestions for improvement for the supervision process as a whole, what would they be?

Question 14: What is something unique you get from your university supervisor that you don't get from your mentor teacher? Is there anything you feel your university supervisor is particularly knowledgeable about?

Question 15: What do you get from your mentor teacher that you don't get from your university supervisor?

Question 16: Is there anything else you think I should have asked about during this interview? 


\section{Appendix $F$}

\section{Mentor Teacher Interview Questions}

Thank you very much for your time today. I sincerely appreciate your willingness to be here. Please remember that what we discuss today will be confidential. Feel free to not answer any questions that you are uncomfortable with. If you have any questions about a question I have asked, please do not hesitate to ask for clarification. Do I have consent to conduct and record this interview?

\section{Probes (will be used as needed)}

Please tell me more about that.

Can you give me an example?

Why do you say that?

Could you expand on that a little bit more?

Can you tell me more about that?

I am not sure I understand what you are saying.

What do you mean by that?

What would that look like?

It sounds like you are saying, “...” Is that a fair summary?

Yes.

Mm hmm.

\section{Topic: Triad Conferences}

Question 1: First, I would like to gather some demographic information. Please tell me a little about yourself. What is your experience as a mentor teacher? And as a classroom teacher?

Question 2: Walk me through a typical triad conference. What is your role during the conference? What do you usually talk about? And the student teacher and university supervisor?

Question 3: How do you feel about the conferences in general? Would you characterize your feelings as mostly positive or negative? 
Question 4: Do you view the conferences as helpful in the development of your student teacher? In what ways?

Question 5: What influence do the conferences have on the student teacher's future instructional practices or decision-making? Do you have any examples of this?

Question 6: Is there anything about the conferences that you would characterize as problematic?

Question 7: If you had two suggestions for improvement for how the conferences could be more beneficial to the student teacher, what would they be? How could they be more beneficial to you as a mentor teacher?

Question 8: Tell me about the summary/action plan that you receive after your conference. What do you find to be helpful or unhelpful about it?

Question 9: In the conference I observed, I noticed Can you tell me a little more about that, please?

\section{Topic: University Supervisor Practices}

Question 10: Let's switch gears a little to talk specifically about the US. What are some specific things the university supervisor does that you think are helpful? What about these practices make them helpful?

Question 11: Are there any practices that you think are problematic or view as unhelpful? How and why are they problematic or unhelpful?

Question 12: If you had two suggestions for improvement for the university supervisor, what would they be?

Question 13: If you had two suggestions for improvement for the supervision process as a whole, what would they be?

Question 14: What is something unique you think the university supervisor provides that you don't provide as a mentor teacher? Is there anything you feel the university supervisor is particularly knowledgeable about?

Question 15: What is something unique you provide as a mentor teacher that the university supervisor does not?

Question 16: Is there anything else you think I should have asked about during this interview? 


\section{Appendix $G$}

\section{University Supervisor Interview Questions}

Thank you very much for your time today. I sincerely appreciate your willingness to be here. Please remember that what we discuss today will be confidential. Feel free to not answer any questions that you are uncomfortable with. If you have any questions about a question I have asked, please do not hesitate to ask for clarification. Do I have consent to conduct and record this interview?

\section{Probes (will be used as needed)}

Please tell me more about that.

Can you give me an example?

Why do you say that?

Could you expand on that a little bit more?

Can you tell me more about that?

I am not sure I understand what you are saying.

What do you mean by that?

What would that look like?

It sounds like you are saying, “...” Is that a fair summary?

Yes.

Mm hmm.

\section{Topic: Triad Conferences}

Question 1: First, I would like to gather some demographic information. Please tell me a little about yourself. What is your experience as a mentor teacher? And as a classroom teacher?

Question 2: Next, can you tell me a little about your teaching background before you became a supervisor? Do you have any additional roles at UVA?

Question 3: Walk me through a typical triad conference. What is your role during the conference? What do you usually talk about? And the mentor teacher and student teacher? 
Question 4: How do you feel about the conferences in general? Would you characterize your feelings as mostly positive or negative?

Question 5: Do you view the conferences as helpful in the development of a student teacher? In what ways?

Question 6: What influence do the conferences have on the student teacher's future instructional practices or decision-making? Do you have any examples of this?

Question 7: Is there anything about the conferences that you would characterize as problematic?

Question 8: If you had two suggestions for improvement for how the conferences could be more beneficial to the student teacher, what would they be? How could they be more beneficial to you as a university supervisor?

Question 9: Tell me about the summary/action plan that you send out after your conference. What do you think is helpful or unhelpful about it in the development of the student teacher?

Question 10: In the conference I observed, I noticed . Can you tell me a little more about that, please?

\section{Topic: University Supervisor Practices}

Question 11: Let's switch gears a little to talk specifically about your role as a university supervisor. What are some specific things that you do as a university supervisor that you think are helpful? What about these practices make them helpful?

Question 12: If you had two suggestions for how to improve the role of university supervisor, what would they be?

Question 13: If you had two suggestions for improvement for the supervision process as a whole, what would they be?

Question 14: What is something unique you think you provide as a university supervisor that the mentor teacher does not? Is there anything you feel you as the university supervisor are particularly knowledgeable about?

Question 15: What is something unique the mentor teacher provides that you do not?

Question 16: Is there anything else you think I should have asked about during this interview? 


\section{Appendix $H$}

\section{Informed Consent Agreement}

\section{Please read this consent agreement carefully before you decide to participate in the study.}

Purpose of the research study: The purpose of this study is to explore specific practices and utility of both post-observation triad conferences and university supervisors. I hope to learn specifically about the features of the conferences and specific practices of university supervisors that all members of the triad find to be most helpful in the development of preservice teachers. You will not be compensated for participation. What you will do in the study:

The study will consist of an observation of a triad post-observation conference as well as one hour long interview of each participant. As part of this study, I will also be collecting conference summaries/action plans from the university supervisor. As I engage in analysis of the data collected, I will be asking you to review transcriptions and preliminary analysis for accuracy, and you will have the opportunity to provide more information as needed. This will be completed via email. The observations and interviews will be audio taped, and all files will be kept in password-protected locations. During any of the interviews, you are welcome to skip any question that makes you uncomfortable, and you are able to stop the interview at any time.

Time required: This study will require about $1 \frac{1 / 2}{2}$ hours of your time. This study will primarily take place during the month of November 2016 and will consist of a triad conference observation (approximately 20-45 minutes) and an interview (approximately 1 hour). It is possible that I will email you with one or two follow-up questions. I will make every effort to work around your schedule.

Risks: There are no anticipated risks to this study. I have minimized potential risk for loss of confidentiality (see information below).

Benefits: There are no direct benefits to you for participating in this research study. The study may help me understand the work of university supervisors and the utility of triad conferences.

Confidentiality: In order to protect your privacy and maintain confidentiality, you will be assigned a pseudonym. The pseudonym will be used during all parts of the study, including data collection, analysis, and reporting. At no point in the study will any personally identifiable information be included. The observations and interviews will be audio recorded and transcribed. All electronic materials for the study will be stored in a password-protected folder on my password protected computer that will either be with me or secured in a private locked location. All hard-copy materials will be either kept with me or in a private locked location.

Voluntary participation: Your participation in the study is completely voluntary. Right to withdraw from the study: You have the right to withdraw from the study at any time without penalty.

How to withdraw from the study: If you want to withdraw from the study, simply tell the researcher you would like to withdraw. There is no penalty for withdrawing.

Payment: You will receive no payment for participating in the study.

If you have questions about the study, contact: 
Katie Loftin

Department of Curriculum, Instruction, and Special Education

Curry School of Education

Telephone: (918)361-2012

Email: K15wd@ virginia.edu

Dr. Susan Mintz, Ph.D.

Department of Curriculum, Instruction, and Special Education

Curry School of Education, Bavaro Hall 315

University of Virginia, Charlottesville, VA 22903

Telephone: (434) 924-3128

Email: slm4r@virginia.edu

If you have questions about your rights in the study, contact:

Tonya R. Moon, Ph.D.

Chair, Institutional Review Board for the Social and Behavioral Sciences

One Morton Dr Suite 500

University of Virginia, P.O. Box 800392

Charlottesville, VA 22908-0392

Telephone: (434) 924-5999

Email: irbsbshelp@ virginia.edu

Website: www.virginia.edu/vpr/irb/sbs

\section{Agreement:}

I agree to participate in the research study described above.

Signature:

Date:

You will receive a copy of this form for your records. 